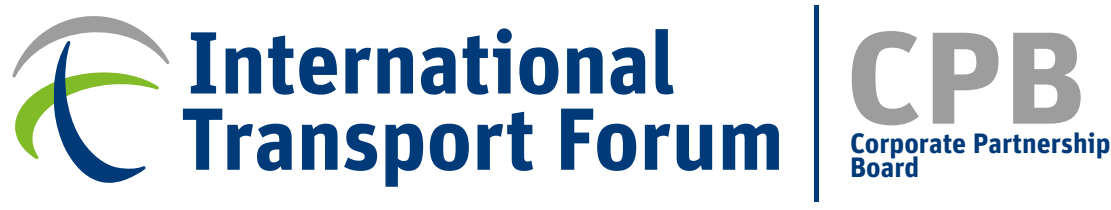

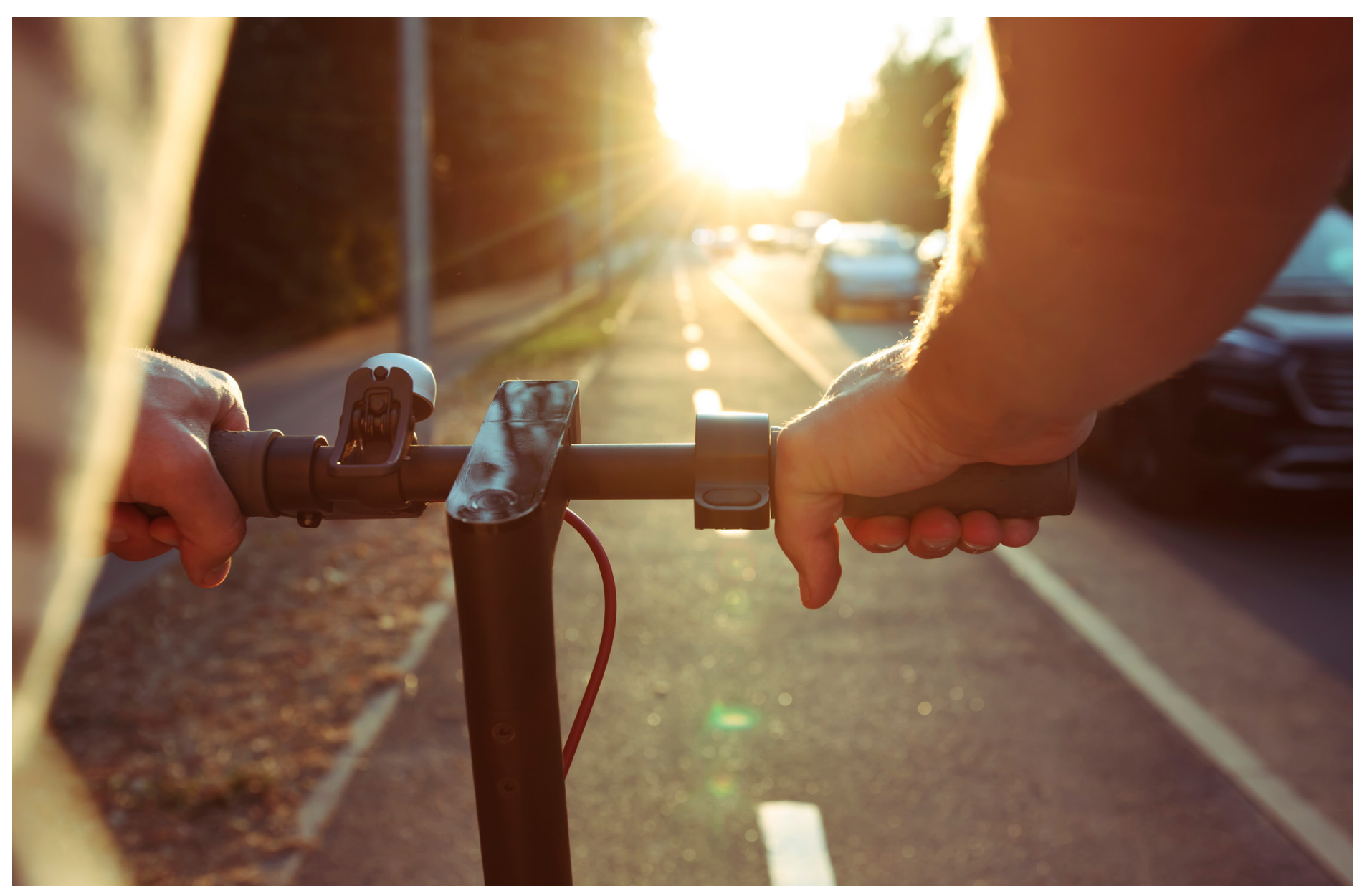

\section{Safe Micromobility}

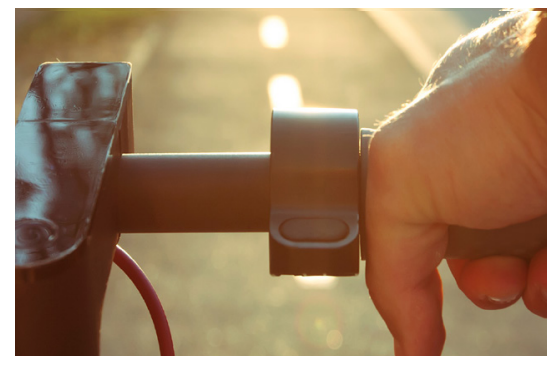

Corporate Partnership Board Report 
Safe Micromobility

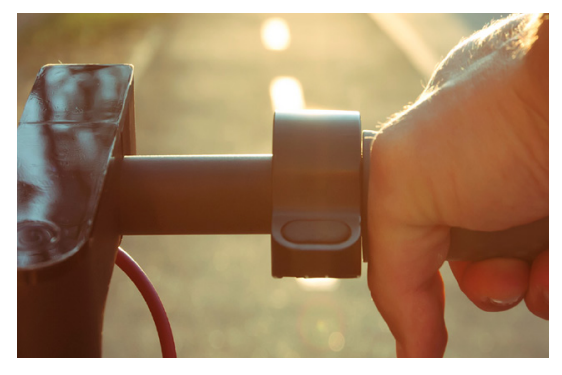

Corporate Partnership Board

Report 


\section{The International Transport Forum}

The International Transport Forum is an intergovernmental organisation with 60 member countries. It acts as a think tank for transport policy and organises the Annual Summit of transport ministers. ITF is the only global body that covers all transport modes. The ITF is politically autonomous and administratively integrated with the OECD.

The ITF works for transport policies that improve peoples' lives. Our mission is to foster a deeper understanding of the role of transport in economic growth, environmental sustainability and social inclusion and to raise the public profile of transport policy.

The ITF organises global dialogue for better transport. We act as a platform for discussion and prenegotiation of policy issues across all transport modes. We analyse trends, share knowledge and promote exchange among transport decision-makers and civil society. The ITF's Annual Summit is the world's largest gathering of transport ministers and the leading global platform for dialogue on transport policy.

The Members of the Forum are: Albania, Armenia, Argentina, Australia, Austria, Azerbaijan, Belarus, Belgium, Bosnia and Herzegovina, Bulgaria, Canada, Chile, China (People's Republic of), Croatia, Czech Republic, Denmark, Estonia, Finland, France, Georgia, Germany, Greece, Hungary, Iceland, India, Ireland, Israel, Italy, Japan, Kazakhstan, Korea, Latvia, Liechtenstein, Lithuania, Luxembourg, Malta, Mexico, Republic of Moldova, Montenegro, Morocco, the Netherlands, New Zealand, North Macedonia, Norway, Poland, Portugal, Romania, Russian Federation, Serbia, Slovak Republic, Slovenia, Spain, Sweden, Switzerland, Tunisia, Turkey, Ukraine, the United Arab Emirates, the United Kingdom and the United States.

\section{About the Corporate Partnership Board}

The Corporate Partnership Board (CPB) is the International Transport Forum's platform for engaging with the private sector and enriching global transport policy discussion with a business perspective. The members of the ITF Corporate Partnership Board are: AB InBev, Airbus, Alstom, Aramco, Bird, Bosch, Cruise, ExxonMobil, Grin, Iberdrola, Incheon International Airport, Kakao Mobility, Kapsch TrafficCom, Kyyti Group, Latvian Railways, Michelin, NXP, Penta Security, PTV Group, RATP Group, The RenaultNissan-Mitsubishi Alliance, Siemens, SNCF, Spea Engineering, Total, Toyota, Uber, Valeo, Volvo Cars, Volvo Group and Waymo.

\section{Disclaimer}

Funding for this work has been provided by the ITF Corporate Partnership Board. This report is published under the responsibility of the Secretary-General of the ITF. It has not been subject to the scrutiny of ITF or OECD member countries and does not necessarily reflect their official views or those of the members of the Corporate Partnership Board. 


\section{Acknowledgements}

The principal author of this report is Alexandre Santacreu of the International Transport Forum (ITF). Substantial contributions came from George Yannis (National Technical University of Athens), Ombline de Saint Léon (ITF) and Philippe Crist (ITF).

The author is thankful for information and thoughts shared by Annie Chang (SAE International), Marko Dozza (Chalmers University), Tina Gehlert (German Insurance Association), Catherine Pérez (Public Health Agency of Barcelona), Adrià Gomila (City of Barcelona), Sophie Hamada (Inserm), Jean-Louis Martin (Ifsttar), Pernille Ehlers (Danish Road Safety Council), Candida Castro (University of Granada), Urs Walter (Swiss Federal Roads Office), Vaughn Allan (Institute for Sensible Transport), Adriana Jakovcevic (Buenos Aires City Government), Alexis Merkling and Antonin Nonis (French Insurance Federation), Valentin Löwenstein (Dekra) and AXA.

The report also draws on contributions and discussions during an expert's workshop, organised 18 October 2019 in Lisbon. The ITF wishes to thank Deputy Mayor Miguel Gaspar, Pedro Homem de Gouveia, Vasco Mora, Cristina Rocha and Pedro Machado for hosting this event. Workshop participants are listed in Annex E.

At the International Transport Forum, credits go to Stephen Perkins and Sharon Masterson for contributions to the workshop and reviewing of the document. Sokob Challener supported the project and Hilary Gaboriau edited the draft.

Special thanks go to the members of the ITF Safer City Streets network for their contributions and for helping to develop a better understanding of urban road safety challenges.

The work for this report was carried out in the context of a project initiated and funded by the ITF's Corporate Partnership Board (CPB).

CPB projects are designed to enrich policy discussion with a business perspective. They are launched in areas where CPB member companies identify an emerging issue in transport policy or an innovation challenge to the transport system. Led by the ITF, work is carried out in a collaborative fashion in working groups consisting of CPB member companies, external experts and ITF staff.

The authors wish to thank the members of the Corporate Partnership Board involved in this project: Bird, Bosch, Grin, Incheon Airport, Kapsch TrafficCom AG, Michelin, PTV Group, Toyota and Uber.

The project was managed by Alexandre Santacreu and Philippe Crist. Sharon Masterson manages the Corporate Partnership Board and its activities. 


\section{Table of contents}

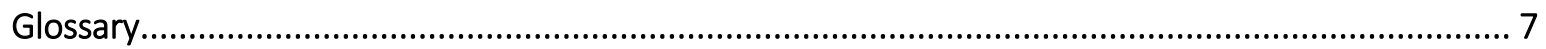

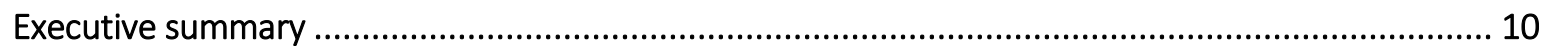

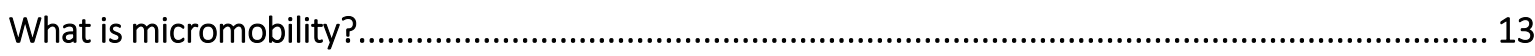

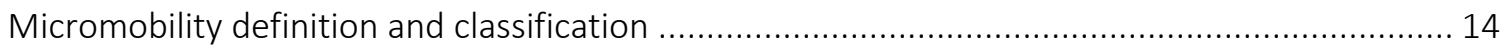

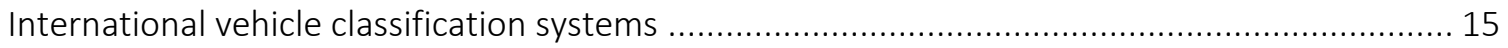

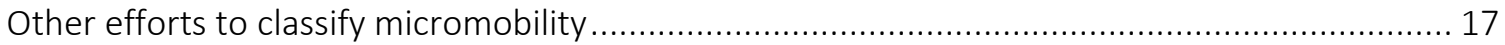

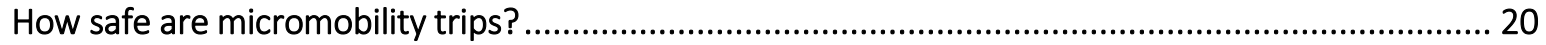

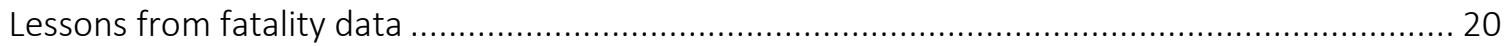

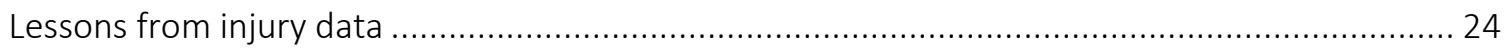

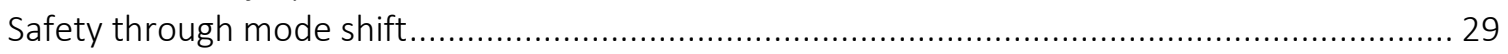

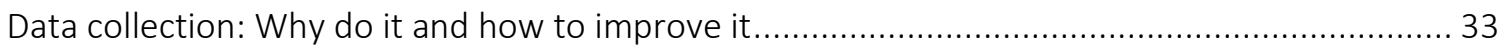

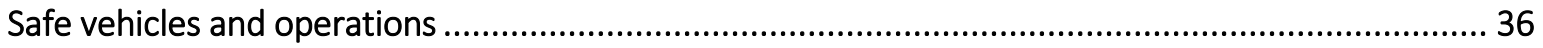

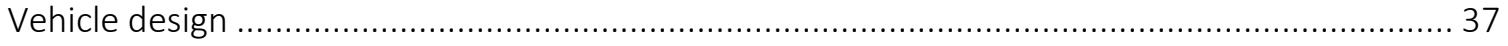

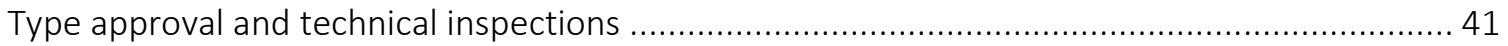

Shared fleet operations: Best practice in maintenance, recharging and redistribution ................ 46

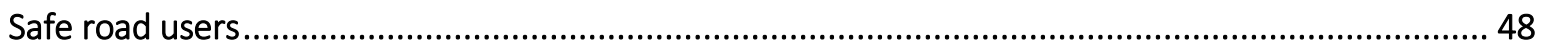

Experience, training and education: Will micromobility become safer over time? ..................... 48

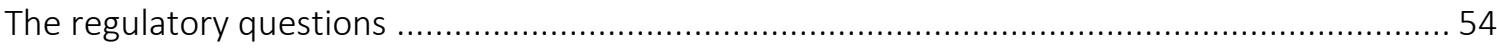

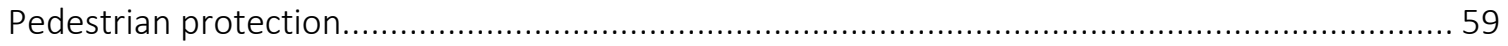

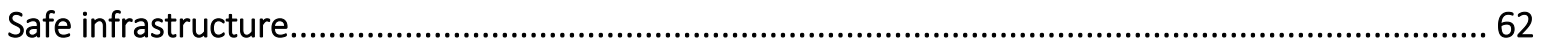

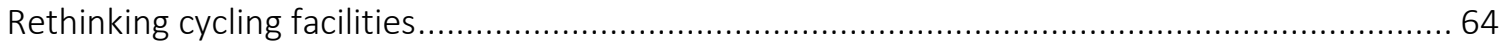

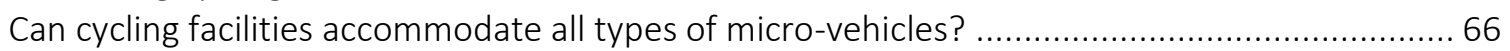

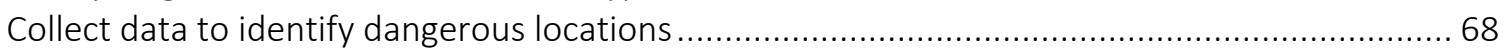

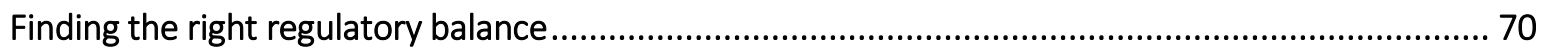

Vehicle types: Ensuring regulations are proportionate to public health and safety impacts ........ 71

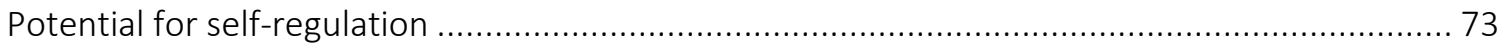

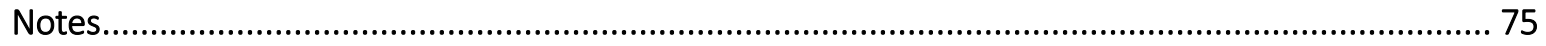

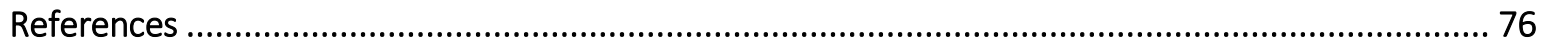

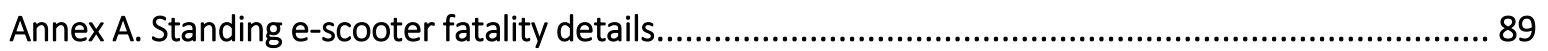

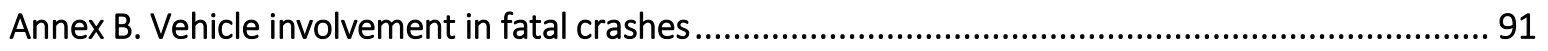

Annex C. Micromobility safety research priorities: Survey results................................................. 92

Annex D. Summary of vehicle requirements in European regulation No. 168/2013 ....................... 94

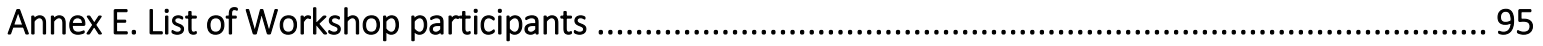




\section{Figures}

Figure 1. Proposed micromobility definition and classification .................................................... 15

Figure 2. Types of powered micromobility vehicles as defined by SAE........................................ 18

Figure 3. NUMO's framework for mapping vehicle characteristics with policy requirements ............ 19

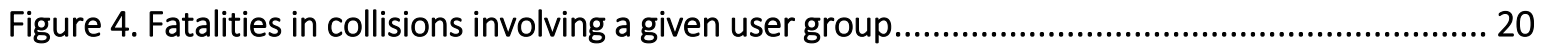

Figure 5. Vehicle occupant fatalities by third party involvement .................................................. 21

Figure 6. Population density and land areas of cities from the ITF Safer City Streets database .......... 23

Figure 7. Number of crashes reported by riders of two standing e-scooter companies .................... 28

Figure 8. Number of fatalities in collisions involving a given user group in selected cities, 2011-15... 29

Figure 9. Poster to assist medical staff with the coding of micromobility injuries ............................ 33

Figure 10. Taxonomy adopted by police and public health departments in San Francisco................. 34

Figure 11. German vehicle dynamics testing elements .............................................................. 42

Figure 12. Cargo bike used in maintenance and battery swap operations .................................... 46

Figure 13. Contractors or "juicers" use private vehicles to collect and recharge e-scooters .............. 47

Figure 14. In-app taxi passenger alerts for the safe opening of car doors near bikes ....................... 51

Figure 15. Screen captures from online traffic school RideLikeVoila ............................................... 53

Figure 16. In Europe, Germany has the most cities with shared standing e-scooters........................ 54

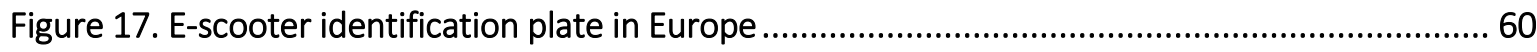

Figure 18. Design standard for identification stickers in Singapore ............................................... 61

Figure 19. Bicycle Network Analysis of New York City by PeopleForBikes ...................................... 64

Figure 20. Road surface damage and illegal parking at a bus stop ................................................. 65

Figure 21. Desired infrastructure improvements, responses from a Bird Rider Survey .................... 66

Figure 22. Micromobility safety research priorities: Survey results................................................. 93

\section{Tables}

Table 1. Standing e-scooter injury studies comparison 24

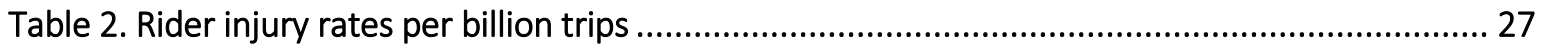

Table 3. Mode shift reported by shared standing e-scooter users .................................................. 31

Table 4. Approval requirements for powered cycles and two-wheel mopeds in Europe 44 
Table 5. Requirements for bicycles and slow e-bikes in the United States ....................................... 45

Table 6. Details of e-scooter related deaths, May 2018 to end October 2019 ................................. 89

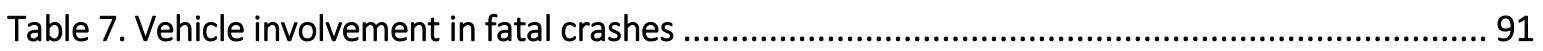

Table 8. Number of survey responses by type of organisation...................................................... 92

Table 9. Summary of vehicle requirements in European regulation No. 168/2013 .......................... 94

\section{Boxes}

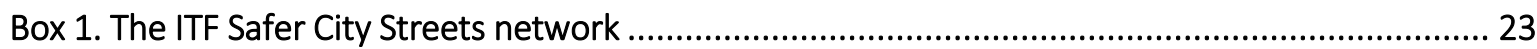

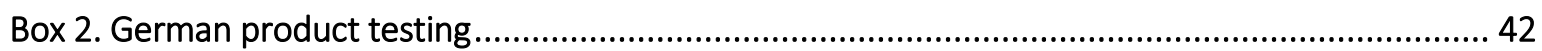

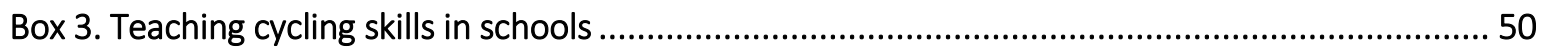

Box 4. Where speed pedelecs are classified as bicycles ................................................................. 52

Box 5. Online e-scooter traffic school by VOI.................................................................................. 53

Box 6. Current situation of electric scooters in Germany............................................................. 55

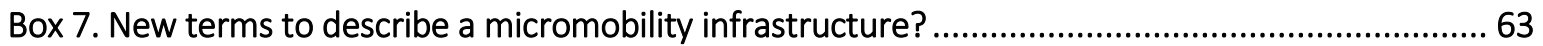




\section{Glossary}

This report proposes a glossary of terms to reflect some globally understood language and definitions regarding vehicle types. It does not seek to present legal terms and regulations from specific countries.

\section{Micromobility}

Personal transportation using devices and vehicles weighing up to $350 \mathrm{~kg}$ and whose power supply, if any, is gradually reduced and cut off at a given speed limit which is no higher than $45 \mathrm{~km} / \mathrm{h}$. Micromobility includes the use of exclusively human-powered vehicles, such as bicycles, skates, skateboards and kick-scooters.

\section{Micro-vehicle}

Device or vehicle used for micromobility (see micromobility).

\section{Powered (adj.) (Synonym: motorised)}

Qualifies a vehicle which can be propelled without human energy input. Throttlecontrolled or self-balancing micro-vehicles can be described as powered. Bicycles and pedal-assisted bicycles do not qualify as powered.

\section{Motor vehicle}

In the context of this report, a motor vehicle is a moped, motorcycle, car, van, truck, bus or coach.

\section{Motor scooter}

Vehicle shape or "form factor" found across different vehicle classes that consists of a low platform between the back and front wheels. Motor scooters can be legally classified as mopeds or motorcycles depending on their power and speed.

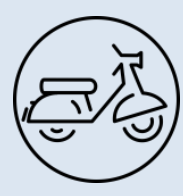

\section{Powered two-wheeler}

A class of motor vehicle which includes mopeds and motorcycles. It includes both petrol-powered and electric models.

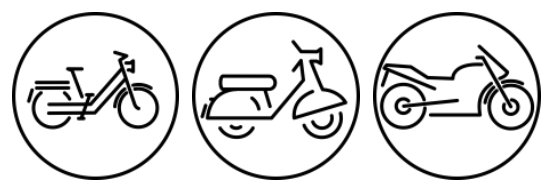

\section{Motorcycle}

Powered street vehicle, with two to three wheels and a seat, designed to reach speeds greater than $45 \mathrm{~km} / \mathrm{h}$.

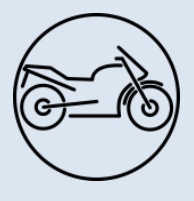

\section{Moped}

Powered street vehicle, with two to three wheels and a seat, sometimes equipped with pedals. When powered by internal combustion engine, its capacity is typically limited to $50 \mathrm{cc}$. Maximum vehicle speed depends on national regulations but is typically limited to $45 \mathrm{~km} / \mathrm{h}$. Number plates are imposed in some countries and on

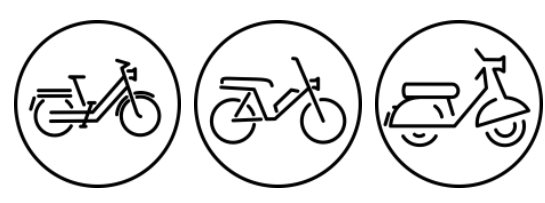
some classes of mopeds. 
Bicycle (Synonym: bike, cycle)

A road vehicle that has two or more wheels and is generally propelled by the muscular energy of the persons on that vehicle, in particular by means of a pedal system, lever or handle (e.g. bicycles, tricycles, quadricycles and invalid carriages). Included are cycles with a supportive power unit (e.g. e-bikes, pedelecs).

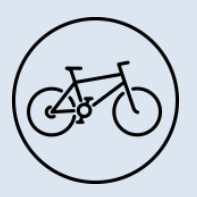

E-bike (Synonym: electric bicycle)

A type of bicycle with a supportive power unit, providing pedal assistance or fully throttle-controlled propelling force.

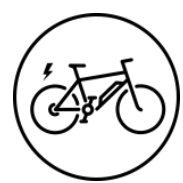

\section{Pedal assisted bicycle}

A type of e-bike which only provides assistance when the user is pedalling. It includes models of various power output levels, such as pedelecs and speedpedelecs.

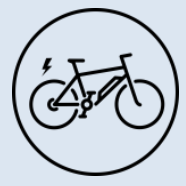

Pedelec (Synonym: slow e-bike)

A type of pedal-assisted bicycle where the electric power cuts off when the vehicle reaches approximatively $25 \mathrm{~km} / \mathrm{h}$ (exact limit depends on local regulations).

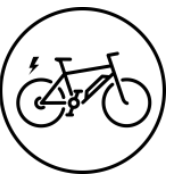

Speed-pedelec (Synonym: fast e-bike)

A type of pedal-assisted bicycle where the electric power cuts off when the vehicle reaches approximately $45 \mathrm{~km} / \mathrm{h}$ (exact limit depends on local regulations).

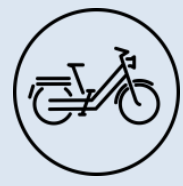

\section{Mobility scooter}

Electrically powered vehicle specifically designed for people with restricted mobility, typically those who are elderly or disabled. The term scooter is used in reference to the flat vehicle frame and the foot platform.

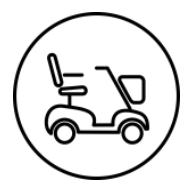

\section{Standing scooter (Synonym: kick scooter, push scooter)}

Human-powered street vehicle with a handlebar, deck, and wheels propelled by a rider pushing off the ground. Models exist with two, three or four wheels. Standing scooters can be distinguished from skateboards by the presence of a central control column and a set of handlebars.

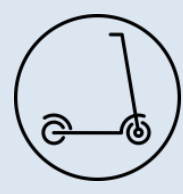

\section{E-scooter (Synonym: Standing Electric Scooter)}

A stand-up or seated scooter that can be propelled by the electric motor itself, irrespective of the user kicking.

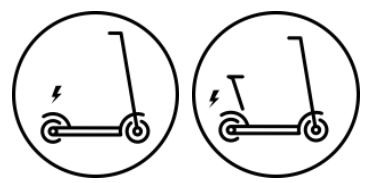

\section{Skateboard}

Board with four wheels on two axles, propelled by the user kicking against the ground.

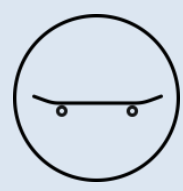




\section{Electric skateboard (e-skateboard)}

Skateboard with electric battery, motor, and wireless remote controller.

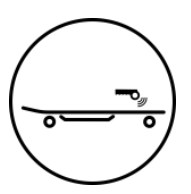

\section{Self-balancing (adj.)}

Qualifies a number of electrically powered micro-vehicles whose upright position is maintained by the stabilising effect of an electric motor. Such micro-vehicles can have one or more wheels positioned on a single axle. Motion is controlled by the direction in which the rider leans, but can be controlled by hand in the case of electric wheelchairs. Only a minority of self-balancing vehicles come equipped with a central column and a handlebar.

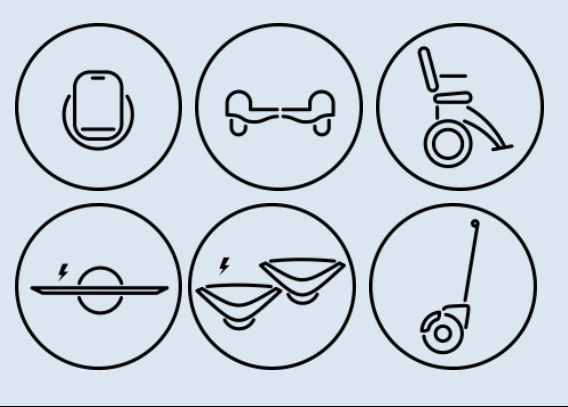

\section{Hoverboard (Synonym: self-balancing board)}

Self-balancing micro-vehicle consisting of two motorised wheels connected to a pair of articulated pads on which the rider places their feet. The rider controls the speed by leaning forwards or backwards, and direction of travel by twisting the pads.

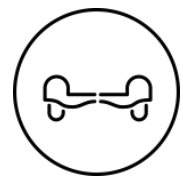

\section{Onewheel}

Self-balancing electric personal transporter, on which the user stands and places feet perpendicular to the direction of travel, on front and back platforms.

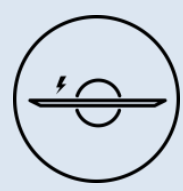

\section{Electric unicycle (abbreviated: EUC)}

Self-balancing electric personal transporter with a single wheel. The rider controls the speed by leaning forwards or backwards, and steers by twisting the unit using their feet. Some dual-wheel models exist, but the principle remains that of a single axle device, used with feet in the direction of travel and placed either side of the

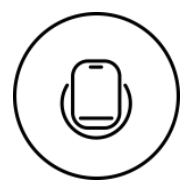
wheel(s).

\section{Electric skates (e-skates)}

Skates with electric battery and motor, controlled by the user leaning forward or backward or using a remote controller.

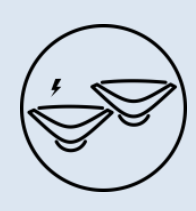

\section{Skates}

Pair of boots with a set of wheels fixed to the bottom. 


\section{Executive summary}

\section{What we did}

This report examines the traffic safety of pedal cycles, electrically assisted cycles and electrically powered personal mobility devices such as e-scooters, whether owned or shared, in an urban context. In a fastevolving urban transport environment, micromobility is changing how people move on a daily basis. This brings new and urgent challenges for national policymakers and city officials. The report proposes a framework to define micromobility which includes all the above vehicles and suggests certain limits on mass and speed to classify them. It also compares the safety of powered standing scooters (e-scooters) to that of bicycles, mopeds and motorcycles.

The report defines micromobility as the use of vehicles with a mass of less than $350 \mathrm{~kg}$ and a design speed of $45 \mathrm{~km} / \mathrm{h}$ or less. This definition limits the kinetic energy of such micro-vehicles to $27 \mathrm{~kJ}$, one hundred times less than the kinetic energy reached by a compact car at top speed. The report classifies micro-vehicles into four types based on their speed and mass: Type A micro-vehicles have a mass of up to $35 \mathrm{~kg}$ and their power supply (if any) is electronically limited so the vehicle speed does not exceed $25 \mathrm{~km} / \mathrm{h}$ (15.5 mph). Many bicycles, e-bikes, e-scooters and self-balancing vehicles fall into this category. Other types of micro-vehicles have a higher mass (Type B) or speed (Type C) or both higher mass and higher speed (Type D).

The report proposes a range of safety improvements for micromobility. These relate to vehicle design, fleet operation, infrastructure, regulatory enforcement and training. It proposes future-proof, balanced safety regulations proportional to the risks imposed.

The analysis draws on the results of a workshop attended by 40 participants from 15 countries in October 2019.

\section{What we found}

A trip by car or by motorcycle in a dense urban area is much more likely to result in the death of a road user - this includes pedestrians - than a trip by a Type A micro-vehicle. A modal shift from motor vehicles towards Type A micro-vehicles can thus make a city safer. A shift from walking to Type A microvehicles would have the opposite effect.

The very limited available data reveals similarities and differences between e-scooters and bicycles in terms of risks. A road fatality is not significantly more likely when using a shared standing e-scooter rather than a bicycle. The risk of an emergency department visit for an e-scooter rider is similar to that for cyclists. Two studies, however, found the risk of hospitalisation to be higher with e-scooters, which calls for further investigation.

Strategically, Type A micromobility could improve traffic safety by reducing the number of car and motorcycle trips in a city. It can increase the catchment area of public transport by allowing wider access to stations. It can also offer a convenient door-to-door transport solution. Not least, it can support existing sustainable mobility policies by increasing demand for a safe and connected network of cycle paths, facilitating construction - a process that may otherwise be slow and politically controversial. 
E-scooter safety, in particular, will likely improve once users learn to navigate urban traffic and car drivers become accustomed to novel forms of mobility. Safety will also improve as governments put in place safe cycling infrastructure and targeted safety regulations for micro-vehicles and shared mobility operations. Considerable regulatory challenges exist due to the rapid pace of innovation in micro-vehicle design.

\section{What we recommend}

\section{Allocate protected space for micromobility and keep pedestrians safe}

Where pedestrians do not feel safe on sidewalks, the number of people walking will decline. The use of micro-vehicles on sidewalks should be banned or subject to a low, enforced speed limit. Authorities should create a protected and connected network for micromobility, either by calming traffic or by redistributing space to physically protected lanes for micro-vehicles. This network should be more attractive than sidewalks; design guidelines for wide and protected cycling infrastructure should be developed. For its rapid, low-cost development, light separation on busy streets and traffic filtering on residential streets are proven techniques. Speed limits for all motor vehicles should be no higher than $30 \mathrm{~km} / \mathrm{h}$ where motorised vehicles and vulnerable road users share the same space.

\section{To make micromobility safe, focus on motor vehicles}

Motor vehicles are involved in about $80 \%$ of crashes that result in the death of bicycle or e-scooter riders. The novelty of e-scooters should not distract from focusing on known solutions to reduce the risk imposed on all vulnerable road users by motor vehicles. Authorities at all levels should intensify their efforts to address risky driver behaviour including speeding, distracted driving and driving under the influence of alcohol. They should impose safe speed limits. They should require safe motor vehicle designs that include both active and passive safety solutions. Relevant active safety features include intelligent speed assistance (available on all new cars in Europe from 2022) and autonomous emergency braking (AEB). AEB should be able to reliably identify all types of micro-vehicles.

\section{Regulate low-speed e-scooters and e-bikes as bicycles, higher-speed micro-vehicles as mopeds}

If regulated well, micromobility can support broader policy goals including sustainability, efficiency, inclusiveness and public health. To encourage it, relatively light bicycle regulations should apply to all forms of low-speed, low-mass (Type A) micro-vehicles. Moreover, a simple set of rules for all is more likely to be understood and adhered to, facilitating enforcement, signage and parking restrictions. Powered micro-vehicles with a maximum speed of $45 \mathrm{~km} / \mathrm{h}$ should be regulated as mopeds. Derogations for high-speed pedal-assisted e-bikes should be based mainly on their potential to contribute to public health goals by increasing physical activity. Throttle-assist bicycles should not be eligible. Where faster micro-vehicles (types $C$ and D) are allowed on cycling facilities, regulations should ensure that riders adopt lower speeds in order not to undermine the perception of safety among people of all ages and abilities cycling at a slower pace.

\section{Collect data on micro-vehicle trips and crashes}

Relatively little is known about the safety performance of different micro-vehicle types and models, about the role of various crash factors, and about which counter-measures would be most effective. Research on micromobility safety requires accurate crash data to be collected by the police and health services, and trip data to be collected by governments through operators, travel surveys and on-street observation. Collecting this data should be a priority for road safety agencies. 


\section{Proactively manage the safety performance of street networks}

Authorities should prioritise proactive crash prevention on the street network. Many shared microvehicles are equipped with motion sensors and live positioning via GPS. These systems can yield useful data on potholes, falls and close-calls to map the places where crashes are most likely to happen. Authorities and operators should work together to exploit these sources of information. Governments should also monitor damage to the road network, improving preventive maintenance to quickly repair potholes and other damage that create risks for users of micro-vehicles.

\section{Include micromobility in training for road users}

Authorities should ensure that car, bus and truck drivers are trained to avoid crashes with micro-vehicle riders. Relevant training should be mandatory for obtaining a driving license. Cycle training should be part of the school curriculum so that children acquire the skills to safely navigate a micro-vehicle in traffic. All adults should have access to affordable micromobility safety training. All training programmes should be regularly evaluated for their effectiveness and revised accordingly.

\section{Tackle drunk driving and speeding across all vehicle types}

Governments should define and enforce limits on speed and alcohol and drug use among all traffic participants. This includes motor vehicle drivers and micromobility users.

\section{Eliminate incentives for micromobility riders to speed}

Shared micromobility operators should review their pricing mechanisms to ensure these do not encourage risk taking. By-the-minute rental can be an incentive to speed or to ignore traffic rules. Companies should therefore reduce minute-based charging and compensate with alternatives. These could include a fixed-amount trip charge, a distance-based charge or a membership fee.

Improve micro-vehicle design

Manufacturers of micro-vehicles should seek to enhance stability and road grip. Solutions could be found in pneumatic tyres, larger wheel size and frame geometry, but also in areas yet to be explored. Regulators should consider imposing indicator lights on powered micro-vehicles controlled by switches on the handlebar. On shared micro-vehicles, brake cables should be protected from accidental damage and vandalism.

\section{Reduce wider risks associated with shared micromobility operations}

Many shared micromobility services rely on vans for repositioning or recharging e-scooters or bicycles. Operators should minimise the vehicle-kilometres driven by these support vans in order to reduce the additional risk imposed on all road users. Using removable or higher capacity batteries and plug-in docks offer solutions to reduce the need for collecting vehicles for recharging. Cities should allocate space for on-street micro-vehicle parking in the proximity of delivery bays so that support vehicles can park safely. 


\section{What is micromobility?}

Micromobility is an ambiguous term associated with a rapidly evolving range of light vehicles that are increasingly populating streets across the globe. "Micro-vehicles" seem to be released daily, for private or shared use, to more easily navigate congested city streets. The breadth of their popularity was perhaps unforeseen but is well illustrated by the expansion of shared e-bike and e-scooter companies. The term micromobility also includes privately-owned vehicles invented over a century ago: conventional bicycles, kick scooters and even powered standing scooters (Gibson, 1915) and powered skates (Scientific American, 1906).

The term micromobility was popularised by Horace Dediu, an American industry analyst and investor. It emerged around 2016 with connected bicycle, scooter and moped sharing services. According to Dediu (2019), the term "micro" can refer to the vehicles used, which are typically less than $500 \mathrm{~kg}$, but also to the short-distance trips that can be fun, cheap and convenient. This report examines other attempts to define and classify micromobility, and proposes a framework that might facilitate the elaboration of safety regulations.

Micromobility appears to be here to stay. The portable electric power revolution that started with the creation of the lithium-ion battery in 1991, made possible by the development of light-weight, powered vehicles. Such micro-vehicles have a low environmental impact, with little noise and zero tailpipe emissions. Their light weight suggests a smaller carbon footprint over the vehicle life cycle when compared to other vehicle types, a question that is under investigation by the ITF (forthcoming a). Bicycles and other human-powered micro-vehicles provide additional public health benefits by keeping the population physically active. Smaller vehicles also consume less of the city's most valuable resource, space. For all these reasons, micromobility is attractive to individuals and policy makers alike.

Who uses micromobility? The majority of cyclists in car-oriented cities are young to middle-aged males. In bicycle-friendly cities, however, cycling is inclusive with a larger share of women, children and seniors (Garrard et al., 2012). The use of standing e-scooters in shared fleets may follow the same pattern but may also be affected by the cost of such services. The City of Santa Monica (2019a) collected data on shared electric scooters and bikes operated by private companies in a pilot test. It found that the early adopters were predominantly male (67\%) and aged 25-34 (64\%), with higher-than-average income distribution. Data collected in Washington D.C., however, suggests that shared micromobility delivers new options to communities that have been traditionally underserved, and that the adoption of shared micromobility was higher amongst black and African-American residents (Clewlow, 2018).

The safety performance of micro-vehicles and shared micromobility services is the focus of intense media attention. Countries and cities have started to adapt their road safety regulations to include micromobility, leading to sometimes divergent rules. In France and Germany "personal mobility devices" were integrated into traffic regulations in 2019, requiring micro-vehicles users to ride on cycling facilities when they exist (JORF, 2019; BMVI, 2019). In Portugal, kick-scooters and e-scooters have been subject to the same traffic regulations as bikes and e-bikes since 2013. Conversely, in South Korea micro-vehicles are required to follow the same regulation as cars and are not given access to bike lanes (RTA, 2006). In 
the United Kingdom and Ireland, motorised micro-vehicles are simply excluded from public roads until definitions of vehicles permitted for use on the road are updated to include them.

This report examines how micro-vehicles can best be classified and approved for on-street use. Should they be licenced on a technology-specific basis or on a more general mass, power and speed basis? Where should they be allowed to operate? Will infrastructure need to be adapted to allow for their safe use? Which traffic safety requirements should national and local authorities place on shared micromobility operators?

This report proposes regulating micromobility in a way that is adapted to the indeterminate boundaries of the sector. Innovation in vehicle design will undoubtedly bring new device types. Will policy makers have to revise their road safety regulations each time a new type of micro-vehicle appears on the market? Instead, this report offers a set of rules for defining and classifying micromobility vehicles based on safety criteria, and a framework for sharing street space and protecting road users from crash risks coherent with overall policy for promoting more sustainable mobility.

\section{Micromobility definition and classification}

This report proposes to define micromobility as the use of micro-vehicles: vehicles with a mass of no more than 350 kilograms (771 pounds) and a design speed no higher than $45 \mathrm{~km} / \mathrm{h}$. This definition limits the vehicle's kinetic energy to $27 \mathrm{~kJ}$, which is one hundred times less than the kinetic energy reached by a compact car at top speed. Speed and weight together determine the kinetic energy of a vehicle, which correlates with the risk of fatal or serious injuries (Khorasani-Zavareh et al., 2015).

This definition includes human-powered and electrically-assisted vehicles, such as bicycles, e-bikes, skates and kick scooters. The broad definition includes vehicles much heavier and faster than a bicycle. Most experts do not think that bike lanes should accommodate $350 \mathrm{~kg}$ powered vehicles with a speed capacity of $45 \mathrm{~km} / \mathrm{h}$. As an illustration of this debate, countries are unable to reach a consensus on where to place speed pedelecs. The broad definition used in this report is not intended to prescribe which vehicles are allowed onto bike lanes. Authorities should acknowledge that the micro-vehicle spectrum is wide and heterogeneous, and consider the risks and value of different vehicles to society when regulating them.

This report proposes to classify micro-vehicles as follows:

- Micro-vehicles can be classified primarily according to their maximum speed (Figure 1). Type A and Type B micro-vehicles include human-powered vehicles such as bicycles, as well as vehicles whose power supply cuts off at $25 \mathrm{~km} / \mathrm{h}$. Many bicycles, e-bikes, e-scooters and self-balancing vehicles would fall into this category. The threshold of $25 \mathrm{~km} / \mathrm{h}$ is known to separate the main categories of e-bikes in Europe. Up to $25 \mathrm{~km} / \mathrm{h}$, e-bikes are generally considered and regulated as bicycles. When their design speed is beyond $25 \mathrm{~km} / \mathrm{h}$ and up to $45 \mathrm{~km} / \mathrm{h}$, e-bikes are often excluded from bike lanes and subject to further safety regulation (Santacreu, 2018).

- Micro-vehicles can be further classified by weight, with a threshold of $35 \mathrm{~kg}$, beyond which regulators could impose more safety requirements. Vehicle weight has indeed an influence on kinetic energy and braking systems. Weight can also be seen as a proxy for the capacity to transport additional passengers and goods.

Micro-vehicles are polymorphic devices that do not share a common form factor. They cannot be defined by the number of wheels, nor by the riding position, which can be seated or standing. Micro- 
vehicles may be powered by muscular energy, electric batteries, a fuel tank or a combination of these. Defining micro-vehicles by a specific power source is, therefore, of little value. In the process of regulating micro-vehicles, however, it is worth accounting for the physical activity which the vehicle requires to operate. Unpowered and pedal-assisted vehicles have a positive impact on public health through physical activity which throttle-powered vehicles do not, everything else being equal.

Figure 1. Proposed micromobility definition and classification

\section{Type A}

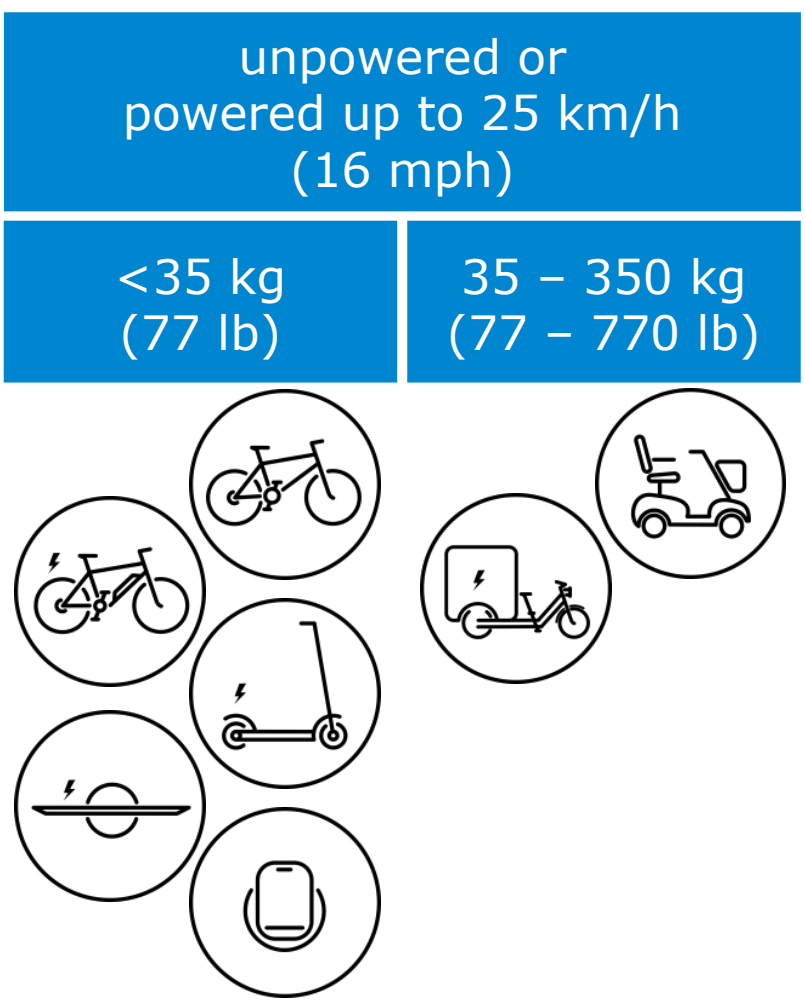

\section{Type C}

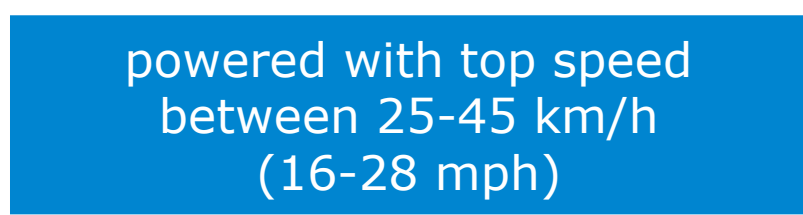

Type D

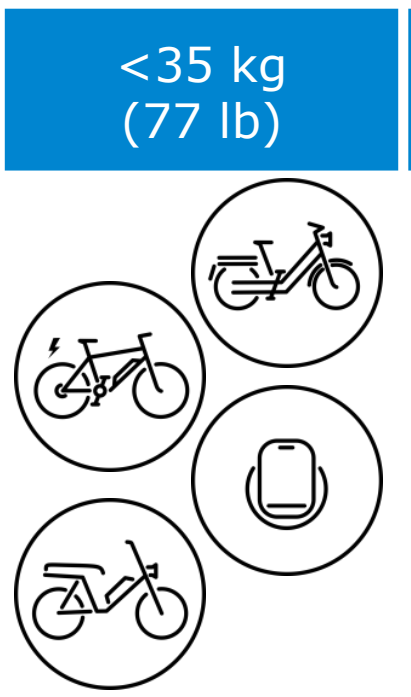

$35-350 \mathrm{~kg}$ $(77-770 \mathrm{lb})$

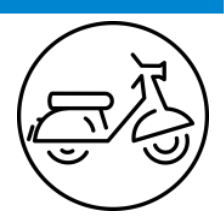

\section{International vehicle classification systems}

Definitions, classifications and regulatory frameworks for micromobility vary across the world. Bicycles are the smallest vehicle in most countries' classifications. Consequently, a range of micro-vehicles - such as standing e-scooters, e-skateboards and self-balancing vehicles - are excluded from classifications. In some cases, they are classified as toys, hence not allowed to circulate in public streets. As a temporary solution, Korea classified these devices with cars. Authorities in Singapore decided to create a new vehicle category called "personal mobility device" (PMD). In light of the obvious international impact of micro-vehicles and the difficulty in defining and categorising them, there could be value in shaping an internationally recognised classification system for them. 


\section{Micromobility in Europe}

European Union regulation $N^{\circ} 168 / 2013$ established the L-category vehicles as a reference for member countries. L-category vehicles are powered two-, three- and four-wheel vehicles. The category uses power, power source, speed, length, width and height as classification criteria.

Some types of micro-vehicles can be mapped to the L1e category called "light two-wheel powered vehicle":

- L1e-A powered cycle: electric bicycle equipped with auxiliary propulsion with a maximum speed of $25 \mathrm{~km} / \mathrm{h}$ and a net power between 250 watts and 1000 watts. This category includes lowpowered throttle only electric bikes.

- L1e-B two-wheel moped: any two-wheel vehicle with a maximum design speed of more than $25 \mathrm{~km} / \mathrm{h}$ and up to $45 \mathrm{~km} / \mathrm{h}$ and a net power of up to 4000 watts. It includes speed-pedelecs, though most speed-pedelecs have a power of 500-750 watts.

Other micro-vehicles are left outside the L1e category, most notably:

- human-powered vehicles, such as bicycles, skates and kick scooters

- pedelecs, defined as bicycles with pedal assistance up to $25 \mathrm{~km} / \mathrm{h}$ and with an auxiliary electric motor having a maximum continuous rated power of up to 250 watts.

- self-balancing vehicles and vehicles not equipped with a seat (ie. standing scooters).

The United Nations Economic and Social Council published the Consolidated Resolution on the Construction of Vehicles, which included a vehicle classification system and safety standards that are now used as international references. The World Forum for Harmonization of Vehicle Regulations allows open discussions among policy makers. This leads to the construction of a shared reference across countries, even if it still excludes the large part of micro-vehicles cited above (UNECE, 2017).

\section{Micromobility in the United States}

In the United States, vehicles such as e-bikes and e-scooters are predominantly regulated at state level. State-by-state legislation is being passed which distinguishes e-scooters and e-bikes from mopeds and other motor vehicles, thus enabling the use of bike lanes, and avoiding requirements for licencing and registration (NCSL, 2019).

For the use of e-scooters, some states impose a minimum age of $8,12,16$ or 18 , some only require the use of helmets, and others have set both a minimum age and a helmet requirement. State-specific speed limits for e-scooters range from $20 \mathrm{~km} / \mathrm{h}$ (12.5 mph) to $32 \mathrm{~km} / \mathrm{h}$ (20 mph) (Sikka et al., 2019).

For the use of e-bikes, state regulations typically impose that an e-bike falls within one of the following three classes:

- Class 1 electric bicycle: a bicycle equipped with a motor that provides assistance only when the rider is pedalling, and that ceases to provide assistance when the bicycle reaches the speed of $20 \mathrm{mph}(32 \mathrm{~km} / \mathrm{h})$.

- Class 2 electric bicycle: a bicycle equipped with a motor that may be used exclusively to propel the bicycle, and that is not capable of providing assistance when the bicycle reaches the speed of $20 \mathrm{mph}(32 \mathrm{~km} / \mathrm{h})$. 
- Class 3 electric bicycle: a bicycle equipped with a motor that provides assistance only when the rider is pedalling, and that ceases to provide assistance when the bicycle reaches the speed of $28 \mathrm{mph}(45 \mathrm{~km} / \mathrm{h})$ and is equipped with a speedometer.

\section{Micromobility in Asia}

In People's Republic of China, electric bicycles are classified as bicycles. The latest regulation stipulates that electric bicycles must have working pedals, with a maximum design speed not exceeding $25 \mathrm{~km} / \mathrm{h}$, weight (including battery) up to $55 \mathrm{~kg}$, motor power up to $400 \mathrm{~W}$, and battery voltage up to $48 \mathrm{~V}$ (Large, 2019).

Singapore created a new category of vehicle called the "personal mobility device" (PMD). E-scooters fall within this category. It differentiates PMD from cars, but also from bicycles and e-bikes (SLA, 2019).

In Korea, all power-driven vehicles are considered as motor vehicles (KMVSS, 2019). However, there is no specific classification to categorise the different vehicle types. Authorities are currently using the UNECE regulation and safety requirements as a reference (UNECE, 2019).

\section{Micromobility in Latin America}

Latin American countries classify micro-vehicles according to the speed they can develop through assistance or propulsion engines, according to experts.

In Mexico City, the traffic regulations clearly define that any vehicle capable of autonomously developing a maximum of $30 \mathrm{~km} / \mathrm{h}$ is a non-motorised vehicle. Any vehicle that exceeds $30 \mathrm{~km} / \mathrm{h}$ is a motorised vehicle that needs a licence plate, registration and must follow the common rules applicable to cars.

In Colombia, a vehicle type exists for pedal-assisted e-bikes with a motor power of up to $300 \mathrm{~W}$, a weight of up to $35 \mathrm{~kg}$ and with a maximum design speed not exceeding $25 \mathrm{~km} / \mathrm{h}$ (MDT, 2017). PMDs were defined as a new vehicle category, just as they were in Singapore. They are defined as electrical motorised individual vehicles with one or more wheels, a minimum design speed of $6 \mathrm{~km} / \mathrm{h}$ and maximum design speed of $25 \mathrm{~km} / \mathrm{h}$ (DGT, 2019). According to this definition, PMDs include e-scooters, e-bikes, e-skateboards, one-wheels and more micro-vehicle forms, insofar as they respect the limit applied to the design speed.

\section{Other efforts to classify micromobility}

SAE International is a U.S.-based, globally active professional association and standards developing organisation for engineering professionals in various industries. Their taxonomy can be used by authorities at the local and national level to develop policy that is compatible with their policy objectives and with the infrastructure available.

SAE International published the $\mathrm{J}_{3194^{\mathrm{TM}}}$ Standard defining powered micromobility as a category of powered vehicles that can be classified according to four main criteria (SAE, 2019):

- vehicle weight of up to $227 \mathrm{~kg}(500 \mathrm{lb})$

- vehicle width of up to $1.5 \mathrm{~m}(5 \mathrm{ft})$

- $\quad$ top speed of up to $48 \mathrm{~km} / \mathrm{h}(30 \mathrm{mph})$

- $\quad$ power source by an electric motor or a combustion engine. 
The (trademarked) J3194 standard distinguished six types of powered micro-vehicles: powered bicycle, powered standing scooter, powered seated scooter, powered self-balancing board, powered non-selfbalancing board, and powered skates. It only includes vehicles that are primarily designed to transport people and to be used on paved roadways and paths.

Figure 2. Types of powered micromobility vehicles as defined by SAE

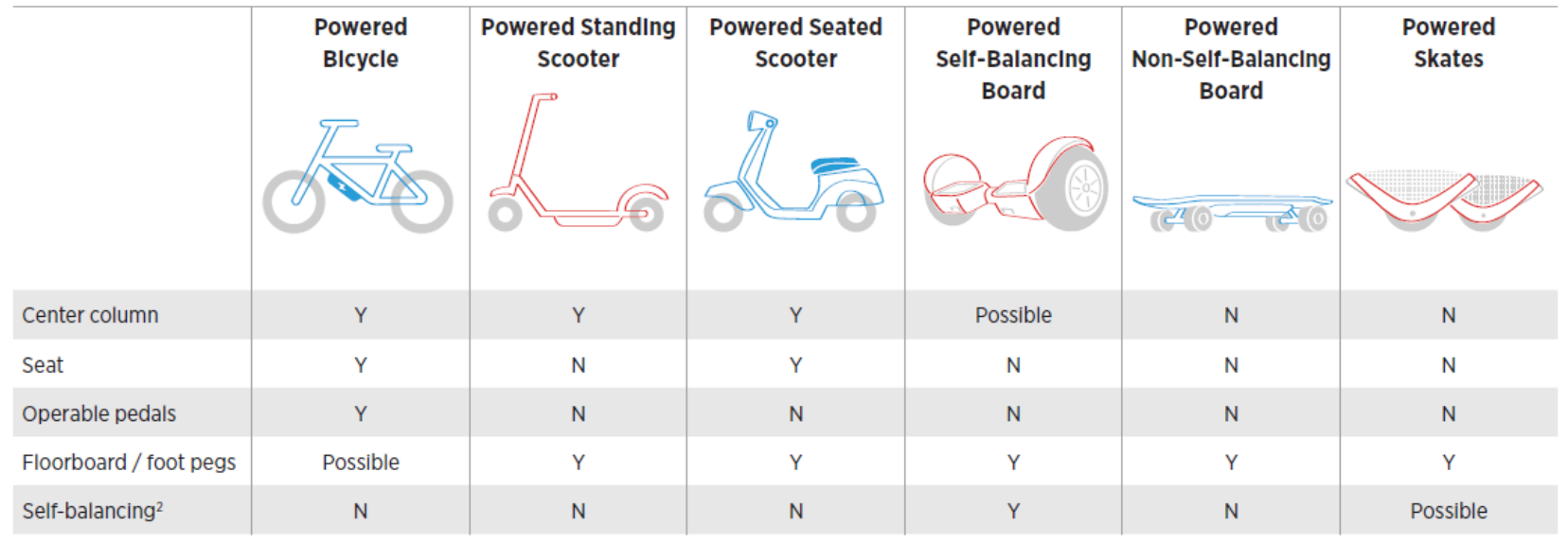

Source: SAE (2019).

It excludes solely human-powered vehicles like traditional bikes. However, it distinguishes between three classes of e-bikes:

- Class 1: pedal assist (or "class 1 e-bikes", "pedelecs", “low-speed, pedal-assisted e-bike")

- Class 2: throttle on demand (or "class 2 e-bikes", "low-speed, throttle-assisted e-bike")

- Class 3: speed pedelec (or "class 3 e-bike", "speed pedelec" and "speed pedal-assisted e-bike"). 
Figure 3. NUMO's framework for mapping vehicle characteristics with policy requirements

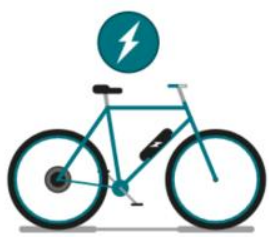

Weight

Sedentary lifestyle

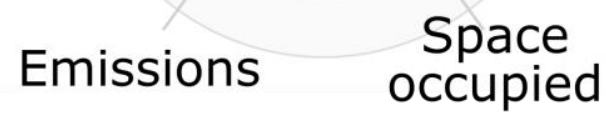

Top speed

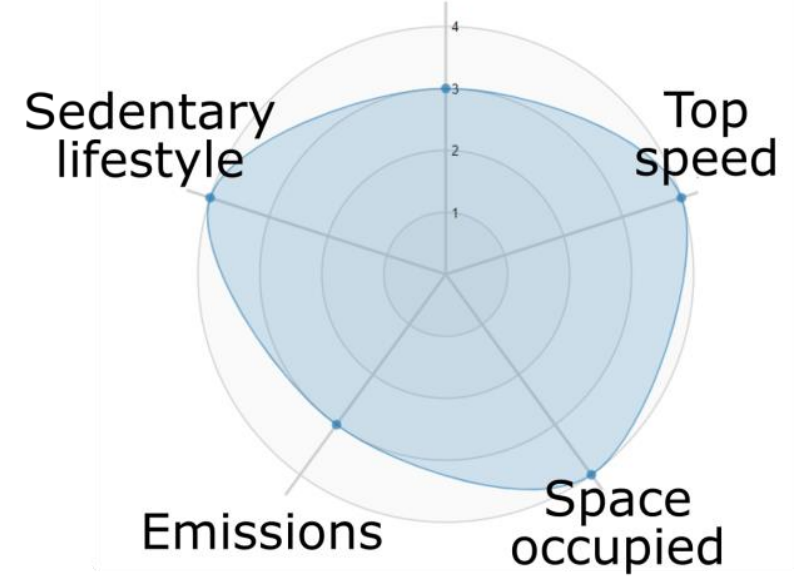

Top speed

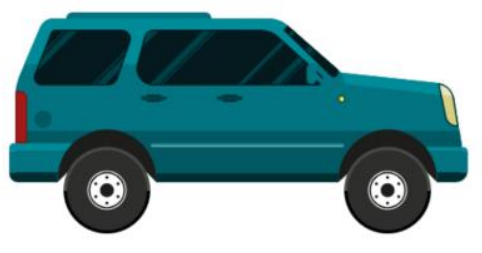

Weight

Source: adapted from NUMO (2020).

An alternative vehicle classification focuses on the vehicle's top speed, weight, emissions, spatial footprint and health footprint (a function of the physical activity input) normalised by the vehicle's passenger capacity. This approach is being formalised by the New Urban Mobility Alliance (NUMO): a global alliance organisation consisting of partners including cities, NGOs and companies from diverse sectors. This approach helps policy makers link these "vehicle profiles" with specific requirements and regulations (e.g. space allocation, data, pricing, licencing). It proposes to use radar charts (Figure 3) to represent vehicle characteristics: the farther from the centre, the more requirements needed. 


\section{How safe are micromobility trips?}

A trip by car or by motorcycle in a dense urban area is more likely to result in a traffic fatality than a trip by micro-vehicle of Type A. This section provides evidence of that and seeks to measure the mode shift achieved by new micromobility solutions.

A trip by shared standing e-scooter is no more likely than a bicycle trip to result in a road traffic death. The risk of hospital admission may be higher on e-scooters, but there have been too few studies to draw firm conclusions. This section provides information on casualties and trips, and compares the safety of e-scooters with that of other modes.

\section{Lessons from fatality data}

The detailed and comprehensive reporting of fatal crashes delivers precious insights. The ITF typically uses traffic death figures to compare cycling safety across various countries (Santacreu, 2018) and cities (ITF, 2019a). Police crash datasets identify bicycle casualties but do not identify standing e-scooter casualties as yet, at least in most countries. This report draws information from 38 media reports of standing e-scooter fatalities, up until end-October 2019 (Annex A). This section examines the risk imposed on pedestrians, the risk imposed by motor vehicles, and the risk experienced by riders of standing e-scooters.

\section{Pedestrian fatalities are rare}

Pedestrians represent less than one in ten fatalities in crashes involving standing e-scooters. Research for this report found that only two such fatalities occurred in the world through October 2019. Both crashes involved privately owned e-scooters, according to one expert, neither of which was equipped with a speed limiter. Similarly, in crashes involving bicycles, pedestrians represent no more than one in ten fatalities. Overall, riders themselves represent over $90 \%$ of fatalities in crashes involving Type A microvehicles (a category which includes bicycles and low-speed standing e-scooters).

Figure 4. Fatalities in collisions involving a given user group

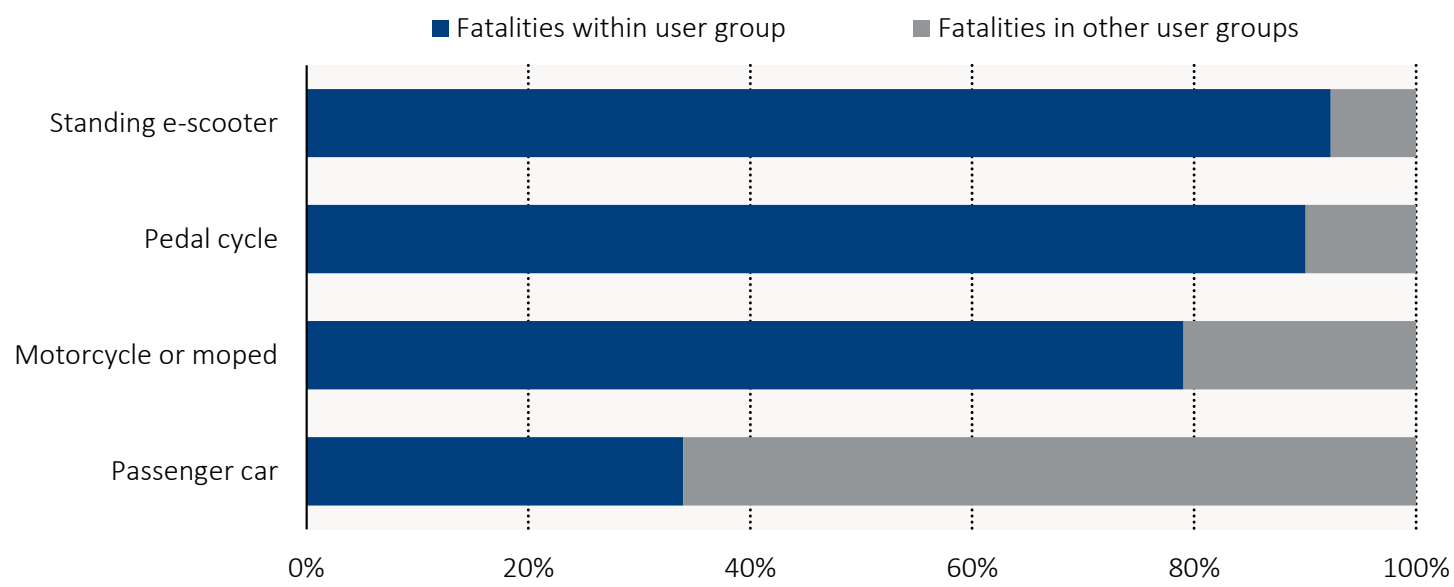

Sources: Standing e-scooter data from media reports compiled by the ITF (Annex A), crash matrices collected from the ITF Safer City Streets network in Bogota, Inner London, Paris, Rome and Milan for various time periods (Annex B). 
In comparison, car occupants represent less than $40 \%$ of fatalities in crashes involving passenger cars (Figure 4). The majority of victims killed in crashes involving a car are found in other, more vulnerable user groups. This finding reflects the impact of the relatively higher mass, speed and driver protection found on passenger cars. Public debate around sidewalk protection and micromobility rider accountability is legitimate but should not distract policy makers from the main sources of danger in the urban environment.

\section{Most fatal crashes involve a heavier vehicle}

Over $80 \%$ of cyclist and e-scooter rider deaths result from crashes with heavier vehicles (Figure 5). In comparison, car occupants are more likely to be killed in crashes where no other motor vehicle is involved. This once again reflects the higher speed of these vehicles, even in urban areas where this data was collected.

Figure 5. Vehicle occupant fatalities by third party involvement

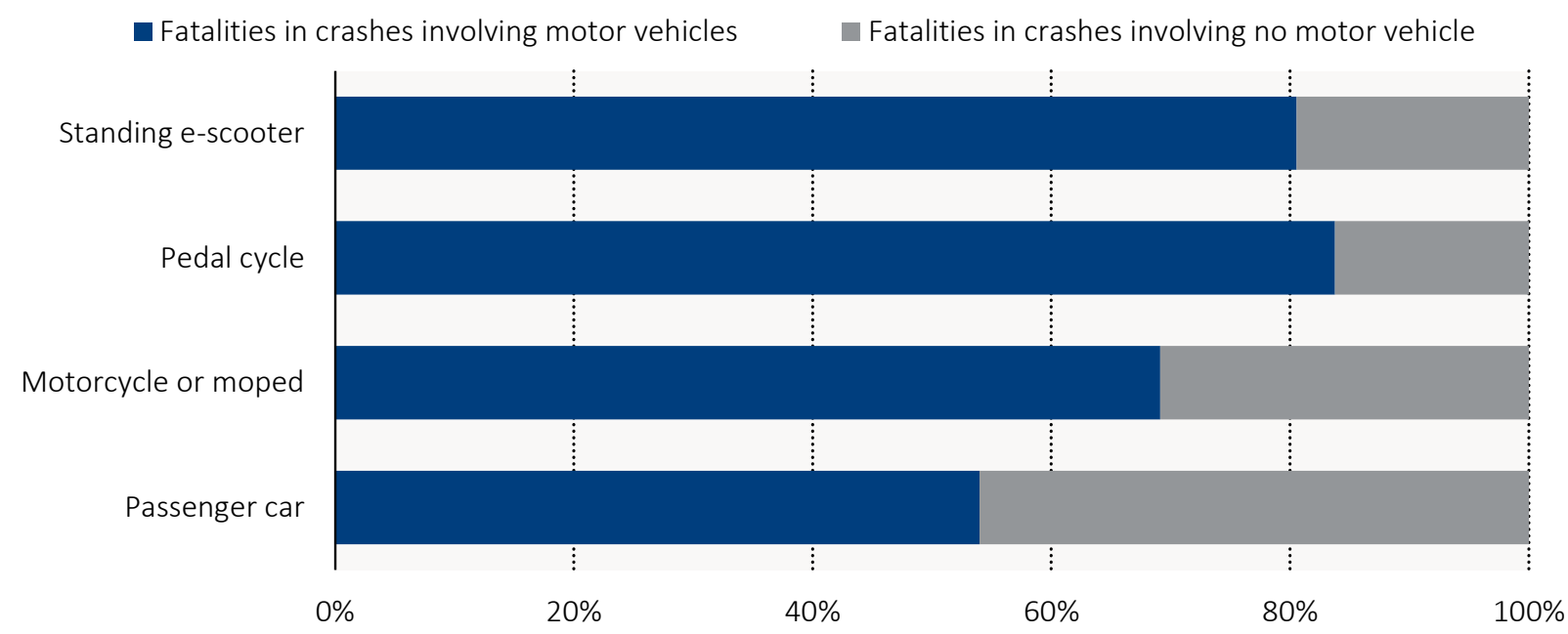

Sources: Standing e-scooter data from media reports compiled by the ITF (Annex A), crash matrices collected from the ITF Safer City Streets network in Bogota, Inner London, Paris, Rome and Milan for various time periods (Annex B).

Several caveats should be borne in mind when interpreting these figures:

- not all fatalities are reported in the media, especially as the novelty aspect of e-scooters fades

- some media reports lack clarity with regards to the exact e-scooter type (with/without seat, shared/private)

- three media reports lack clarity on the role of third parties in the crash, in which case the ITF assumed a motor vehicle was involved.

\section{Fatality risk: Similar results for cycle and e-scooter trips}

The risk of being killed on a shared standing e-scooter trip is no different from that of being killed on an average bicycle trip, and substantially lower than on an average motorcycle trip. In high- and middleincome countries, one bicycle rider is killed in every 10 million bicycle trips on average. This figure provides the reader with an order of magnitude but hides dramatic differences between countries and 
cities. Shared e-scooters belong to Type A in the micro-vehicle classification proposed here. This report could not find data to assess the safety of e-scooters reaching higher speeds (Type C).

Three people were killed in the United States on shared standing e-scooters in 2018, according to media reports, for an estimated 38.5 million trips (NACTO, 2019a). Worldwide, one of the most popular e-scooter companies, Lime, reported its first 100 million rides on 16 September 2019. Of these, industry experts assume that over 90 million are e-scooter rides, the rest being bike-share rides. Over the same period of time, the media reported nine fatalities among Lime e-scooter riders (Annex A). The risk for Lime riders is therefore estimated at fewer than 100 fatalities per billion trips. Another e-scooter company, Bird, reported their first 50 million rides in August 2019 (Scoot, 2019), at a time when five of their riders had died in crashes according to media reports, a number confirmed by the company.

Available figures for shared e-scooter risk range between 78 and 100 fatalities per billion trips. This range should be considered an order of magnitude. Its precision is limited by the number of fatalities which, in terms of statistical robustness, should be considered as small.

Cycling risk across cities ranges between 21 and 257 fatalities per billion trips. Figures come from the ITF Safer City Streets network and database (Box 1) and are consistent with other research (Bassil et al., 2015).

Motorcycles and mopeds together are called powered two-wheelers (PTW). Riding a PTW in cities comes with a risk of fatality ranging between 132 and 1164 per billion trips. The risk of being killed in a PTW trip is at least two times higher than in a cycle trip, according to the information the ITF collected for both modes in eight different cities.

The comparison between e-scooters, bicycles and other modes is delicate, due to the absence of data in a comparable global sample of cities. Indeed, previous ITF research revealed great differences in risk across countries and cities. Cycling risk in the United States was found to be six times higher than in Northern European countries (Santacreu, 2018). City-level data collected through the ITF Safer City Streets network (Box 1) showed that the same difference in cycling risk (a factor of six) is observed between Berlin (with 21 fatalities per billion trips) and New York City (128 fatalities per billion trips).

The risk analysis per unit distance travelled, as opposed to the analysis per ride, would be marginally less favourable to e-scooter riders, due to a lower average trip distance. E-scooter sharing companies provide a wide range of estimates for average trip distances. This can reflect specific local circumstances but can also raise doubts on the reliability of trip distance data. Distances could be very sensitive to GPS sampling rates and signal noise, and be severely under-estimated if derived from start and end points alone.

Limited studies have not yet managed to assess the risks of riding an e-bike. Riding a Class 1 e-bike, known as a pedelec and limited to $25 \mathrm{~km} / \mathrm{h}$, does not appear to be more dangerous than riding a bicycle, once trip distances and age are controlled for (Schepers, Klein Wolt and Fishman, 2018). More studies should investigate the risk of fatality on e-bikes. Research protocols should control for the number of older riders and for the trip distances, often higher with e-bike riders. 


\section{Box 1. The ITF Safer City Streets network}

The ITF Safer City Streets initiative is a platform for road safety experts working at city level to share their experience and develop a global traffic safety database. It is funded by the FIA and shaped on the national-level permanent working group of the ITF called the International Road Traffic Safety Analysis and Data group (IRTAD).

Over 40 cities have joined the ITF Safer City Streets network, and its database includes over 70 urban areas. In Figure 6, the bubble size represents the population of urban areas found in the database. Some are defined by an administrative boundary, and others are defined by commuting flows. The latter are called functional urban areas (FUAs): they tend to occupy a larger land area and have lower population density. The plot reveals the diversity of situations:

- land area varies from $80 \mathrm{~km}^{2}$ (The Hague) to over $9000 \mathrm{~km}^{2}$ (Vienna FUA)

- population varies from 400000 (Zürich) to over 12 million (London FUA)

- population density varies from 130 people per $\mathrm{km}^{2}$ (Graz FUA) to over 21000 per $\mathrm{km}^{2}$ (Paris City).

Figure 6. Population density and land areas of cities from the ITF Safer City Streets database

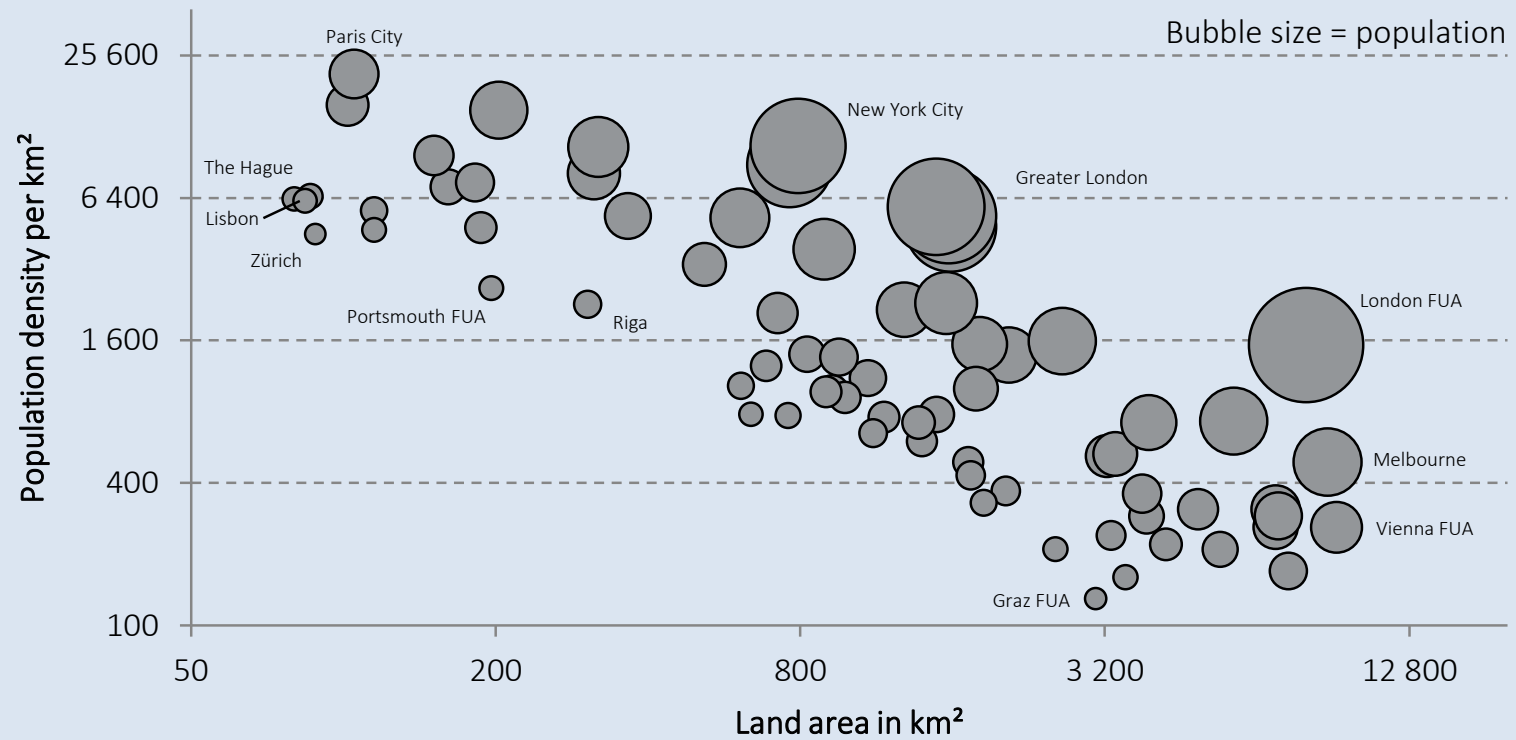

The network enabled the ITF to collect data on casualties and trips for each mode of transport, and calculate the risk of being killed per trip for each mode, making the comparison possible between e-scooter, bicycle and motorcycle fatality numbers.

Members of the network provided responses to the ITF survey on micromobility safety research priorities (Annex C) and participated in the CPB workshop that informed this report.

Source: ITF (2019a). 


\section{Lessons from injury data}

The ITF identified eight published studies shedding light on crash circumstances and injury severity following standing e-scooter crashes (Table 1). This section draws conclusions from the studies and compares e-scooter with cycling and motorcycle injury data where available.

Table 1. Standing e-scooter injury studies comparison

\begin{tabular}{|c|c|c|c|c|c|c|c|c|}
\hline Ref. & Area & Sample & $\begin{array}{l}\text { E-scooter } \\
\text { riders }\end{array}$ & $\begin{array}{l}\text { Non- } \\
\text { riders }\end{array}$ & $\begin{array}{l}\text { Helmet } \\
\text { use }\end{array}$ & Male & $\begin{array}{l}\text { Motor } \\
\text { vehicle } \\
\text { involved }\end{array}$ & $\begin{array}{l}\text { Admitted } \\
\text { to } \\
\text { hospital }\end{array}$ \\
\hline [1] & Austin, Texas, United States & $\begin{array}{l}\text { ED / EMS } \\
\text { patients }\end{array}$ & 190 & 2 & $0.5 \%$ & $55 \%$ & $16 \%$ & $14 \%$ \\
\hline [2] & $\begin{array}{l}\text { Portland, Oregon, } \\
\text { United States }\end{array}$ & $\begin{array}{l}\text { ED } \\
\text { patients }\end{array}$ & 174 & 2 & & & $14 \%$ & \\
\hline [3] & $\begin{array}{l}\text { Baltimore, Maryland, } \\
\text { United States }\end{array}$ & $\begin{array}{l}\text { ED } \\
\text { patients }\end{array}$ & 63 & & & $75 \%$ & $23 \%$ & \\
\hline [4] & Auckland, New Zealand & $\begin{array}{l}\text { ED } \\
\text { patients }\end{array}$ & 244 & 2 & & $56 \%$ & $2 \%$ & $31 \%$ \\
\hline [5] & $\begin{array}{l}\text { Santa Monica, California, } \\
\text { United States }\end{array}$ & $\begin{array}{l}\text { ED } \\
\text { patients }\end{array}$ & 228 & 21 & $4.4 \%$ & $59 \%$ & $9 \%$ & $6 \%$ \\
\hline [5] & $\begin{array}{l}\text { Santa Monica, California, } \\
\text { United States }\end{array}$ & $\begin{array}{l}\text { On-street } \\
\text { survey }\end{array}$ & 193 & & $5.7 \%$ & & & \\
\hline [6] & $\begin{array}{l}\text { San Francisco, California, } \\
\text { United States }\end{array}$ & $\begin{array}{l}\text { Police } \\
\text { injury data }\end{array}$ & 28 & 4 & $7 \%$ & $78 \%$ & & \\
\hline [6] & $\begin{array}{l}\text { San Francisco, California, } \\
\text { United States }\end{array}$ & $\begin{array}{l}\text { Trauma } \\
\text { patients }\end{array}$ & 8 & 1 & $25 \%$ & $100 \%$ & $50 \%$ & \\
\hline [7] & $\begin{array}{l}\text { San Diego, California, } \\
\text { United States }\end{array}$ & $\begin{array}{l}\text { Trauma } \\
\text { patients }\end{array}$ & 103 & & $2.0 \%$ & $65 \%$ & & \\
\hline [8] & $\begin{array}{l}\text { Santa Monica, California, } \\
\text { United States }\end{array}$ & $\begin{array}{l}\text { Police } \\
\text { collision } \\
\text { data }\end{array}$ & 122 & 9 & & & $47 \%$ & \\
\hline
\end{tabular}

Notes: ED: emergency department; EMS: emergency medical services; E-scooter: standing e-scooter.

Sources: [1] Austin Public Health (2019); [2] PBOT (2019) and Multnomah County Health Department (2019); [3] Baltimore City (2019); [4] Bekhit et al. (2020); [5] Trivedi et al. (2019); [6] VZSFIPR Collaborative (2019a);

[7] Kobayashi et al. (2019); [8] City of Santa Monica (2019b).

\section{Serious e-scooter crashes often involve motor vehicles}

Studies have acknowledged that the involvement of motor vehicles in e-scooter crashes is broadly proportional to injury severity (VZSFIPR Collaborative, 2019a). Between 2\% and 23\% of emergency department (ED) patients involved in e-scooter crashes declare that a motor vehicle was involved. Among e-scooter trauma patients, however, half declare that a motor vehicle was involved. Cyclists experience similar outcomes: crashes involving motor vehicles result in more severe injuries (Cripton et al., 2015).

Among hospital-reported bicycle crashes in Sweden, only 13\% involved a motor vehicle (Rizzi, Stigson and Krafft, 2013). In the Netherlands, motor vehicles were involved in $22 \%$ of bicycle injuries scoring $2+$ on the Maximum Abbreviated Injury Scale (Weijermars et al., 2016). Collisions with motor vehicles accounted for $34 \%$ of hospital-reported cyclist injuries in Vancouver and Toronto (Cripton et al., 2015). 
The analysis of non-fatal crash factors in this section is essentially based on hospital data due to the limitations of police data. Police tend to over-estimate motor vehicle involvement in bicycle crashes for at least two reasons: 1) bicycle crashes and single bicycle crashes, in particular, are rarely reported to the police and 2) some countries exclude single bicycle crashes from the scope of police data collection. Reporting of bicycle crashes to the police was found to be as low as $10 \%$ in the Rhone region (Blaizot et al., 2012) and 15\% in England (Aldred, 2018).

\section{Pedestrian injuries: Rare or under-reported}

Non-riders, mainly pedestrians, represent between $1 \%$ and $14 \%$ of standing e-scooter related injuries, averaging $4 \%$ across all studies. A major caveat is the likely under-reporting of injuries, a phenomenon that may be greatest among pedestrians. Their injuries may be treated as falls and, as such, lie outside the traditional scope of traffic safety data (Bekhit et al., 2020). Police data from Santa Monica found pedestrians to be involved in 7\% of shared micromobility collisions (City of Santa Monica 2019b).

One of the studies listed in Table 1 explicitly excluded patients aged 55 and older on the grounds that mobility scooter injuries may be misinterpreted as standing e-scooter injuries. Such a protocol should be avoided because it may exclude a number of pedestrian injuries genuinely involving e-scooters.

Serious pedestrian injuries in collisions with cyclists are also rare, especially when compared to injuries sustained by pedestrians from collisions with motor vehicles (O'Herne and Oxley, 2019). In 2016, 11 pedestrians were seriously injured in Germany in collisions with pedelecs, whilst more than 7000 were seriously injured in collisions with cars (Santacreu, 2018). Adjusting for fleet size, a car is nearly 50 times more likely to be linked with a serious pedestrian injury.

\section{Helmet use is rare}

Helmet use was rare among standing e-scooter riders across all studies, ranging from $0.5 \%$ to $25 \%$, averaging 4\%. Trivedi et al. (2019) conducted a field survey of helmet use and found no significant difference between field observations and ED patient stated helmet use ( $p=0.53$ from a Chi-square test).

The lower use of helmets among riders of shared bikes and shared standing e-scooters is documented by Haworth and Schramm (2019) and well understood: it can be explained to some extent by the spontaneous nature of shared-vehicle use. A 2019 survey of standing e-scooter riders in Brussels demonstrated that $47 \%$ of riders of privately owned vehicles always used a helmet, as opposed to $7 \%$ of shared-vehicle riders (Lefrancq, 2019).

E-scooter riders seem less likely than cyclists to wear a helmet. This is observed for both shared and private vehicle use in Brisbane, where helmet use is obligatory for all age groups and rideable devices. (Haworth and Schramm, 2019)

\section{Male riders suffer most injuries}

The proportion of male riders is consistently above $50 \%$ across all e-scooter injury studies. The average across all studies is $62 \%$. Among trauma patients, whose injuries are more severe, the proportion of male riders is higher, although not in a statistically significant manner ( $p>0.05$ from a Chi-square test).

The over-representation of males in injury statistics is consistent with ridership data from e-scooter sharing companies (City of Santa Monica, 2019a) but may also reflect the higher occurrence of risky behaviour by male riders. 
The share of male riders in standing e-scooter fatalities ( $86 \%$, or 30 out of 35 ) is significantly higher $(p<0.01)$ than their share among ED patients $(59 \%)$. The higher severity of injuries sustained by men is not specific to the use of e-scooters but already observed across all vehicle types. In England, Feleke et al. (2018) used the National Travel Survey to reveal that fatality rates for walking, cycling and driving were higher for males than females, controlling for distances travelled.

\section{Road surface conditions}

In Austin, Texas, half of e-scooter ED patients reported that road surface conditions contributed to their crash (Austin Public Health, 2019). In St Louis, Missouri, more than half of the patients said road conditions caused their falls (Petrin, 2019). In France, road surface conditions were mentioned by $40 \%$ of shared standing e-scooters users who had experienced a crash. The weather was mentioned by $25 \%$, essentially reflecting the negative effect of wet weather on handling (6t-bureau de recherche, 2019a).

Future research on e-scooter injuries and crash circumstances should apply the same protocol on bicycle injuries so that crash factors can be compared and vulnerability to road surface condition can be understood. The influence of vehicle design, including wheel size, on crash risk is discussed in this report's chapter on vehicle safety.

\section{E-scooter injury risk}

Standing e-scooter injury rates range from 87 to 251 ED visits per million trips. These injuries are of various severity levels, however, with approximately one in ten requiring hospital admission. In comparison, the 2009 cycling injury rate in the United States can be estimated at 110 to 180 ED visits per million trips.

An alternative way to quantify injury risk consists of counting the number of people admitted to a hospital bed. The ITF collated estimates for hospital admission rates for various modes of transport (Table 2):

- shared standing e-scooters: 29 per million trips in Austin, Texas (United States) and 62 in Auckland (New Zealand)

- bicycles: five to ten per million trips in the United States, four in France and one to two in Germany

- motorcycles and mopeds, together called powered two-wheelers: 28 per million trips in France.

Bicycle and standing e-scooter risks are broadly similar in terms of fatalities and ED visits, but seem to differ in terms of hospital admissions. The safety performance of e-scooters in comparison with other transport modes remains a topic where evidence is weak. Further investigation is essential for at least two reasons:

- No study has yet compared the injury rates per trip across e-scooter riders and cyclists using a consistent protocol, over the same observation area and timeframe. This is illustrated in Table 2. This is important because hospital practices may vary from place to place, even within the same country. Practice may differ on whether casualties should be admitted to hospital for observation, especially if head injuries are suspected (ITF, 2011).

- Studies conducted in 2018 reflect the safety performance of a new vehicle type in its first few months of operations. They may not reflect gradual improvements in vehicle design and in user skills that have occurred since then. 
The hospital admission rate of e-scooter riders should not be assessed on two studies alone. It is essential that more research is conducted.

Table 2. Rider injury rates per billion trips

\begin{tabular}{|c|c|c|c|c|}
\hline Ref. & City, Time & Standing e-scooter & Bicycle & $\begin{array}{l}\text { Powered } \\
\text { two-wheeler }\end{array}$ \\
\hline & & \multicolumn{3}{|c|}{ Injuries (ED visits) per billion trips } \\
\hline 1 & $\begin{array}{l}\text { Austin, Texas, United States } \\
2018\end{array}$ & 203000 & & \\
\hline 2 & $\begin{array}{l}\text { Baltimore, Maryland, United States } \\
\text { 2018-2019 }\end{array}$ & 87000 & & \\
\hline 3 & $\begin{array}{l}\text { Portland, Oregon, United States } \\
2018\end{array}$ & 251000 & & \\
\hline 10 & $\begin{array}{l}\text { Auckland, New Zealand } \\
\text { 2018-2019 }\end{array}$ & 200000 & & \\
\hline \multirow[t]{2}{*}{4} & $\begin{array}{l}\text { United States } \\
2009\end{array}$ & & $\begin{array}{l}110000 \\
\text { to } 180000\end{array}$ & \\
\hline & & \multicolumn{3}{|c|}{ Injuries (hospital admissions) per billion trips } \\
\hline 1 & $\begin{array}{l}\text { Austin, Texas, United States } \\
2018\end{array}$ & 29000 & & \\
\hline 10 & $\begin{array}{l}\text { Auckland, New Zealand } \\
\text { 2018-2019 }\end{array}$ & 62000 & & \\
\hline 5 & $\begin{array}{l}\text { Germany } \\
2008-2009\end{array}$ & & $\begin{array}{l}1000 \\
\text { to } 2000\end{array}$ & \\
\hline 6 & $\begin{array}{l}\text { Rhone, France } \\
\text { 2005-2006 }\end{array}$ & & 4000 & 28000 \\
\hline 7 & $\begin{array}{l}\text { Toronto, Canada } \\
2008-2012\end{array}$ & & circa 1000 & \\
\hline 4 & $\begin{array}{l}\text { United States } \\
2009\end{array}$ & & $\begin{array}{l}5000 \\
\text { to } 9000\end{array}$ & \\
\hline \multirow[t]{2}{*}{5} & $\begin{array}{l}\text { United States } \\
2008-2009\end{array}$ & & $\begin{array}{l}6000 \\
\text { to } 10000\end{array}$ & \\
\hline & & \multicolumn{3}{|c|}{ Injuries (MAIS3+) per billion trips } \\
\hline 8 & $\begin{array}{l}\text { Barcelona, Spain } \\
2012-2014\end{array}$ & & 100 & 515 \\
\hline 8 & $\begin{array}{l}\text { Melbourne, Australia } \\
\text { 2011-2015 }\end{array}$ & & & $\begin{array}{l}2000 \\
\text { to } 3200\end{array}$ \\
\hline 6 & $\begin{array}{l}\text { Rhone, France } \\
\text { 2005-2006 }\end{array}$ & & 1920 & 1450 \\
\hline 9 & $\begin{array}{l}\text { Sweden } \\
2011-2015\end{array}$ & & $\begin{array}{l}600 \\
\text { to } 1000\end{array}$ & \\
\hline
\end{tabular}

Notes: The term "powered two-wheeler" refers to motorcycles and mopeds, as per the Glossary. Where a data source provides a cycling injury rate per kilometre, the ITF calculated a low- and a high-risk estimates, per trip, assuming the average bicycle trip distance is between three and five kilometres.

Source: [1] Austin Public Health (2019); [2] Baltimore City (2019); [3] PBOT (2019); [4] CDC WISQARS (2019); [5] Buehler and Pucher (2017); [6] Blaizot et al. (2013); [7] Bassil et al. (2015); [8] ITF Safer City Streets database; [9] MAIS3+ from ITF IRTAD database, exposure from Castro, Kahlmeier and Gotschi (2018); [10] Bekhit et al. (2020).

Injury severity should be measured using a globally agreed medical assessment standard. The International Transport Forum proposes to define a serious injury as one scoring 3+ on a globally accepted trauma scale used by medical professionals: the Maximum Abbreviated Injury Scale (MAIS). It 
provides an objective and reliable basis for data collection and international comparisons (ITF, 2011). The injury score is determined at the hospital with the help of a detailed classification key. The score ranges from one to six. Injuries classified as three and above (or $3+$ ) on the MAIS scale are the most serious injuries and ones that involve significant or long-term consequences and costs. The European Commission adopted MAIS3+ as the definition of a serious injury in 2013 (European Commission, 2015).

None of the studies reported on the number of seriously injured e-scooter patients using the MAIS scale, but data exists for other modes. In terms of MAIS3+ per million trips, cycling is safer than riding a motorcycle or moped in Barcelona, but not as safe as riding a motorcycle or moped in the Rhone region. This again shows the difficulty of drawing conclusions from limited studies. It also shows the need to agree on common standards for estimating MAIS scores across the world. Comparability is indeed compromised by the number of different methods used across countries (Weijermars et al., 2018).

\section{E-scooter crash reports and insurance claims data}

E-scooter sharing companies collect crash data from riders, but such data should be interpreted with care. Only a fraction of users report their crashes to the company (Baltimore City, 2019; Bird, 2019).

Bird reported 37 crashes per million rides (Bird, 2019) while Tier, operating in Europe, where crash risks are lower than in other markets, reported 25 crashes per million rides (Lunden, 2019). The ITF collected time series from two other e-scooter companies and combined the data to show a decreasing trend over time (Figure 7). This trend may explain why some 2018 figures were significantly higher. In San Francisco, for instance, 200 incidents were reported per million rides in 2018 (VZSFIPR Collaborative, 2019a).

Fifteen collisions were reported to the police in Santa Monica for every million shared micromobility ${ }^{1}$ trip (City of Santa Monica, 2019b). This relatively low figure is consistent with the known under-reporting of cycling crashes to the police.

Figure 7. Number of crashes reported by riders of two standing e-scooter companies

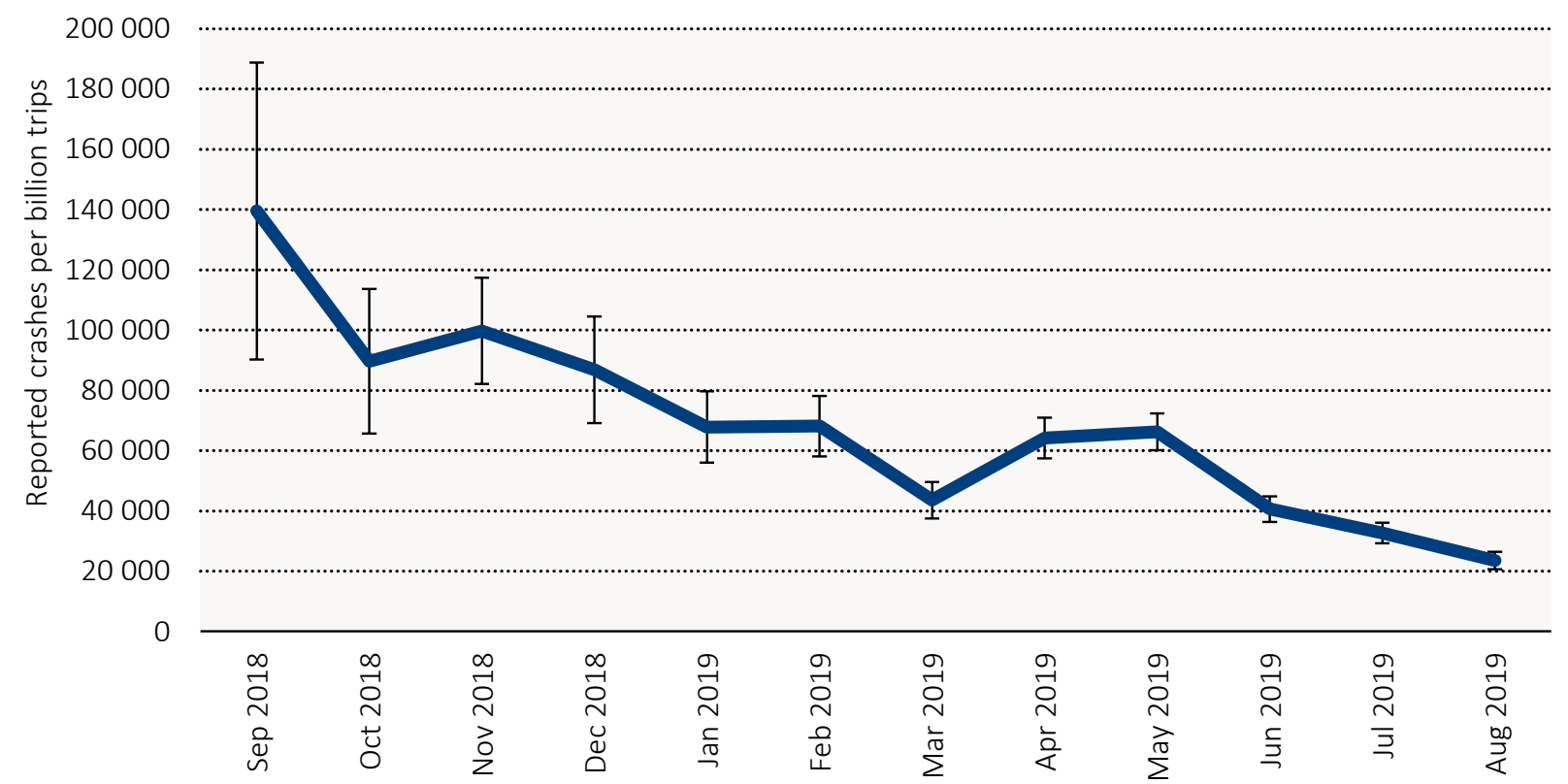

Source: ITF elaboration, based on data from two companies. 
In New Zealand, the Accident Compensation Corporation (ACC) delivered several insights. It found e-scooter injury claims for males and females were evenly split at 50\% each (Insurance Business, 2019). In Auckland, it also found that about 50 times less insurance claims are made for e-scooter crashes than for falls ${ }^{2}$. Insurance data also revealed the total medical cost of all shared e-scooter injuries in the Auckland region. Divided by the number of shared e-scooter trips ${ }^{3}$, this cost represents between USD 0.60 and USD 0.70 per trip (Bekhit et al., 2020).

\section{Safety through mode shift}

Car crashes cause four to seven times more deaths among vulnerable road users than among vehicle occupants. This information comes from the analysis of crash matrices in Bogotá, Colombia; Paris, France; and inner London, United Kingdom. It indicates that car occupants in dense urban areas represent a greater risk to other road users than to themselves as a group. (ITF, 2019a) In comparison, the total number of third parties killed in collisions with e-scooters or with bicycles is no more than $10 \%$ of the total number of fatalities in collisions involving e-scooters or bicycles.

To compare the traffic safety impact of different modes and assess the benefits of modal shift, the concept of risk is essential. Fatality risk is computed as the total number of fatalities involving each mode, divided by the number of trips, kilometres or hours travelled with each mode. Figure 8 shows the total fatality risk as the sum of the risk to oneself and the risk imposed on others. In these two components of risk, the latter has yet to be investigated in more cities. For this reason, results should be seen as indicative, representing only an order of magnitude. (ITF, 2019a)

Figure 8. Number of fatalities in collisions involving a given user group in selected cities, 2011-15

(per passenger trip in this user group)

Fatalities per billion passenger-trips (order of magnitude)

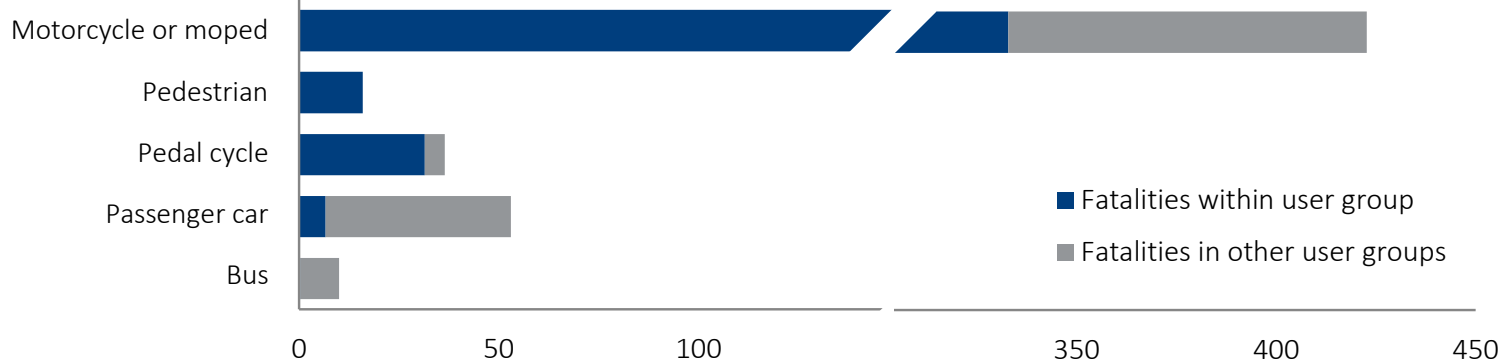

Note: Figures for standing e-scooters and slow e-bikes are not available but are thought to be similar to figures for pedal cycles. Fatalities, trips and travel distances from Auckland, Barcelona, Berlin, Greater London, Paris Area. Crash matrices from Bogota, Inner London, and Paris.

Source: ITF (2019a).

\section{Largest fatality risk for trips by motorcycle or moped}

Figure 8 suggests that riding a motorcycle or moped is associated with over 11 times more fatalities than riding a bicycle in urban areas, controlling for the number of trips. This takes into account fatalities among both riders and pedestrians. Motorcycles and mopeds together make up the powered twowheeler (PTW) category, as per the Glossary. 
Cycling is second only to walking in imposing the smallest fatality risk on other road users. People experience a higher risk to themselves when they cycle in comparison to when they travel by bus or car. Trips by car and PTW impose a greater overall fatality risk than a trip that is walked, cycled or travelled by bus. This analysis of fatality risk suggests that a modal shift away from cars and motorcycles could deliver significant road safety benefits in dense urban areas, not to mention wider public health benefits linked with physical activity and air quality.

Some see a regulatory failure in the extremely high risk that PTW riders experience and impose on third parties. Current transformations in urban mobility create an opportunity to better regulate vehicle use and eliminate speeds which are incompatible with the vision of eradicating deaths and serious injuries in traffic. Economists have calculated that PTWs generate much higher external costs than other transport modes per passenger kilometre, due to their poor safety and noise performance (Schroten et al., 2019).

The number of fatalities is likely to increase in places where powered micromobility is unregulated and allowed to reach the sort of speeds adopted by PTW riders. Regulators need to learn from mistakes of the past and make sure that micromobility does not ruin the efforts made elsewhere towards the elimination of road traffic deaths.

Fast e-bikes, with assistance up to $45 \mathrm{~km} / \mathrm{h}$, can reach the speed of mopeds. As such, they are a particular road safety concern and were discussed in a recent ITF roundtable (Santacreu, 2018). Their speed may be too high for cycling facilities. Other road users may also under-estimate the speed of a fast e-bike, as it looks like a conventional bicycle. Most countries therefore apply additional regulations on fast e-bikes, in comparison to conventional bicycles, such as helmet use and liability insurance. However, among fast e-bikes, those which are pedal assisted, do provide some health benefits. For this reason, they are often subject to a lighter regulation than mopeds, such as access to some of the bicycle network. Because fast e-bikes look like bicycles, they are practically immune to on-street identification and enforcement. Researchers and policy makers should develop solutions to limit the speed of fast ebikes where relevant and to ensure specific regulations are observed by riders.

\section{Substituting for cars, taxis and motorcycles}

Can micromobility help mitigate the danger of motor vehicle traffic by spurring a mode shift from private cars, taxis and motorcycles? Potentially, yes. Two-thirds of car trips made by London residents could be cycled in under 20 minutes (GLA, 2015).

In a survey of shared bike and shared e-scooter users in Santa Monica, California, a majority of respondents reported driving less often. A majority also reported ride hailing less often (City of Santa Monica, 2019a). In Portland, Oregon, 34\% of shared e-scooter users said they would have driven a personal car (19\%) or hailed a taxi, Uber or Lyft (15\%) if they had not taken an e-scooter for their most recent trip (PBOT, 2018).

The free-floating model has dramatically increased the popularity of micromobility. Among free-floating bike share users, $40 \%$ had never used a bicycle before (6t-bureau de recherche, 2016). In Portland, 78\% of people using shared e-scooters had never used the local bike-share system before (PBOT, 2018). This suggests that diverse forms of micromobility can complement each other, appeal to different user groups, and together contribute to reducing the mode share of cars, taxis and motorcycles.

Some jurisdictions (e.g. Korea and New South Wales) require users of shared e-scooter systems to possess a valid motorcycle or driving licence. The effect of such a policy on mode shift and safety is unclear and could be the focus of future research. Where this policy is motivated by the need to identify individuals, other forms of identification should be accepted for shared micromobility to deliver its full 
strategic potential. Where this policy is motivated by the need to ensure knowledge of road traffic rules, other solutions should be envisaged, which include child and adult road safety and micromobility training. One could also argue that driver licencing requirements should be proportional to the speed and mass of a vehicle. The same requirements would apply, then, to e-scooters and e-bikes if their speeds were capped at the same level.

Table 3. Mode shift reported by shared standing e-scooter users

\begin{tabular}{|c|c|c|c|}
\hline Ref. & Location & Mode & $\begin{array}{l}\text { Mode shift from car/taxi } \\
\text { trips }\end{array}$ \\
\hline 1 & Paris, Lyon and Marseille, France & e-scooter, Lime & $8 \%$ \\
\hline 7 & Paris, France & e-scooter, Dott & $10 \%$ \\
\hline 2 & Lisbon, Portugal & e-scooter, Lime & $21 \%$ \\
\hline 3 & Austin, Texas, United States & e-scooter, Bird & $22 \%$ \\
\hline 2 & Auckland, New Zealand & e-scooter, Lime & $22 \%$ \\
\hline 4 & $\begin{array}{l}\text { Auckland, Hutt Valley, Christchurch, Dunedin, } \\
\text { New Zealand }\end{array}$ & e-scooter & $23 \%$ \\
\hline 3 & Atlanta, Georgia, United States & e-scooter, Bird & $28 \%$ \\
\hline 2 & Seattle, Washington, United States & e-scooter, Lime & $30 \%$ \\
\hline 3 & Denver, Colorado, United States & e-scooter, Bird & $32 \%$ \\
\hline 3 & Los Angeles, California, United States & e-scooter, Bird & $32 \%$ \\
\hline 3 & Phoenix, Arizona, United States & e-scooter, Bird & $33 \%$ \\
\hline 5 & Portland, Oregon, United States & e-scooter (residents and commuters) & $34 \%$ \\
\hline 2 & Atlanta, Georgia, United States & e-scooter, Lime & $37 \%$ \\
\hline 2 & Austin, Texas, United States & e-scooter, Lime & $40 \%$ \\
\hline 2 & Kansas City, Missouri, United States & e-scooter, Lime & $40 \%$ \\
\hline 2 & Los Angeles, California, United States & e-scooter, Lime & $40 \%$ \\
\hline 5 & Portland, Oregon, United States & e-scooter (visitors) & $48 \%$ \\
\hline 6 & Santa Monica, California, United States & e-scooter and bike share & $50 \%$ \\
\hline
\end{tabular}

Notes: Mode shift refers to the mode (the survey only allows for a single choice) which would have been chosen for the most recent e-scooter trip would an e-scooter not have been available. Results from surveys allowing multiple choices are not represented here.

Sources: [1] 6t-bureau de recherche (2019a); [2] Lime (2019); [3] Bird (2019); [4] Fitt and Curl 2019; [5] PBOT (2018); [6] City of Santa Monica (2019a); [7] 6t-bureau de recherche (2019c).

Table 3 reveals the proportion of shared standing e-scooter trips which are reported to replace a car or taxi trip. This proportion ranges $8 \%$ to $50 \%$, with lowest figures observed in Europe and New Zealand, and highest figures observed in the United States. This most likely reflects the varying levels of car use across the world. In a city with very low car use, it is only natural that a very small fraction of e-scooter trips replace car trips.

E-scooters may be a solution for people experiencing minor physical mobility challenges, giving them an alternative to car use. Some users indeed reported that they would not have walked (8\%) or cycled (7\%) 
the last e-scooter trip they made, specifically because of their physical condition. (6t-bureau de recherche, 2019a)

Note that several survey results could not be included in Table 3 due to inconsistent survey design. The main issue is when multiple choices are given to answer the mode shift question. There would be great value in using harmonised questionnaires when conducting surveys. The ITF recommends that a single choice is allowed and that the question specifically refers to the most recent trip made by the user.

However small the figures are in European cities, shared vehicles could have a greater impact on car-use than is suggested by the relatively low mode shift figures observed:

- Among users of shared standing e-scooters in France, $12 \%$ declare that the service has changed their use of the private car, despite only $4 \%$ declaring that their last e-scooter trip would have been done by car (6t-bureau de recherche, 2019a).

- Likewise, $14 \%$ of French users of shared mopeds declare that the service has changed their use of the private car, despite only $3 \%$ declaring that their last moped trip would have been done by car (6t-bureau de recherche, 2019b).

Shared e-scooters can reduce car dependence, as they offer an occasional substitute where and when alternatives are not competitive. Competition between micromobility, walking and public transport is feared by many but may well be necessary for people to transition towards a car-free urban mobility. French survey data (6t-bureau de recherche, 2019c) suggests that shared e-scooter riders have not significantly reduced how much they walk or use public transport:

- Whilst $44 \%$ of local users would have walked to take their last trip if an e-scooter had not been available, only $6 \%$ of users walked less overall since they started using e-scooters.

- Whilst 30\% would have used public transport, only 6\% use public transport less often.

- In $44 \%$ of trips, only one leg of the return journey was made on an e-scooter. When this happens, the other leg is made on public transport $62 \%$ of the time.

\section{How can greater mode shift be achieved?}

Could more people cycle? A survey of nine European cities revealed that traffic safety is the biggest obstacle to cycling more frequently (De Ceunynck et al., 2019). In London, for example, dense traffic and the fear of being involved in a collision are by far the main barriers mentioned by non-cyclists (Transport for London, 2015). Improving traffic safety is essential to unlocking a modal shift towards cycling. The same principle is likely to apply to the use of e-scooters and other forms of micromobility.

Cycling, and micromobility more broadly, can feed into public transport and solve the first- and last-mile problem. It is likely to support public transport ridership on routes with an attractive commercial speed (e.g. rail, light rail and bus rapid transit) or on routes serving areas with poor walkability. In San Francisco, a survey revealed that $39 \%$ of e-scooter trips were made in connection with public transit (Lime, 2018). Public transport is the safest travel mode by far, and cities should promote using micromobility to connect with these services. Road deaths could be avoided if such inter-modal trips replaced those by car, taxi, moped or motorcycle. Micromobility can provide users with access to rail links that may be further afield but allow for direct transport to their destination, minimising the use of cars and boosting the capacity of a public transport system, which is often constrained by bottlenecks at interchanges (Veryard and Perkins, 2018). 


\section{Data collection: Why do it and how to improve it}

All jurisdictions should update their police and hospital data collection systems so as to identify micromobility crashes and precise vehicle types. Some authorities will choose to update their forms and coding systems ${ }^{4}$, others will promote the use of well-defined keywords (figures 9 and 10) in free text fields. Whichever solution is used, mobility scooters that aid persons with limited mobility should not be categorised with power-scooters or standing scooters. Since 2018, French police have been using revised data collection tools that identify powered personal mobility devices. This category is separate from bicycles and slow e-bikes, facilitating the analysis and interpretation of micromobility crash data.

Figure 9. Poster to assist medical staff with the coding of micromobility injuries
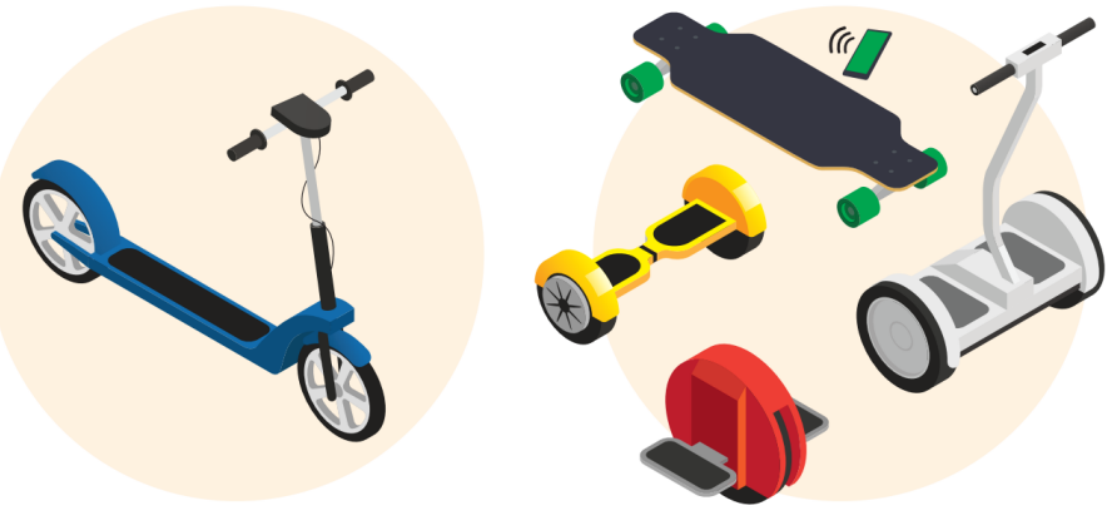

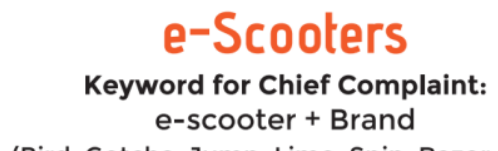

(Bird, Gotcha, Jump, Lime, Spin, Razor, etc.)

\section{Other Devices \\ Keywords for Chief Complaint: e-skateboard, e-hoverboard, Segway ${ }^{\circledR}$, e-unicycle}

NOT considered e-scooters

These devices are not considered e-scooters and have their own set of ICD-10-CM codes.
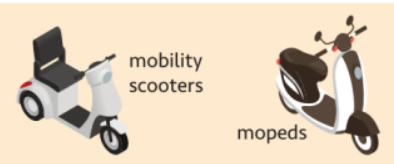

motor

scooters

Source: adapted from CSCRS (2019).

Keywords for e-scooter use can be searched in police or patient data; this is the protocol used in most studies presented in Table 3. It is a flexible and resilient solution in the fast-evolving mobility landscape, where new forms of micro-vehicle are yet to come. However, it requires training for health professionals so that the right keywords are used. The use of text mining software capable of correcting spelling mistakes is recommended.

There is a clear need for national and international guidelines for the consistent and comparable capture of micro-vehicle types across police and health data systems over time. Public health professionals and statistical authorities should work together to revise and expand codes that describe precisely which vehicles are involved in injuries. The most commonly used vehicle classification is the International Classification of Disease ICD-10. Yet the diversity and novelty of micro-vehicles have resulted in a lack of standardisation in both practice and guidance on how to capture injuries associated with micro-vehicles in medical records. (VZSFIPR Collaborative, 2019b) 
Researchers at CSCRS (2019) propose to revise ICD-10 to include new codes for e-scooters and prevent the confusion of vehicles in medical datasets. They propose guidance for medical professionals to adopt (Figure 9).

Police and public health casualty databases should also accommodate information on the shared or private ownership of the vehicle and on the name of the shared micromobility company if applicable. This is to enable linkages with trip data that is available from each company, and because trip data is likely less available for privately owned vehicles.

Trip data is essential to assess and monitor the level of risk associated with the use of a service or vehicle type. Governments should collect trip numbers and durations from shared micromobility companies and survey the population to assess the use of privately owned vehicles. Household travel survey questionnaires have to acknowledge the popularity of new vehicle types and be revised similarly to police and hospital forms.

Figure 10. Taxonomy adopted by police and public health departments in San Francisco

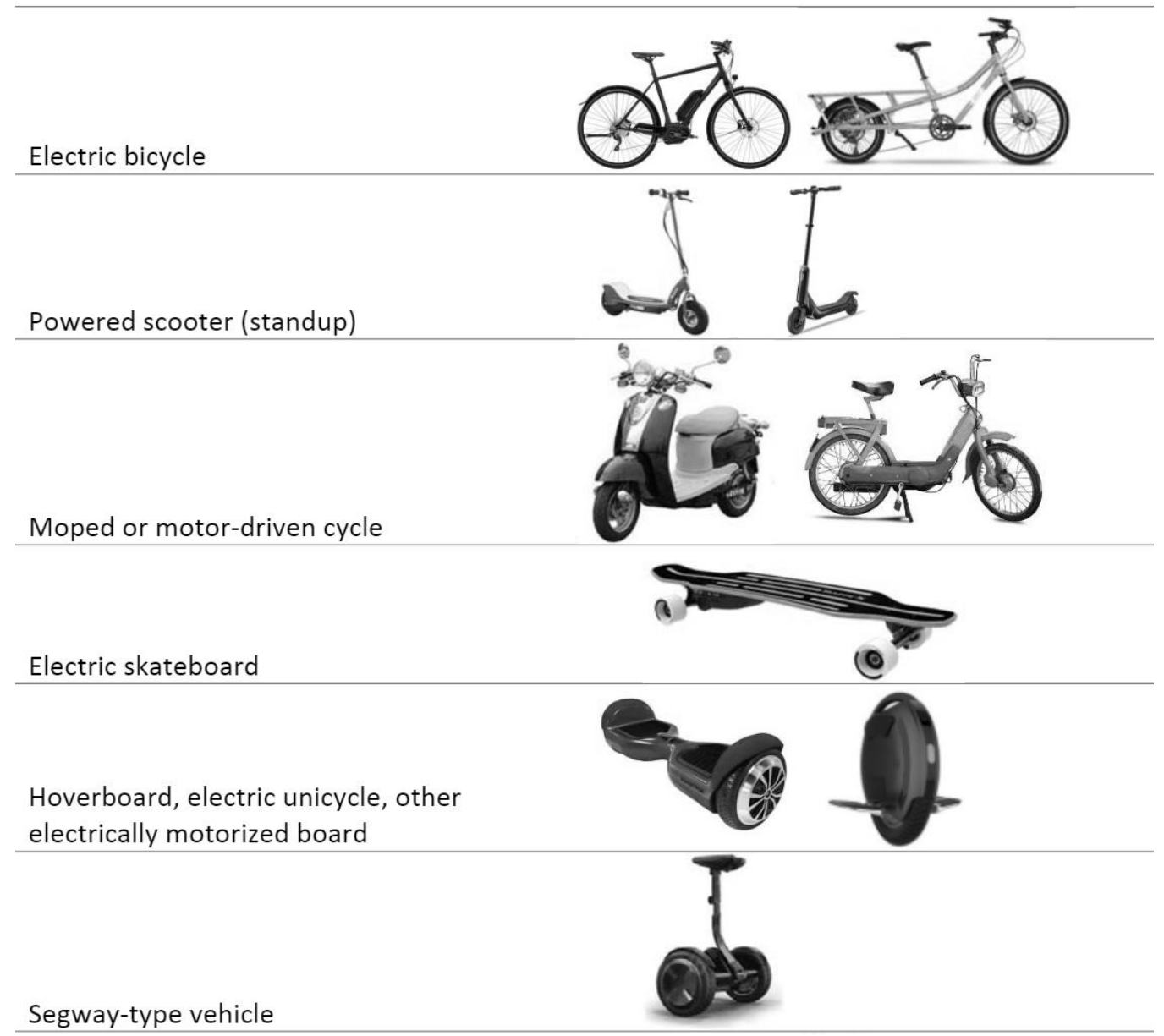

Source: VZSFIPR Collaborative (2019b).

A consistent minimum set of information should be reported in all e-scooter safety publications; this includes pedestrian injuries, motor vehicles involved and overnight hospital admission. Additional data on alcohol and drug testing methods and results, age, gender, and injury severity according to international medical standards would also be helpful. 
There is indeed little value in a data collection effort dedicated solely to e-scooters, since their crash typology severity and rate should be compared with that of other modes. Comparing e-scooter incidents with a sample of bicycle crashes or injuries would provide precious insight into the specificity - if any - of e-scooter safety. This could support investigations into the stability of each vehicle type and into the effect of rider experience.

What is needed is a comprehensive data collection effort from both the police and hospital services. The reporting of injuries by body region was proposed in some studies but these lacked comparability. Public health professionals should harmonise their reporting of injuries by body region and severity. 


\section{Safe vehicles and operations}

The Safe System approach to road safety was elaborated in Sweden and in the Netherlands in the 1990s. It is based on the idea that death and serious injury in road collisions are not an inevitable price to pay for mobility. The Safe System approach accepts that people make mistakes and acknowledges that collisions will continue to occur, but it aims to ensure that such mistakes do not result in fatalities or serious injuries. Better vehicle construction, improved road infrastructure and lower speeds can all contribute to reducing the impact of crashes, and better data can help us to understand and avoid future crashes. The responsibility for the Safe System is shared in a coordinated manner across the public and private sectors. Its application is closely monitored to assess results and, if necessary, review measures, taking into account experience, new data and new technologies. (ITF 2019b)

In a Safe System approach to micromobility, vehicle design should play a significant role. This section highlights the design elements which are most important and discusses the regulatory solutions towards safe vehicles.

Riders of standing e-scooters largely injure themselves in falls. For this reason, vehicle stability is a design priority. The stability of a micro-vehicle is influenced by a number of design factors including wheel size, tyre design, frame geometry, weight distribution and the presence of a seat and handlebar.

Pedestrian protection is also a design priority. Vehicle mass is an important factor here. Technology may offer solutions to prevent sidewalk riding and to limit speed in pedestrian areas.

Most e-scooter fatalities involve heavier vehicles. This naturally leads to several recommendations:

- Micro-vehicles should be visible in traffic. Regulators should acknowledge that different vehicle form factors will come with different design solutions for lights and reflectors.

- Heavier vehicles (ie. cars and trucks) should meet higher active and passive safety standards.

Occasionally, riders are injured by hardware failure. This raises the question of type approval, and which micro-vehicle approval and inspection system would be relevant and proportionate to the risks.

In the area of shared micromobility, design and operational questions are linked:

- A heavier battery means less frequent recharging; a swappable battery means lighter recharging operations. The use of vans in recharging and redistribution tasks has potentially negative impacts on traffic safety. This section will highlight some of them.

- Shared vehicle fleets, particularly exposed to harsh weather and vandalism, may require higher design standards than privately owned micro-vehicles. For example, remote diagnosis of faulty equipment and the protection of brake cables would be important steps towards safer vehicles. 


\section{Vehicle design}

The design of brakes, wheels, tyres and suspension attracted a high priority score in a survey circulated among industry experts and experts from the ITF Safer City Streets network (Annex 3). This section covers these aspects and explores other questions, such as the benefits of having a seat or a handlebar, and the need to improve the design of motor vehicles.

\section{Braking systems}

Industry experts prioritise reliable braking systems over performance improvements. They did not express a particular urge to see anti-lock braking systems (ABS) installed on all micro-vehicles. Regulators should nonetheless envisage this technology on heavier and faster micro-vehicles (types B, C and D), and regulatory alignment with motorcycles and mopeds.

Some regulators impose two independent braking systems on pedal cycles. This rule can be transposed to e-scooters without difficulty. However, other vehicle form factors exist where it is not physically possible to have two independent braking systems. Should this rule be applied to self-balancing microvehicles, they would become illegal. Dialogue with users and with the industry would help define an alternative set of rules for the approval and inspection of self-balancing devices.

Imposing two independent braking systems on those vehicles above a certain mass (types B and D) could be justified by the higher likelihood that these vehicles will carry a number of passengers or a significant cargo load. The case for regulation is reinforced by the ability of heavier micro-vehicles to carry more than two children, raising the stakes of brake failure.

For braking systems to be reliable, companies operating shared fleets of micro-vehicles should protect brake cables from vandalism. The use of fully-enclosed and tamper-proof brake cables is recommended by NACTO (2018).

Minimum performance requirements should be specified and tested during vehicle approval. These could be expressed in terms of outcome (e.g. average deceleration), under specific speed, load and gradient conditions. Regulators could seek to simplify vehicle approval by aligning procedures for microvehicles of types $A$ and $B$ with those applicable to e-bikes, and procedures for types $C$ and $D$ - vehicles with a higher speed - with those applicable to mopeds.

\section{Bells and other acoustic alerting systems}

An acoustic alerting device, such as a bell, is mandated on pedal cycles in the vast majority of countries that participate in the permanent working group of the ITF on road traffic safety, known as IRTAD ${ }^{5}$ (Yannis et al., 2019). Micro-vehicles with a handlebar could easily be equipped with a bell. Other vehicles, such as electric skateboards and self-balancing devices, could be sold with a handheld acoustic device or a remote control. But the regulatory approach should be relatively simple as these systems are of little interest to police and industry experts and regulation for them likely unenforced.

A significant number of bells on shared standing e-scooters in Paris are damaged, possibly due to frequent and rough handling of vehicles during charging and redistribution operations. A bell should be designed to withstand the potential vandalism and lack of care in a shared vehicle's operating life. Some e-scooter companies propose a potentially more robust rotating bell integrated into the handlebar. Others propose replacing the relatively fragile mechanical bell by an electronic sound activated by a button (Loritz, 2019). 


\section{Visibility}

The analysis of e-scooter crashes to date reveals that a significant proportion of rider deaths occur in night-time crashes.

Lights and reflectors are mandatory on pedal cycles in the vast majority of ITF IRTAD countries (Yannis et al., 2019). Some countries also impose the use of reflective vests in certain conditions. As part of a Safe System approach, however, it seems more appropriate to request reflective material from vehicle designers rather than from end-users. Not only are humans known for disregarding the rules, they are even more likely to do so when engaging in spontaneous trips on shared micro-vehicles. This report considers that the use of reflective accessories is a matter of personal choice, whereas vehicle equipment must provide sufficient visibility at all times.

When regulating for micro-vehicle visibility, policy makers should acknowledge that different vehicle forms will come with different design solutions for lights and reflectors. Some micro-vehicles have limited space for reflective surfaces. Skateboards, skates and electric unicycles, for example, are very small in size, whereas branding on shared vehicles can reduce the space available for reflectors. Regulators should impose clear specifications for minimum reflective surfaces. For example, they could specify the minimum amount of light that should be reflected by the micro-vehicle from any angle without stipulating if those reflectors should be placed on the wheel or the pedal. The use of reflective paint could become more widespread, as well.

\section{Weight}

Vehicle weight, along with speed, contributes to the kinetic energy of a vehicle and to the severity of injuries in the case of a collision with a pedestrian. In Paris, motorcycles and mopeds are involved in 20\% of pedestrian fatalities. With a similar traffic volume, pedal cycles are involved in just $4 \%$ of pedestrian fatalities. For this reason, it is natural to impose greater safety regulations on heavier vehicles.

First generations of shared electric standing scooters were typically below $20 \mathrm{~kg}$. As new generations are produced more robustly to withstand shared outdoor operations, to carry larger batteries and to prevent casual vandalism, typical vehicle weight is now over $20 \mathrm{~kg}$. The impact of micro-vehicle weight on pedestrian safety should be investigated.

\section{Wheels and tyres}

Road condition is mentioned as a crash factor by most individuals injured in electric standing scooter crashes. Regulators may specify road-handling tests or prefer to specify design characteristics, or combine both options.

Vehicles with small wheels are more likely to crash on poorly maintained roads. This is the reason why e-scooter companies propose vehicles with greater wheel size as they update their fleets. Paine (2001) conducted a series of tests comparing the road handling of several models of bicycles and standing scooters. These tests revealed that scooters (motorised and human-powered) are less stable and controllable than bicycles. Scooters are more susceptible to road irregularities. Sudden falls sideways into the path of passing cars are more likely on scooters than on bicycles. Paine states, "there do not appear to be any ways to significantly improve the design of scooters to increase their stability at higher speeds." This may have as much to do with centre of gravity, wheel caster effects or geometric effects, as wheel size. Authorities could nonetheless envisage imposing a minimum wheel size. 
Industry experts believe that pneumatic tyres offer a better road grip than solid tyres. Regulation in Amsterdam requires that standing electric scooters be equipped with pneumatic tyres (Abend, 2019).

Regulators may choose to specify a number of tests that micro-vehicles must pass in different operating conditions before being used on the roads. In Germany, for example, standing scooters must pass a series of obstacles which include vertical curbs (Box 2).

\section{Handlebars and turn indicators}

Cyclists make hand gestures to signal turns and stops. German regulation states that anyone riding a small electric vehicle must announce a change of direction with a hand signal unless turn indicators are available. However, most first-time users, and a significant portion of regular users, keep both hands on the handlebar of an e-scooter at all times, not making any signal at all. This could be for various reasons, such as a lack of stability and the need to keep one hand on the throttle. Manufacturers and regulators should, therefore, consider the case for having indicator lights on standing e-scooters. The German Association of Vehicle Testing Services suggests revising regulations for standing e-scooters, requiring that they be equipped with turn indicators (VdTÜV, 2019). One could imagine using foot signals as an alternative to hand gestures and indicator lights. Such an approach, however, comes with a significant risk of being misunderstood.

Electric skateboards, skates and most self-balancing micro-vehicles have no handlebar. Their safety performance is largely undocumented. They are not exposed to some of the safety challenges observed with e-scooters because the learning phase for the user is longer. This eliminates touristic use and user over-confidence from which e-scooters suffer. The French regulation on powered micro-mobility has legalised their use, which can facilitate a robust assessment of their safety performance over time.

The presence of handlebars on micro-vehicles may well have an effect on safety, positive or negative. This report makes several hypotheses for researchers to investigate:

- handlebars may facilitate emergency braking

- handlebars may facilitate the rapid familiarisation with the vehicle (a reason why all shared micro-vehicles have handlebars)

- handlebars may impede the use of hand gestures to signal turns and stops (gestures may destabilise the rider, cause the loss of throttle pressure or cause the loss or braking capacity)

- handlebars may contribute to injuries to the face and elbows in falls where hands could have better absorbed the crash-landing.

\section{Seats}

The height from which a human body falls can make the injury outcome worse. The height of the foot platform on a standing micro-vehicle may also determine which body parts come into contact with which motor vehicle parts in the event of a collision.

Certain safety benefits may derive from having a seat on an electric scooter because: 1) seating can lower the rider's centre of gravity, in comparison to a standing scooter and 2) seating may help the rider make hand signals without losing control. Future research should investigate differences in risk between seated and standing scooters, everything else being equal.

Should seated e-scooters be regulated as mopeds? This report suggests that factors such as mass and speed should determine the relevant safety regulations. The presence of a seat, of which the impact on 
safety performance is yet unknown, is best ignored in safety regulations - especially since a seat is removable on some models.

\section{Assistance systems}

Industry experts are working to develop innovative assistance systems to enhance micromobility safety. Sidewalk riding is a priority safety concern for $70 \%$ of traffic safety experts, according to an ITF survey (Annex C). Potential solutions are pedestrian detection cameras mounted on micro-vehicles, and autonomous braking. However, autonomous brakes on vehicles without a restraint system put the rider at risk of being thrown from the vehicle. What is needed is a system to prevent sidewalk use where it is not allowed.

Stability control solutions would be most welcome, be it mechanical, or electronic. Mechanical stabilisation for the e-scooter market should draw from over a century of pedal cycle design development. Some bicycles have a spring connecting the front fork to the frame to provide a progressive torque that tends to steer the bicycle straight ahead. This is especially common on cargo bikes and other bikes designed to carry loads over the front wheel. Most bicycles also have an angle and a bend - called fork rake - in the front fork, which contributes to stabilising the vehicle. Last, the gyroscopic effect is the tendency of a rotating body to keep its axis of rotation stable. The size and mass of the wheels greatly contribute to the gyroscopic stabilisation. E-scooter manufacturers should explore the safety benefits of larger wheels, fork rake and steering stabilisation.

Electronic stabilisation could strengthen the steering resistance at higher speeds and apply a corrective steering input when a fall is predicted. This could facilitate the use of hand signals on standing electric scooters. A prototype has been developed and fitted on a bicycle by TU Delft (2019). In the longer term, pedal cycles and scooters may become fall-proof thanks to such steering assistance.

\section{Car design}

Whilst the focus of this report is on micro-vehicles, vehicle safety considerations should not overlook the significant improvements which are needed in the design of heavier vehicles. This section considers both active safety (to prevent a crash) and passive safety (to mitigate the severity of a crash).

Intelligent speed assistance (ISA) is an active safety system helping drivers adhere to posted speed limits. ISA will be imposed on new cars sold in Europe from 2022 and there is potential for this to become a global standard. Autonomous vehicles must not be allowed to drive over the legal speed limit. Imposing strict speed limits on micro-vehicles would be disproportionate if limits applicable to heavier and faster vehicles were not strictly enforced.

Autonomous Emergency Braking (AEB) is another active safety system, designed to avoid crashes caused by late braking or braking with insufficient force. AEB involves a set of sensors on the vehicle which detect critical situations and apply full braking force autonomously, independently of the driver. As micromobility gains popularity, AEB should evolve to reliably detect all types of micro-vehicles. As for ISA, AEB will be mandatory for all new vehicles in the EU by 2022.

Cooperative Intelligent Transport Systems, or C-ITS, offer wireless solutions for vehicles to exchange trusted messages and cooperate with other vehicles, road infrastructure and other road users. Those messages are often time-critical and safety-related. Micro-vehicles could use C-ITS to broadcast their position and reduce crash risk. However, it is a matter of principle that collision avoidance systems should detect all road users, whether they are equipped with a transponder or not, for fairness reasons (ITF, 2019b). There is still value in a scenario where all shared micro-vehicles come equipped with a 
transponder and signal their presence to heavy vehicles in their surroundings. By doing so, shared microvehicle fleets could literally train existing collision avoidance systems, calibrating sensor sensitivity, and reducing the number of false negative detections.

In the area of C-ITS, governments could incentivise the use of best-practice technology to collect data from on-board vehicle sensors and learn about places where crashes are most likely to happen. Highway authorities could broadcast the position of risky locations in real time where feasible. Car sensors could identify potholes along their route. Now more than ever, there is scope for car manufacturers to share pothole data with local government on a permanent basis.

Passive safety improvements in cars should also be considered, especially in countries where governments are aiming for a shift towards more walking, cycling and micro-vehicle use. Cars come equipped with an increasing number of airbags, yet in most models, no airbag is protecting vulnerable road users from the consequences of a crash.

Foot platforms on standing micro-vehicles provide the riders with elevated height. This may cause radical changes to which vehicle parts come into contact with which body parts in a collision with a motor vehicle. Research should, therefore, examine whether and how cars' passive safety regulations need to be updated. Such regulations have traditionally prescribed some energy-absorbing materials on bonnets and windscreens. Assumptions on pedestrian height may need to be revised or broadened.

\section{Type approval and technical inspections}

Product safety is an essential part of market access regulation in many countries, even more so when products can be used as vehicles on public roads. Where such regulations exist and apply to motorscooters and bicycles, what do they require? Are they applicable on new forms of micro-vehicles?

Regulators should consider the benefit of aligning the requirements placed on micro-vehicles with existing frameworks:

- Could most requirements placed on Type A micro-vehicles be aligned with those applicable to bicycles and slow e-bikes? Considering the low kinetic energy of these vehicles, one could indeed argue that a formal type approval would be unnecessarily burdensome and might slow innovation.

- Could most requirements placed on Type $C$ and Type D micro-vehicles be aligned with those applicable to mopeds?

Shared mobility companies should not send a vehicle to landfill when one part is broken: they should recycle components and upgrade parts. An ITF report will explore this aspect as it proposes to assess and compare the life cycle carbon footprints of several mobility solutions (ITF, forthcoming a). Increasingly, shared micromobility vehicles are designed to be modular, not just for their batteries but for every other principal component group (wheels, electronics, body, etc.). Will type approval regulations cope with or discourage such solutions? When a vehicle recombines various components, which homologation permit will it display? Regulators should anticipate these questions as they develop their approval procedure.

Type approval policies should leave some room for outcome-based certification. In this sense, the German test on braking performance and obstacle crossing is a positive development (Box 2). 


\section{Box 2. German product testing}

In the European Union, personal light electric vehicles such as standing e-scooters fall outside of the scope of the Type Approval Regulation (EU) No. 168/2013 for two- or three-wheel vehicles and quadricycles. This is because self-balancing vehicles and vehicles without a seat are explicitly excluded. Instead, vehicle approval can be regulated at a national level. The German regulation known as eKFV specifies the type-approval requirements applicable to electric personal mobility devices.

Maximum speed and braking performance are tested on tracks. The minimum braking performance is set to $3.5 \mathrm{~m} / \mathrm{s}^{2}$. Vehicle dynamics are also tested by riding over specific vertical elements (represented in Figure 11) at maximum speed without loss of control.

Figure 11. German vehicle dynamics testing elements
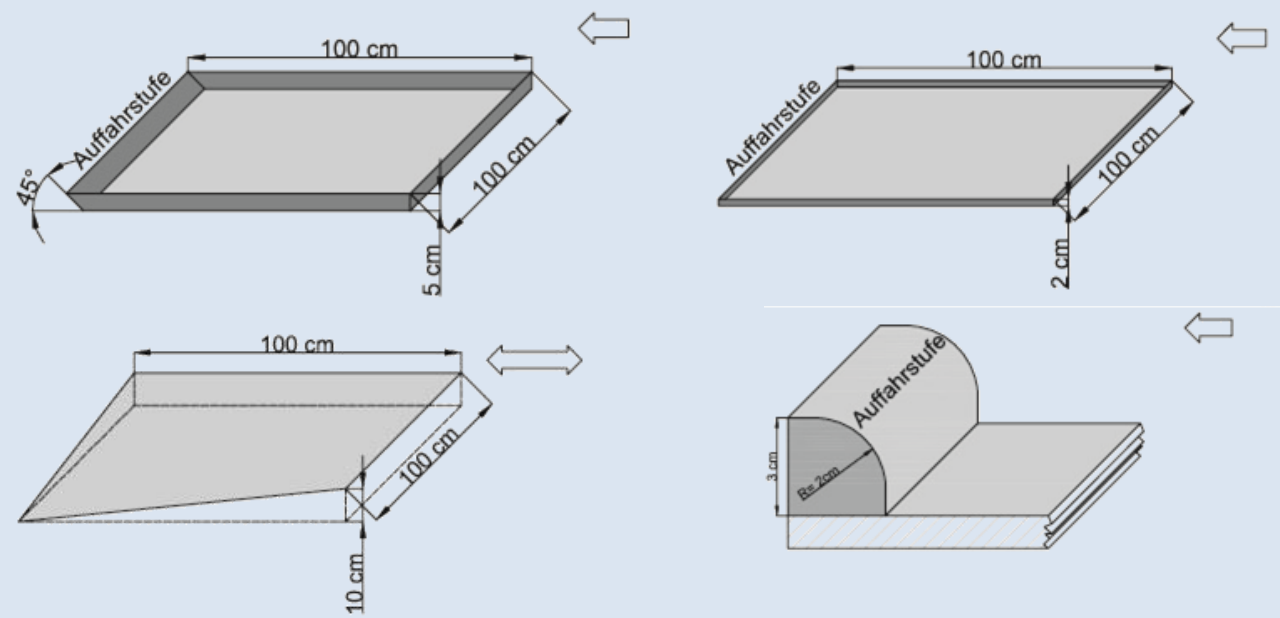

Note: "Auffahrstufe" can be translated as "step".

By the end of October 2019, 29 vehicle types were approved and permits were delivered by the Federal Motor Transport Authority (KBA), as listed on the KBA website. Approved small electric vehicles have a factory plate showing (a) manufacturer, (b) type and (c) permit number.

Source: BMVI (2019).

The type-approval process and safety requirements applicable to light vehicles can differ between countries but also within a country, as observed across the United States. A global harmonisation was proposed by the United Nations Economic Commission for Europe, which is today used by most countries as a reference (UNECE, 2017).

\section{European regulations and directives}

All micro-vehicle manufacturers have the minimum legal obligation to comply with the General Product Safety Directive (GPSD) 2001/95/EC and Directive 2006/42/EC on Machinery (Bike Europe, 2017a). The GPSD is not specifically oriented to vehicles, for which applicable safety rules are designed at a national level, but it establishes general community-level safety standards for any product placed on the market. 
The Machinery Directive is not specific to vehicles, either, but includes relevant health and safety requirements, nonetheless.

Regulation 168/2013 defines a type-approval process for light-powered vehicles, covering a number of areas including safety, construction and environmental performance (Annex D). It applies to:

- all L1e-B category vehicles: these are two-wheel mopeds and "speed pedelecs", which are defined as vehicles with a maximum design speed of up to $45 \mathrm{~km} / \mathrm{h}$, with a continuous rated power assistance of 250-4 $000 \mathrm{~W}$ (though most have 500-750 W)

- some L1e-A category vehicles: light two-wheel-powered vehicles with a continuous rated power assistance of 250-1 $000 \mathrm{~W}$.

Regulation 168/2013 does not apply, however, to devices such as pedelecs limited to $250 \mathrm{~W}$ and $35 \mathrm{~km} / \mathrm{h}$, self-balancing vehicles, electric unicycles or e-scooters, for which approval is managed at a national level. European safety requirements exist nonetheless for these devices (Table 4):

- The European Parliament and the Council of the European Union developed directives on the use of certain hazardous substances, the waste of electric equipment, the electromagnetic compatibility and the voltage limits.

- The European Committee for Standardization (CEN) defined voluntary safety standards, such as EN 50604 for removable lithium-ion battery systems. It also proposed EN 15194 as an adapted standard for Electrically Power Assisted Cycles (EPAC), which is now a global standard (ISO, 2020). CEN is currently developing a standard for personal light electric vehicles (PLEV) that are not, as of the writing of this report, subject to type-approval for on-road use. It will define safety requirements and adapted test methods (CEN, 2019). However, EN 15194 and EN 50604 remain voluntary standards. In most member states manufacturers are under no legal obligation to comply with them. Only a few member states made these standards compulsory, the United Kingdom and France among them.

In the European Union, a vehicle manufacturer can make an application for type approval in any member state. Through a principle of mutual recognition, the approval given in one country becomes valid throughout the European Union without the need for further tests. The certificate of conformity is delivered by a national type-approval authority. This authority can have in-house testing facilities, such as the German Federal Motor Transport Authority (KBA) and the Netherlands Vehicle Authority (RDW). In most cases, however, it designates technical services such as Dekra to test prototypes on its behalf. Selfcertification by manufacturers is also possible. In all cases, the national type-approval authority ensures that the tests are done correctly and remains the only structure entitled to deliver the type approval (European Commission, 2019a).

Light powered vehicles are excluded from periodic technical inspections (PTI) in Europe. Directive 2014/45/EU set minimum emissions and safety standards for vehicles that are currently in operation. It applies only for vehicles with a minimum design speed of $45 \mathrm{~km} / \mathrm{h}$. This remains unchanged since the last ITF report on improving safety for motorcycle, scooter and moped riders (ITF, 2015).

The European Commission (2019b) published a study on the inclusion of two- or three-wheel vehicles in the scope of the periodic roadworthiness testing. The study considers the impact of introducing inspection of mopeds in some Spanish regions between 2007 and 2010. The cost benefit analysis shows a very strong relationship between the introduction of PTI for mopeds in Spain and reduction in the number of crashes. With that in mind, a complete motorised vehicle inspection is recommended. It 
includes all inspection areas set out by Directive 2014/45/EU, with the less rigorous periodicities corresponding to the analysed countries:

- mopeds: first inspection after three years, subsequent inspections every two years

- motorcycles: first inspection after four years, subsequent inspections every two years.

Table 4. Approval requirements for powered cycles and two-wheel mopeds in Europe

\begin{tabular}{|c|c|c|c|c|}
\hline Reference & Title & $\begin{array}{l}\text { Power assisted } \\
\text { bikes, up to } \\
250 \mathrm{~W} \text { and } \\
25 \mathrm{~km} / \mathrm{h}\end{array}$ & $\begin{array}{l}\text { L1e-A category } \\
\text { vehicles up to } \\
1000 \mathrm{~W} \text { and } \\
25 \mathrm{~km} / \mathrm{h}\end{array}$ & $\begin{array}{l}\text { L1e-B category } \\
\text { vehicles up to } \\
4000 \mathrm{~W} \text { and } \\
45 \mathrm{~km} / \mathrm{h}\end{array}$ \\
\hline $\begin{array}{l}\text { Regulation } \\
168 / 2013\end{array}$ & $\begin{array}{l}\text { Approval and market surveillance of two- } \\
\text { or three-wheel vehicles and quadricycles }\end{array}$ & & $x$ & $\mathrm{x}$ \\
\hline $\begin{array}{l}\text { Regulation } \\
134 / 2014\end{array}$ & $\begin{array}{l}\text { Environmental and propulsion unit } \\
\text { performance requirements }\end{array}$ & & $x$ & $x$ \\
\hline $\begin{array}{l}\text { Regulation } \\
3 / 2014\end{array}$ & Vehicle functional safety requirements & & $x$ & $x$ \\
\hline $\begin{array}{l}\text { Regulation } \\
44 / 2014\end{array}$ & $\begin{array}{l}\text { Vehicle construction and general } \\
\text { requirements }\end{array}$ & & $x$ & $x$ \\
\hline $\begin{array}{l}\text { Regulation } \\
901 / 2014\end{array}$ & Administrative provision & & $x$ & $x$ \\
\hline $\begin{array}{l}\text { Directive } \\
\text { 2001/95/EC }\end{array}$ & General product safety (GPSD) & $x$ & $x$ & $x$ \\
\hline $\begin{array}{l}\text { Directive } \\
\text { 2006/42/EC }\end{array}$ & Machinery & $x$ & & \\
\hline $\begin{array}{l}\text { Directive } \\
\text { 2006/66/EC }\end{array}$ & Battery Directive (BD) & $\mathrm{x}$ & $x$ & $\mathrm{x}$ \\
\hline $\begin{array}{l}\text { Directive } \\
\text { 2011/65/EC }\end{array}$ & $\begin{array}{l}\text { Restriction of the use of certain } \\
\text { hazardous substances (RoHS) }\end{array}$ & $x$ & & \\
\hline $\begin{array}{l}\text { Directive } \\
\text { 2012/19/EU }\end{array}$ & $\begin{array}{l}\text { Waste of electrical and electronic } \\
\text { equipment (WEEE) }\end{array}$ & $x$ & & \\
\hline Directive $2014 / 30$ & Electromagnetic compatibility (EMC) & $x$ & & \\
\hline $\begin{array}{l}\text { Directive } \\
\text { 2014/35/EU }\end{array}$ & Voltage limits (VLD) & $x$ & & \\
\hline $\begin{array}{l}\text { EN } 15194 \text { (2009) } \\
\text { standard }\end{array}$ & Electrically Power Assisted Cycles (EPAC) & $x$ & & \\
\hline $\begin{array}{l}\text { EN } 50604 \text { (2016) } \\
\text { standard }\end{array}$ & $\begin{array}{l}\text { Secondary lithium batteries for light } \\
\text { electric vehicle applications }\end{array}$ & $x$ & & \\
\hline
\end{tabular}

\section{Regulation in the United States}

In the United States, the Federal Government regulates vehicles through federal agencies. The Consumer Product Safety Commission (CPSC) handles consumer products, such as bicycles, and its purview is limited only to the manufacturing and first sale of consumer products. Bicycles that fail any of the requirements are banned for sale under the Federal Hazardous Substances Act (FHSA, 2019). The National Highway Transportation Safety Administration (NHTSA) handles motor vehicles, and its purview is limited primarily to safety requirements of motor vehicles. Through administering the Federal Motor Vehicle Safety Standards (FMVSS), NHTSA is able to impose requirements on the design, construction, 
performance, and durability of motor vehicles. However, each state has the possibility to govern the licencing and use of consumer products and motor vehicles insofar as they do not enact laws that reduce safety standards set by the federal agencies (NITC, 2014).

In 2002, the US Congress established requirements for low-speed electric bicycles with Public Law 107-319, which amended the Consumer Product Safety Act. These vehicles are defined as "two- or three-wheeled vehicles with fully operable pedals and an electric motor of less than 750 watts ( $1 \mathrm{hp}$ ), whose maximum speed on a paved level surface, when powered solely by such a motor while ridden by an operator who weighs 170 pounds, is less than $20 \mathrm{mph}(32 \mathrm{~km} / \mathrm{h}) . "$ It also differentiates low speedelectric bicycles from motor vehicles. (Public Law 107-319, 2002)

In 2005, NHTSA addressed the apparent incongruence between a motor vehicle and a low-speed electric bicycle for safety reasons. It followed CPSC orientation and did not consider low-speed electric bicycles as motor vehicles. Thus, NHTSA defers to CPSC to regulate these products (NITC, 2014).

Table 5. Requirements for bicycles and slow e-bikes in the United States

\begin{tabular}{|l|l|}
\hline Federal Regulation & Requirements \\
\hline$\S 1512.5$ & Braking system \\
\hline$\S 1512.6$ & Steering system \\
\hline$\S 1512.7$ & Pedals \\
\hline$\S 1512.8$ & Drive chain \\
\hline$\S 1512.9$ & Protective guards \\
\hline$\S 1512.10$ & Requirements for tyres \\
\hline$\S 1512.11$ & Wheels \\
\hline$\S 1512.12$ & Wheel hubs \\
\hline$\S 1512.13$ & Front fork \\
\hline$\S 1512.14$ & Fork and frame assembly \\
\hline$\S 1512.15$ & Seat \\
\hline$\S 1512.16$ & Reflectors \\
\hline
\end{tabular}

Source: CPSC (2019).

All powered vehicles that exceed 750 watts and a maximum self-propelled speed of $32 \mathrm{~km} / \mathrm{h}$ are considered as "motor vehicles" and must comply with additional requirements that are found in the Federal Motor Vehicle Safety Standards (NHTSA, 2013).

The federal definition of motor vehicles and e-bikes does is not necessarily adopted by state and local governments. They have the power to authorise vehicular registration and licencing, which leads to different implementations (NITC, 2014). States and local governments also define vehicles and operational rules individually, resulting in local context-specific policies that are often incompatible with neighbouring jurisdictions.

There is no federal requirement for technical inspections of motor vehicles in the United States. Only a limited number of states require safety inspection. NHTSA (2017) created vehicle in use inspection standards, which set inspection criteria for several vehicle systems. 


\section{Shared fleet operations: Best practice in maintenance, recharging and redistribution}

The operation of shared fleets of micro-vehicles comes with specific road safety challenges and opportunities which are not found with privately owned devices.

Maintenance is a particular challenge considering the intense and outdoor use of the vehicles, not to mention vandalism. Damaged vehicles could be a hazard, which is why most app-based micromobility companies encourage their users to check if the brakes work before taking a ride. Self-diagnosis is an area where rapid progress is anticipated: vehicles will be able to identify faults as they occur and remotely call for a remedial intervention, thus preventing injuries due to faulty equipment.

Users also have a role to play in diagnosing unsafe vehicles. Shared micromobility companies should enquire feedback at the end of each ride. A natural market pressure exists to make the feedback process quick and painless to the user, at the risk of limiting its capability to diagnose vehicle problems. More use should be made of voice recognition software for this reason.

Staff inspections are also part of the solution, helpful to diagnose problems on various pieces of equipment such as bells or lights. The positive aspect of electric shared micromobility is the regular handling by dedicated staff employed for the recharging of batteries.

Last but not least, regulators should commission regular independent surveys of shared fleet conditions.

Maintenance operations are often conducted using dedicated vans, a solution which comes with added congestion, pollution and crash risk for the city. Instead, some companies use cargo-bikes for maintenance tasks, addressing all three negative impacts. Dockless micromobility company JUMP uses cargo bikes (Figure 12) in Paris, Berlin, Brussels and five other cities ${ }^{6}$, to transport e-bike batteries to swap out in the field (JUMP, 2019). Other operators integrating electric cargo-bikes or other electric vehicles in their operations include VOI and Dott.

Figure 12. Cargo bike used in maintenance and battery swap operations

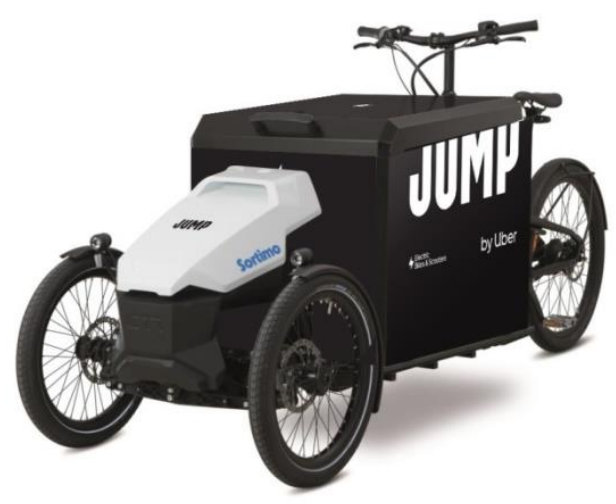

Source: Uber.

The recharging and rebalancing of micro-vehicle fleets also comes with negative impacts. Van or pickup truck rotations are not neutral in terms of road safety (Figure 13). Micromobility companies should take ownership of the safety performance of the staff and contractors involved in this operation. In line with their image of innovators, companies should deploy technology solutions towards safe and eco-driving. 
One way to improve road safety is by creating parking hubs for micromobility vehicles in dense urban environments. This would provide a localised point of collect for rechargers who might otherwise be distracted drivers as they searched the streets for scattered vehicles.

Figure 13. Contractors or "juicers" use private vehicles to collect and recharge e-scooters

(c) Alexandre Santacreu

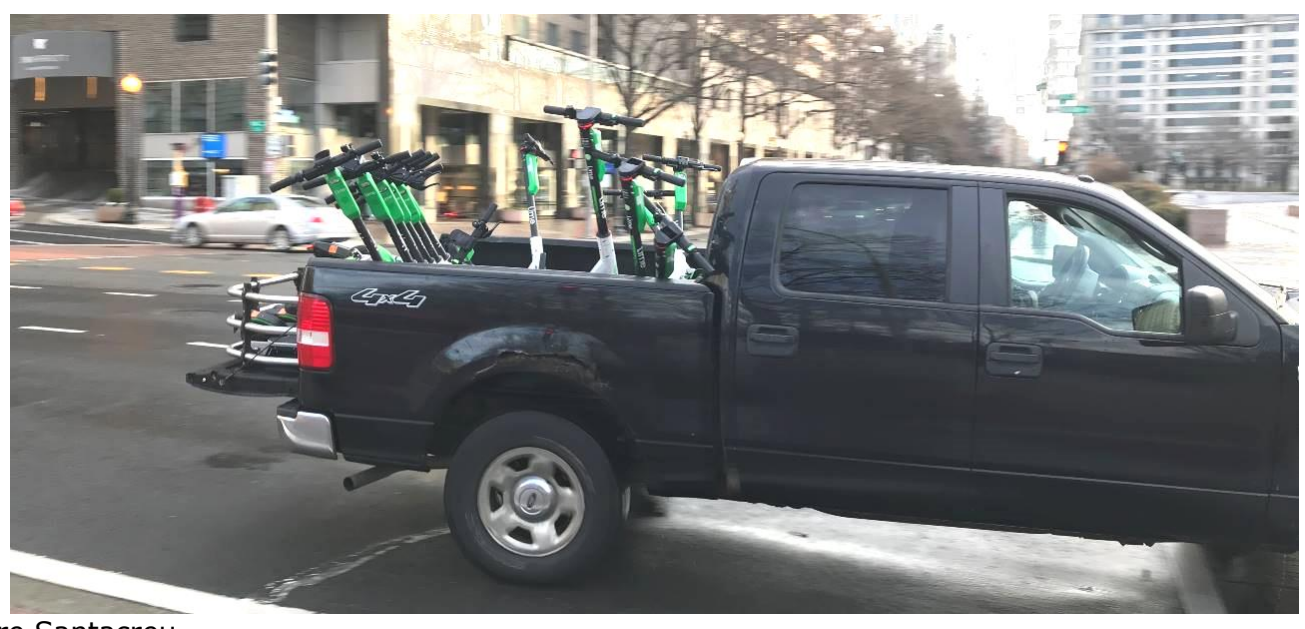

Some companies may rely on bicycle trailers to collect, recharge and rebalance their shared microvehicle fleet throughout the city (Maus, 2016). This method mitigates the impact a van could have but still has an impact on the safety and level of service of the cycling network, as vehicles and trailers used for rebalancing can obstruct a bike lane as they stop to load and unload. When a city paints or builds a parking hub, consideration should be given to where the rebalancing vehicle will park. Local government and shared micromobility companies should work together to identify the most suitable locations for the parking of micro-vehicles.

Some cities have implemented on-street parking zones for shared micromobility. In the United States, the City of Santa Monica (2019b) installed 107 parking and pick-up zones, helping to organise rider parking and manage service provider fleet deployment. It uses geofencing techniques to enforce the use of parking zones. Many industry experts are in favour of the idea of requiring riders of shared dockless micro-vehicles to park their vehicles in dedicated zones. Not only would it reduce clutter on the urban landscape and tripping hazards for pedestrians, it would also facilitate fleet operations.

Could operators deploy a shared dockless micromobility model without collateral vehicle movement? This could be envisaged considering several opportunities:

- Dynamic pricing could encourage people to make greater use of vehicles where their concentration is excessive.

- Sufficiently sized fleets and storage capacity could eliminate the need for rebalancing.

- Swappable batteries could be exchanged using a network of battery banks or local business partners. In this case, the rider benefits from a credit on the cost of the ride.

- Swappable batteries could be exchanged by maintenance staff on cargo bikes.

- Vehicles could be plugged into charging docks in a hybrid model, offering both free-floating and dock-based options to the user.

- Higher capacity batteries could reduce the need for recharging. 


\section{Safe road users}

E-scooter riders impaired by alcohol or riding on sidewalks captured media attention in 2019. Those topics attracted a high priority score in a survey circulated among industry experts and experts from the Safer City Streets network (Annex C).

The survey revealed high expectations that training may reduce the elevated crash risk observed among novice e-scooter riders. Training may indeed help users to better control their vehicle and to better integrate themselves in the traffic system. "Training people how to ride in traffic" is seen as a top or high priority by over $60 \%$ of respondents, which is where synergies could be envisaged with cycle training. "Updating the classic road safety education" attracts a similar score and could be interpreted as the need to revise driver training, a point which this report explores further below.

"Applying the Safe System principles to micromobility" is a top priority for $30 \%$ of the 49 survey respondents. As a result, the assumption should be that people will always make mistakes, no matter how much training or experience they accumulate (ITF, 2016). For this reason, this chapter on behaviour can only deliver part of the solution to address micromobility safety questions. Safe vehicles and a safe infrastructure are indispensable components of a Safe System. Education and raising awareness can complement but must never substitute for other, more effective measures (Polis, 2019).

\section{Experience, training and education: Will micromobility become safer over time?}

The rapid growth of the e-scooter sharing system is fuelled, at least in part, by a travel demand previously unmet: that of a population which does not feel confident enough to cycle and often lacks the skills to do so safely. In countries where very few people cycle, e-scooters are helping the population benefit from a new transport mode that is comparable in both performance and convenience to a bicycle. What is the impact of novice riders suddenly engaging in the traffic environment?

The lack of experience with micromobility has two dimensions: 1) people may not be familiar with new vehicle types such as e-scooters or e-bikes and 2) people may not be familiar with the traffic rules and with techniques for anticipating dangers and staying safe. Governments at all levels should seek to address the second point by providing training to all children. Examples of cycle training in schools exist and are documented in Box 3. Governments should also make cycle training available to adults. Training could be adapted and expanded to include other forms of micromobility including, but not limited to, standing e-scooters. However, one could argue that cycle training would be sufficient to provide a core set of skills applicable to the use of all micro-vehicles in traffic, and that cycle training also helps people lead healthier, physically active lives.

The risk of injury could be highest during a person's first few e-scooter rides. In Austin, Texas, 33\% of e-scooter rider injurys occurred during the user's first ride and 63\% during the first nine rides (Austin Public Health, 2019). The interpretation of such figures is difficult, however, due to the lack of data on 
how much experience the average rider has acquired, since most people had made very few rides at the time of the study. In a city where e-scooters were recently introduced, or where touristic use is important, it is mathematically inevitable that most people who are injured will be injured on their first few rides.

\section{Experience affects behaviour and risk}

Youth and lack of experience have a compound effect on crash risk. This was observed among novice car drivers: the crash rate of older novice drivers is lower than that of younger ones (Curry et al., 2017).

Drivers between 16-24 years old are highly over-represented in crash statistics, with risks that are two to three times higher than those of more experienced drivers. They are more often involved in singlevehicle crashes, in night-time crashes and in crashes involving "loss of control" or "high speeds". Underlying factors contributing to this risk for young drivers are immaturity, lack of experience, impairment, and lifestyles associated with their age and gender. Young drivers engage more frequently in high-risk situations such as night-time driving and driving older cars with fewer safety features (European Commission, 2015).

Driver experience can be expressed in terms of cumulated mileage and time since obtaining a licence; it affects both vehicle control skills and more complex cognitive skills, such as information processing skills, self-calibration, hazard and risk perception, and safety-related motivation or attitudes (Harrison, 1999).

Lack of driving experience, in terms of mileage, affects vehicle manoeuvring, increasing the tendency to commit operative errors and the probability of being involved in near miss crashes. Lack of experience also causes the failure to detect and recognise latent hazards in roads and traffic situations (Harrison, 1999). Moreover, experience enhances visual search strategies and increases cognitive skills, which are more influential than the lack of vehicle control (Deery, 1999; Underwood, 2007). Experience continues to play a role even many years after obtaining the driving licence. A study in Brazil confirmed that the longer professional truck drivers had been driving, the lower the reported involvement in crashes and near-misses, regardless of age (Girotto et al., 2016). It could be assumed that across all transport modes, experienced drivers are more likely to anticipate conflicts and avoid crashes.

Liu, Hosking and Lenné (2009) investigated the differences between hazard perception abilities of experienced and novice powered two-wheeler (PTW) riders. They found that novice riders are overconfident about their abilities and fail to perceive hazards as well as experienced riders. Other research studies have shown that experienced riders respond faster to hazards than inexperienced ones (Hosking, Liu and Bayly, 2010). Another study investigating risk awareness abilities among different populations of motorcyclists concluded that cognitive abilities in both hazard detection and situational criticality assessment depend on and are improved with riding experience (Bellet and Banet, 2012). A more recent study assessed the impact of experience and advanced training on rider behaviour using a motorcycle simulator; the results suggested that advanced training has proven beneficial over more experience (Crundall et al., 2014).

Research should be conducted to examine if some of the experience acquired with one vehicle type, such as a bicycle, may be transferable to another, such as an e-scooter. Such a finding would re-affirm the benefit of conducting cycle training in schools. Research has already found that car driving experience contributes positively to the safety of PTW riders (Lardelli-Claret et al., 2005). Likewise, e-bike riders with car driving experience were statistically less likely to be involved in at-fault crashes (Yao and Wu, 2012). Transferability is, however, limited in other areas. One study found that pedal cycling 
experience was not associated with differences in drivers' attention toward pedal cycles (Robbins and Chapman, 2018).

\section{The role of training}

Driver or rider training is a common road safety strategy and solution for increasing road safety, regardless of road user experience. In road safety literature the terms "training" and "education" are often used interchangeably. Before a policy is defined for e-scooter training, much can and should be learned from other modes. For instance, motorised mobility scooter user training proved positive and reduced conflicts with pedestrians (Toosizadeh et al., 2014).

\section{Box 3. Teaching cycling skills in schools}

Providing cycling lessons at a young age could help to decrease the number of road crashes involving cyclists. These lessons could include traffic rules and on-street riding skills and could lead to a change in children's road safety culture. In 2009, the European Union initiated the Life Cycle project, a kindergarten cycling programme that was adopted in the Austrian city of Graz and in Ljubljana, Slovenia. (Kollinger, Rzewnicki and Fismer, 2011). There are other examples of cycling training programmes for children throughout the world.

The Netherlands is a world leader in terms of high cycling participation and low crash risk per kilometre cycled (Santacreu, 2018). Each year, 200000 children across the Netherlands participate in the national Verkeersexamen, or "traffic test". Following an in-class theory session, the 12-year-olds undertake a practical exam on the streets of their city, designed to familiarise them with various real-life traffic situations. Upon successful completion of the 5-km bicycle ride - evaluated by parent volunteers - the students receive a personalised diploma. This test and the diploma it confers is a rite of passage for every Dutch child starting secondary school. ${ }^{7}$

England has several training programmes to promote safe biking. "Bikeability" is a cycle training programme funded by the Department of Transport. Registered local Bikeability providers organise and conduct the trainings, which take place predominantly in schools (Bikeability, 2019). "Bike it Plus London" is a behaviour change programme for schools that was developed by Sustrans (United Kingdom's leading sustainable transport charity) in partnership with Transport for London. It involves students, staff, parents and the wider school community (Sustrans, 2019).

In New Zealand, the NZ Transport Agency and Accident Compensation Corporation have collaborated in the development of a national cycling education system called "BikeReady". This system is based on giving people the skills they need at the right time in their life - from learning bike handling skills in primary school to learning road rules and how to ride on-road when they are ready (NZ Transport Agency, 2019).

In Australia, the Department of Planning, Transport and Infrastructure (DPTI) runs the successful "Way2Go Bike Ed Program" in primary schools. This programme is funded and managed by the DPTI and provides bicycle education for primary education students aged 9-13 years (Way2Go, 2019). ${ }^{8}$

Graduated driver licencing (GDL) programmes and a probationary licence have been progressively introduced in several countries worldwide since the early 1970s. Their aim was to reduce fatal crashes and high-risk behaviours among teen drivers. GDL is a licencing system designed to provide learners with driving experience and skills gradually over time in low-risk environments. Implementation of GDL 
training has resulted in a $22 \%$ reduction of crashes among 16-year-old and $6 \%$ in 17-18-year-old drivers (Zhu et al., 2013). Most formal pre-licence training (FPLT) focuses on procedural skills relating to vehicle control. It covers many formats, including professional driving instruction, school-based driver education, etc. Regarding the effect of FPLT, it can be measured as a difference in driving performance between drivers who did not complete the same training. Overall, FPLT based on mandatory driver education or computerised training focused on cognitive driving skills is effective in improving novice drivers' road safety (Hay, Etienne and Paire-Ficout, 2017). Early trained drivers have better speed adaptation skills and enhanced lateral and longitudinal vehicle control than traditionally trained ones (Freydier, Berthelon and Bastien-Toniazzo, 2016).

The safety of micromobility depends at least as much on driver training for motor vehicle users as on micro-vehicle rider training. As demonstrated earlier, fatal micromobility crashes typically involve cars or trucks. A core element of driver training could require motor vehicle drivers to spend time cycling in traffic. Another element could consist of adopting safety habits such as the "Dutch reach", which prevents drivers from opening a car door into the path of a person cycling. Police services need also to be trained to place priority on the enforcement of moving offences by drivers of motor vehicles. Passing distances and safe headways, for instance, should be better enforced.

Figure 14. In-app taxi passenger alerts for the safe opening of car doors near bikes
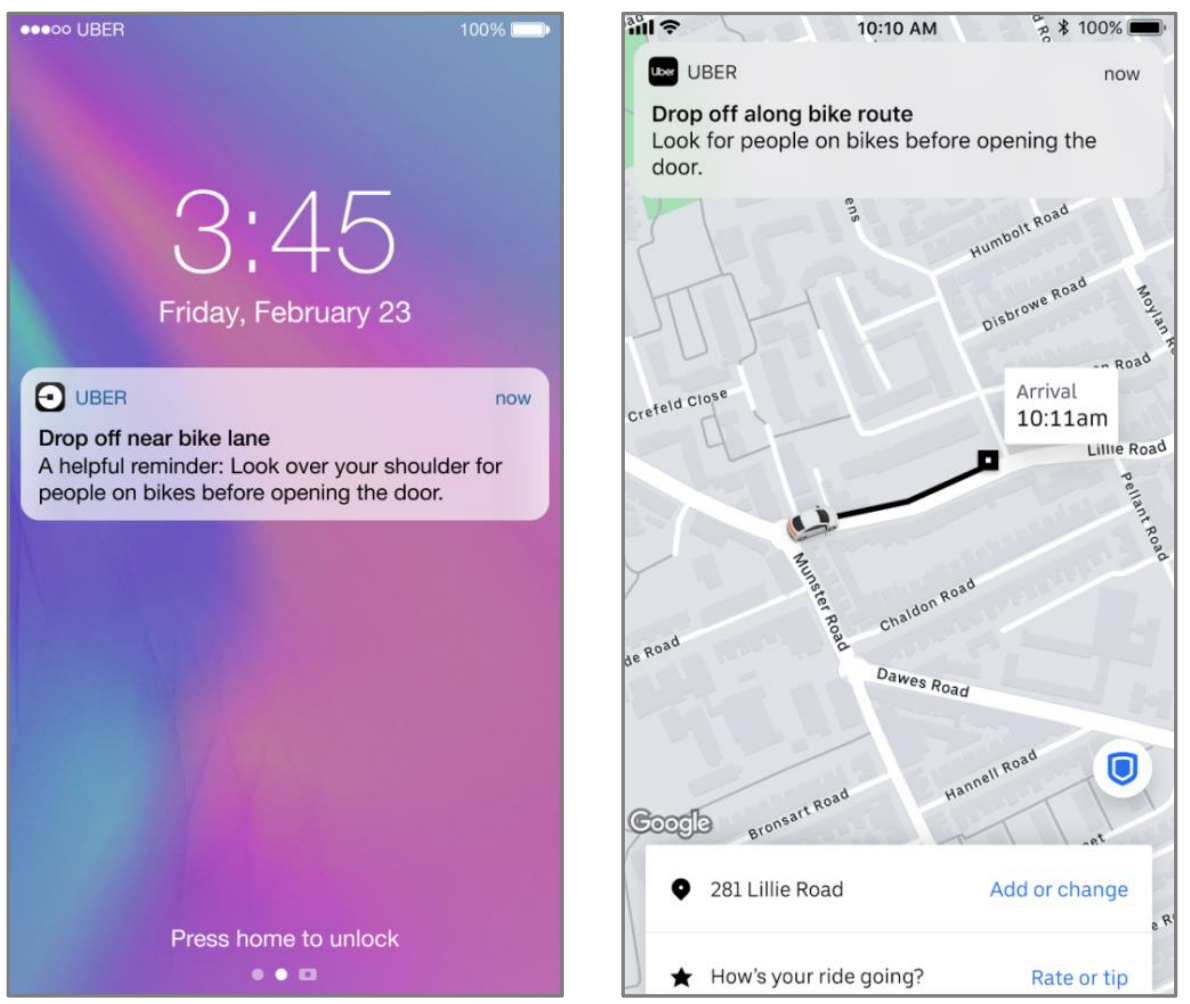

Source: Uber.

Uber has begun using their smartphone app to alert their passengers to the presence of bike lanes. When a trip's arrival point is located close to a bike lane (or to a bus lane where bikes can ride), the passenger receives a notification on their phone 500 metres before the arrival point. These bike lane alerts (Figure 14) are intended to promote awareness among passengers of the surrounding microvehicle traffic, and avoid collisions. They are live in 200 cities across the world. They illustrate the vast 
potential for smartphone apps to carry safety-relevant messages or even training that can include video and virtual-reality.

Ideally, drivers training should be required during the driving licencing process, when people obtain their licence for the first time, and again in the course of a driver's lifetime.

\section{Rider licencing and age limits}

In countries where moped use is regulated, riders must seek a licence which is only available from a specific age. European countries, for instance, impose moped riders to hold a licence of type "AM" which is obtained after formal training. Most European countries allow the use of mopeds from the age of 16, but other countries choose to impose a lower minimum age: 14 in Estonia, France, Hungary, Italy, Latvia and Poland; and 15 in Austria, Czech Republic, Finland, Lithuania, Slovak Republic, Slovenia and Spain.

Riding a bicycle, however, does not require a licence. Pedal assisted bicycles limited to $25 \mathrm{~km} / \mathrm{h}$ by design are treated like bicycles in European countries. Pedal assisted cycles reaching higher speeds, and bicycles providing power without the need to pedal, are generally considered as mopeds and require the same licence and minimum age. Some countries, however, choose to facilitate the use of speed-pedelecs as described in Box 4.

This raises the question of powered micro-vehicles: should they be regulated as bicycles or as mopeds? This report designates speed as the primary factor in traffic safety by far. Therefore, the slowest microvehicles (types $A$ and $B$ ) should be accessible to people without a licence, and a moped-type licence could be required for the use of faster micro-vehicles (types $C$ and $D$ ).

Rider licencing for the use of powered micro-vehicles would give a competitive advantage to bicycles, which could be justified by public health considerations. Powered micro-vehicles do not provide the same levels of physical activity and health benefits which bicycles and pedal-assist bicycles provide.

To obtain a moped driving licence in Germany, drivers are required to complete six 90-minute training sessions of theory in the driving school and one 90-minute session of practical training. This is followed by a purely theoretical test of 20 questions. This could be useful for younger e-scooter users who have neither a car nor a motorcycle licence. (VdTÜV, 2019)

\section{Box 4. Where speed pedelecs are classified as bicycles}

Speed pedelecs are electrically assisted pedal cycles with a top speed of up to $45 \mathrm{~km} / \mathrm{h}$. In many countries, they are classified as mopeds and often banned from cycling facilities, but are often regulated with a lighter touch than mopeds.

In Denmark, for example, speed pedelecs are allowed on cycle paths. The Danish Parliament decided that, as of 1 July 2018, users operating speed pedelecs need only to have turned 15 and to wear a bicycle helmet. The licence and number-plate requirements were lifted.

Switzerland was among the first countries in Europe to facilitate the use of speed pedelecs as an alternative to the common $25 \mathrm{~km} / \mathrm{h}$ pedelecs found in the European Union and the rest of the world. They are categorised as mopeds and must be used on bicycle infrastructure, where conflicts are reported to occur. Riders of speed pedelecs must be at least 14 years old, have a moped rider licence and wear bicycle helmets. 


\section{Shared micromobility companies invest in training}

E-scooter sharing companies should provide substantial help to people who are not familiar with the vehicles or the rules of the road. Standing e-scooter companies are already investing significantly in user training. They recognise that the innovative vehicle types they offer attract people who have no previous experience with cycling facilities or low-speed road use. Micro-vehicles do not benefit from decades- or centuries-old social norms that have defined a place and priority rules for each road user in cities.

\section{Box 5. Online e-scooter traffic school by VOI}

E-scooter company Voi developed an online training platform "RideLikeVoila". The training was inspired by the theory tests required for a driving licence and presented as an illustrated quiz.

Users are encouraged to take the training to receive credits for future rides.

Figure 15. Screen captures from online traffic school RideLikeVoila
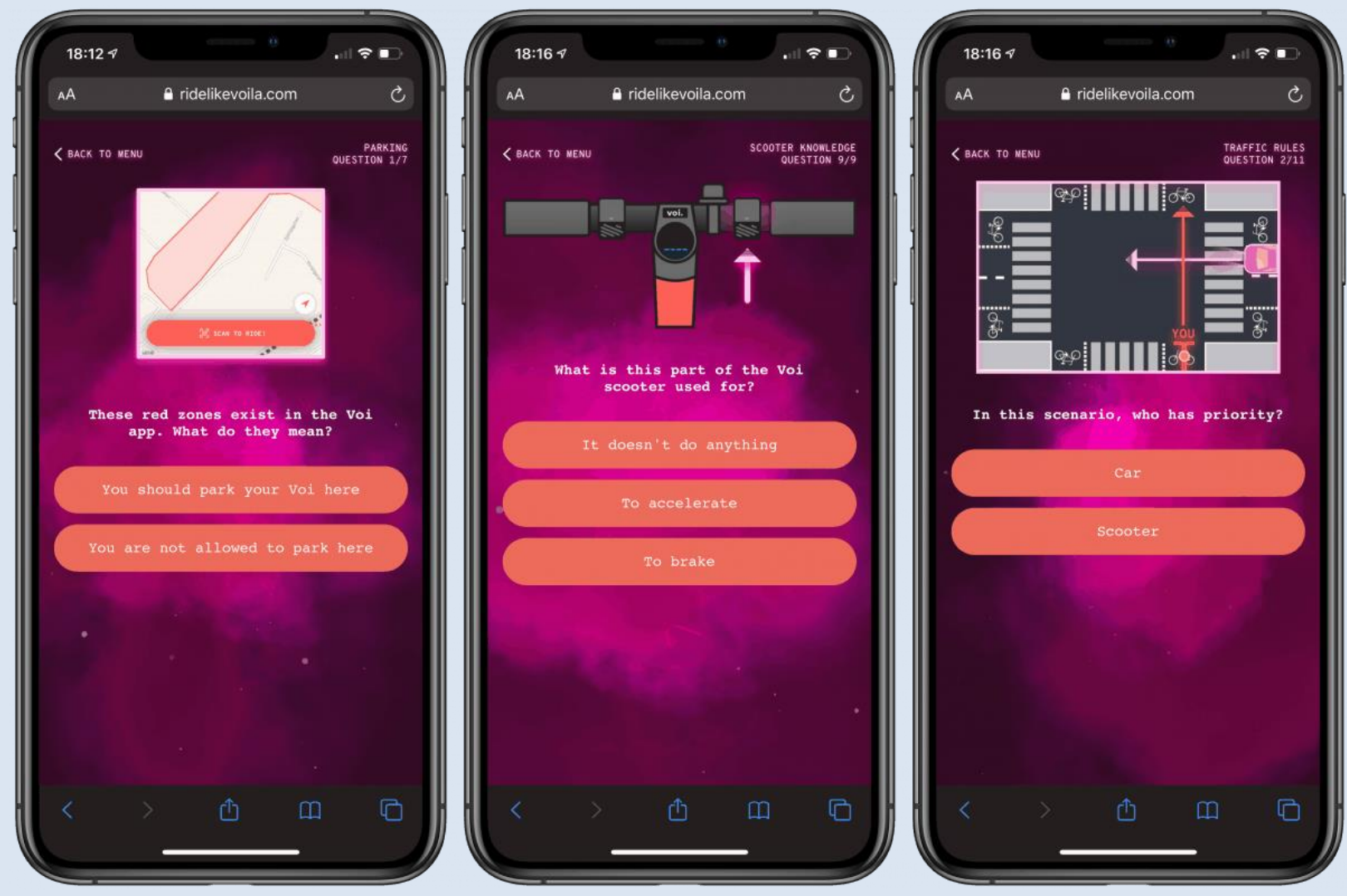

Source: Attefors (2019).

E-scooter company Bird hosted more than one hundred educational events called "s.h.a.r.e. Safe Streets" in 2019. The company provided tips for safe and responsible riding through their website and smartphone app which now include virtual reality videos. Lime, another e-scooter company, allocated over USD 3 million for marketing, outreach, and education, and gave away more than 250000 helmets is 
its campaign "Respect the Ride", which encouraged responsible riding and parking (Hawkins, 2019). In Berlin, Lime organised several free training events called "First Ride Academy".

Customers of shared micromobility companies all rely on smartphones to locate and unlock vehicles. Smartphones could become an effective solution for providing rider training. This is an opportunity which the Swedish e-scooter company VOI explored through an app-based traffic school (Box 5).

Some motor-scooter sharing companies offer free lessons. Small (2019) highlights a 30-minute hands-on training offered by a company called Revel in Washington D.C. It includes lessons in lane positioning (teaching riders how to be seen by other motorists and to avoid car doors) and emergency braking. It seeks to moderate behaviour with lessons such as "It's not if you fall...it's when you fall."

\section{The regulatory questions}

This section examines the role of governments in defining and enforcing requirements regarding road user behaviours, such as speed and alcohol and helmet use. Germany is among the countries that have developed regulations to frame the use of e-scooters. Since establishing this new legal framework in June 2019, Germany has become the European country with the most cities served by shared standing e-scooters (Figure 16). This report, therefore, makes several mentions of the German regulations, which are summarised in Box 6 .

Figure 16. In Europe, Germany has the most cities with shared standing e-scooters
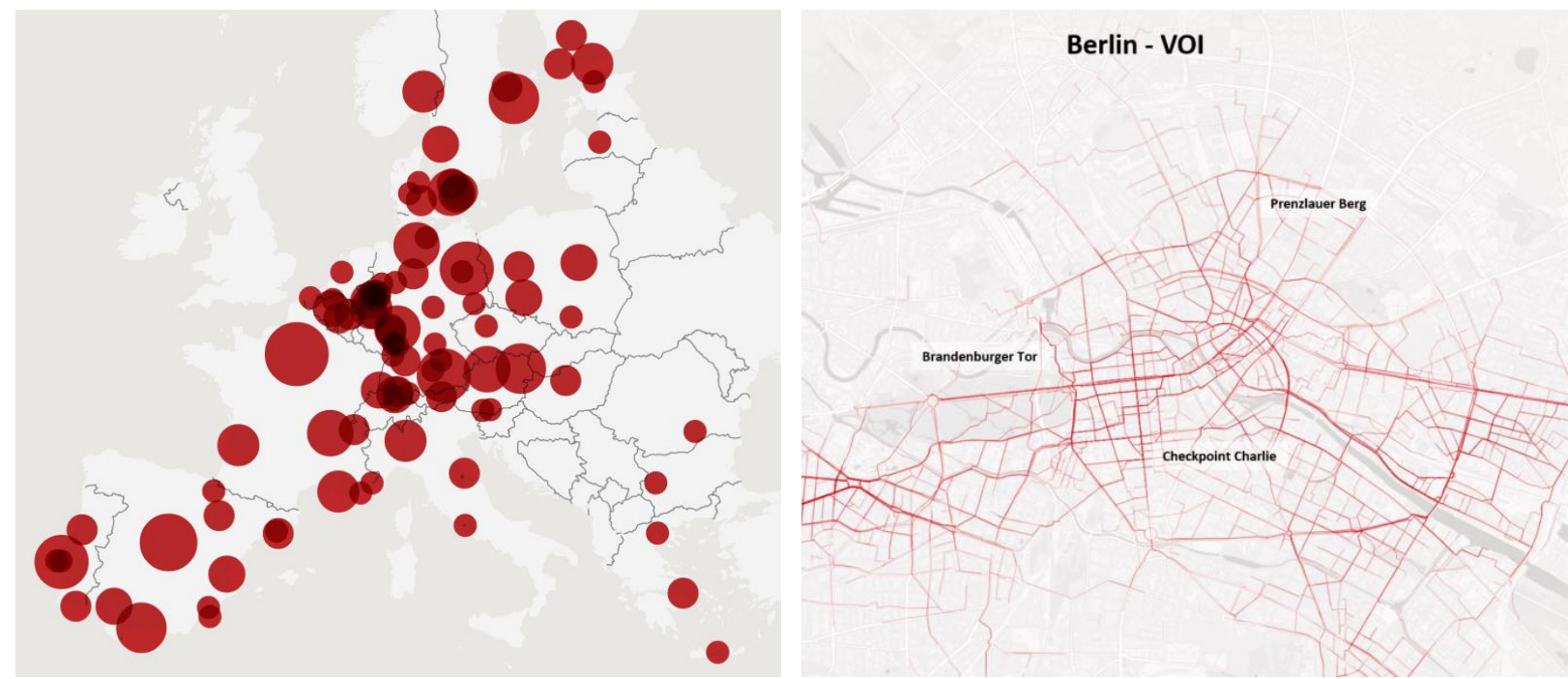

Note: Data as of 30-Sept-2019. Bubble size represents the number of active e-scooter companies, trip traces are estimated from trip start and end point, as extracted from each company's application program interface (API).

Source: Civity (2019).

\section{Alcohol and drugs}

Governments should define and enforce alcohol and drug regulations across all road user groups. Addressing alcohol and drug use among traffic participants requires a systemic approach, as the problem is not specific to micromobility. Several e-scooter riders have already been killed by impaired motor vehicle drivers. 


\section{Box 6. Current situation of electric scooters in Germany}

Standing e-scooters have been allowed on German roads since 15 June 2019. The Federal government enacted the Ordinance on the Participation of Small Electric Vehicles in Road Traffic, known as eKFV. Whilst e-scooters are now classified as motor vehicles, not all rights and obligations of motor vehicles apply. For example, riders do not have to be licenced and they do not have to wear a helmet. However, riders must:

- hold valid liability insurance

- respect the same alcohol limits as motor vehicle drivers

- be at least 14 years of age

- $\quad$ use cycle infrastructure where available (and the road if no such infrastructure exists)

- stay off footpaths.

Standing e-scooters must meet certain technical specifications. They must:

- have a steering and holding rod

- not exceed 0.70 metres in width, 1.40 metres in height and 2.00 metres in length

- $\quad$ not exceed $55 \mathrm{~kg}$ (without rider)

- have a design speed of at least $6 \mathrm{~km} / \mathrm{h}$ but not exceed $20 \mathrm{~km} / \mathrm{h}$

- have a power limitation of 500 watts (1 400 watts for self-balancing vehicles)

- comply with minimum technical requirements for lightning, braking (they must have two independent brakes), etc.

Manufacturers are required to apply for a general operating permit from the Federal Motor Transport Authority (KBA) for their vehicles. It took some time for a significant number of devices to obtain the permit; interested buyers had difficulty finding models with the appropriate permits. Retailers continued to sell models without them.

Users who ignore the regulations outlined in the Ordinance are subject to fines. Anyone who moves a standing e-scooter without a general operating licence, for example, may be fined EUR 70. The penalty for driving without an insurance sticker is EUR 40.

Source: BMVI (2019).

The share of road deaths which are alcohol-related is estimated at over $20 \%$ globally (ITF, 2018) and around 25\% in Europe (Calinescu and Adminaite, 2018). E-scooter injury analysis in the US cities of Santa Monica and San Diego suggest a strong correlation between alcohol consumption and crash severity. Among ED e-scooter patients in Santa Monica, 5\% were alcohol intoxicated (Trivedi et al., 2019). In comparison, a higher prevalence of alcohol impairment was found among trauma patients in San Diego: at least $38 \%$ had a blood alcohol level over $80 \mathrm{mg} / \mathrm{dL}$, and the median among those intoxicated patients was 199 mg/dL (Kobayashi et al., 2019).

Police services should aim for a systematic alcohol testing of every road user actively involved in a fatal or serious crash. If systematic alcohol testing is not possible, a statistical protocol should be defined so to 
estimate the true number of alcohol-related crashes (ITF, 2018). As part of a campaign of roadside or post-crash alcohol tests, drug tests should not be neglected.

Most OECD countries have defined a Blood Alcohol Content limit (BAC) for cyclists. BAC limit for cycling is higher than for driving in both Austria (0.8\%o) and Germany (1.6\%), but lower in Slovenia (0\%). In other countries, the same BAC limit applies to people cycling and driving motor vehicles (Yannis et al., 2019).

Regulators should specify and enforce BAC limits applicable to people cycling and riding micro-vehicles. Neither the limits nor the intensity of the enforcement should be set in a way that encourages the use of faster heavier vehicles among people impaired. Repeated enforcement campaigns targeted on micromobility in car-dependent communities could indeed backfire. The alignment of BAC limits across all modes would arguably prevent confusion, facilitate education campaigns and increase compliance. The alignment of BAC penalty levels across all modes is another debate. Some roundtable participants noted that impaired riders of Type A micro-vehicles are mainly a danger to themselves, comparable to intoxicated pedestrians. The risk they impose on third parties is incomparable with that which a drunk driver would impose. Where penalties exist for public intoxications, these could apply to both pedestrians and Type A micro-vehicle riders.

Industry experts have reported that smartphone apps can measure the level of intoxication through inapp tests that measure reaction time and accuracy. If regulators were to impose such tests, they should target high-risk places and times and apply them to other forms of shared micromobility. However, it seems necessary to broaden roadside alcohol and drug testing to all road user types. The idea is to show that all modes are exposed to the same level of enforcement, avoiding the risk that people drive when drunk because they believe police resources to be primarily focussed on e-scooter riders.

Lime is reportedly working on the detection of impaired riding. Motion sensors found on e-scooters could indeed be trained to detect excessive wobbling and slow the vehicle down (Hawkins, 2019). This technology may also detect tandem riding and deter it through a reduced speed.

The issue of drug use should not be omitted in road safety policies. A roadside survey in the United States indicated that illicit drugs are used by $5.8 \%$ of weekend drivers (Lacey et al. 2009). Among e-scooter trauma patients in San Diego, at least 31\% were intoxicated with illegal substances, primarily cannabis, methamphetamine and amphetamines (Kobayashi et al., 2019).

Some cities have discussed the idea of a night-time curfew for e-scooters, due to the alleged higher risk of riding an e-scooter by night. This policy may seem disproportionate, as it prevents the lawful utilisation of a vehicle type which, for many people, represents a precious addition to the transport mix. Exact crash rates by hour should be monitored by all means in each city. In addition, authorities should intensify education and enforcement campaigns so as to reach all road users.

\section{Personal protective equipment}

Policy makers should mandate and enforce the use of helmets on micro-vehicles travelling above a certain speed. On low-speed micro-vehicles, most countries choose not to impose helmet use. Shared micromobility companies should nonetheless continue promoting the use of helmets, as helmets are known to mitigate the severity of head injuries in some crash types.

A majority of countries in the world encourage but do not require adults to wear a helmet when they cycle. The nuance between encouraging and requiring is important: a number of experts think that mandatory helmet laws reduce the popularity of cycling and reduce its positive effect on public health. The positive health impact of bikes and e-bikes - due to physical activity - indeed far outweighs the risk 
of injury or death (Santacreu, 2018). There is no evidence as of yet that the physical activity involved in the operation of an e-scooter provides health benefits. However, were car trips replaced by e-scooters, e-scooters would have the potential to vastly improve community health by removing noise, air pollution and road danger sources from the streets.

Riders of shared micro-vehicles are less likely to wear a helmet than riders who own a micro-vehicle (Haworth and Schramm, 2019) and more likely to be deterred by mandatory helmet laws. This is demonstrated in countries with mandatory bicycle helmet laws, like Australia, where public bike share systems have very low ridership. Regulators should be conscious of the impact of mandatory helmet laws on ridership and therefore on mode shift.

Where e-scooter and other micro-vehicles are limited in speed to 20 or $25 \mathrm{~km} / \mathrm{h}$, many countries choose not to require adults to wear a helmet, although they do encourage helmet use. This is the case in France, Germany, Denmark and Portugal.

Roadside helmet enforcement is difficult due to the similar appearance of slow and fast e-bikes. Enforcement would be easier if faster micro-vehicle models (types $C$ and $D$ ) could be visually separated from slower models. Regulators have imposed an identification plate on fast e-bikes, which is only helpful until the owner chooses to remove it. Regulations could also impose oversized or recognisable design features on faster vehicles. The challenge comes in finding a balance between a tamper-proof solution (requiring the vehicle frame to be designed specifically to match these requirements), and a more market-friendly one.

E-scooter companies have been very active in the area of helmet promotion. Some gave away free helmets; Bird and Lime together distributed over 300000 helmets globally. Other companies gave discounts to users on the helmet model of their choice. However, helmet ownership and helmet use are different things.

Many trips on shared micro-vehicles are spontaneous, unplanned, and users are less likely to carry a helmet (Haworth and Schramm, 2019). To maximise the actual use of helmets, nudges and rewards may be the way forward. Bird introduced a reward system for users taking a photograph of themselves, a selfie, wearing a helmet at the end of a ride (Lekash, 2019). A similar camera-based artificial intelligence system is used by micromobility company VeoRide to reward people wearing helmets.

\section{Speed}

An essential aspect of managing the safety of micromobility is setting and enforcing the speed limit applicable to standing e-scooters and other electric micro-vehicles.

Generally, France, Portugal, Queensland, Singapore and Spain have imposed a $25 \mathrm{~km} / \mathrm{h}$ speed limit on e-scooters. This corresponds to the $15 \mathrm{mph}$ limit imposed in Los Angeles and recommended by NACTO (2018) and aligns the top speed of an e-scooter with that of a pedelec in the European Union.

Denmark, Germany and Sweden have a $20 \mathrm{~km} / \mathrm{h}$ (or $12 \mathrm{mph}$ ) speed limit for e-scooters. City authorities of Paris (France), Calgary and Edmonton (Canada), Abu Dhabi (United Arab Emirates) and Denver (United States) have imposed the same speed limitation on shared e-scooters.

Where e-scooters are allowed on sidewalks in France, their speed is limited to walking speed. In the city of Singapore, e-scooters had been limited to $10 \mathrm{~km} / \mathrm{h}$ on sidewalks, but were completely banned from operating on them as of January 2020. 
It is probably best left up to each city to assess its current infrastructure, road user behaviour and rider experience to determine a suitable speed limit for powered micro-vehicles. Some would oppose a $20 \mathrm{~km} / \mathrm{h}$ speed limit on the basis that this would make powered micromobility slower than cycling, creating conflicts. However, Allen (1998) reports that a majority of the free-flow bicycle speed observations are between $12 \mathrm{~km} / \mathrm{h}$ and $20 \mathrm{~km} / \mathrm{h}$. Several studies support Allen's findings on average speeds. Greibe and Buch (2016) observed an average speed of $21.6 \mathrm{~km} / \mathrm{h}$ in Denmark. Bernardi and Rupi (2015) found an average speed of between 15 and $22 \mathrm{~km} / \mathrm{h}$ in Italy, depending on survey location. Researchers observed a mean speed of $14.8 \mathrm{~km} / \mathrm{h}$ for regular bikes and $21.9 \mathrm{~km} / \mathrm{h}$ for electric mopeds in Kumming, China (Lin et al., 2008) and later found lower values of 13.5 and 17.1 in Hangzhou, China (Xu et al., 2015).

Whilst a $20 \mathrm{~km} / \mathrm{h}$ speed limit does not make powered micro-vehicles slower than the average person cycling, it could still create conflicts. This is due to the greater performance of those micro-vehicles when accelerating, in comparison to a person cycling. It is common to see shared e-scooters accelerating faster than pedal cycles from standstill but travelling slower - if capped at $20 \mathrm{~km} / \mathrm{h}$ - than many cyclists between junctions. This generates a number of potentially dangerous overtaking manoeuvres and could be avoided if powered micro-vehicle acceleration was electronically limited or if they could reach higher speeds.

The rationale for allowing speeds up to $25 \mathrm{~km} / \mathrm{h}$ or beyond is to make micro-vehicles competitive with cars, addressing car-dependence and the external costs on the environment and public health that come with it. As previously mentioned, a fundamental traffic safety benefit of micromobility is the potential it has to reduce the number of car trips.

Average car speeds are already well below $25 \mathrm{~km} / \mathrm{h}$ in dense cities at peak hour. If micromobility is limited to a $25 \mathrm{~km} / \mathrm{h}$ maximum to protect users from death through collision with motor vehicles, it would be only logical to limit cars to the same speed. A single speed limit for all in mixed-use streets would be easier to enforce and make traffic more homogenous.

Further research might cast light on the shape of the risk curve: is there a speed beyond which the chances of serious injuries rise exponentially?

The pay-per-minute method is an incentive to adopt speeds which are not appropriate with respect to the rider's immediate environment (Polis, 2019). It is also an incentive to make dangerous manoeuvres, such as running red lights, and to adopt inconsiderate behaviour, such as failure to yield to pedestrians. Vehicles for hire should reduce their reliance on time in their pricing system. This could be by adding a charge for distance travelled, or a charge per trip, or a monthly subscription. This could be by stopping the clock for up to 90 seconds when the vehicle is not moving, presumably stopped at a red light or giving way to pedestrians. This should apply on municipal bike-share systems and dockless e-scooter and bike-share systems. This should also apply to motor-scooter sharing and car-sharing schemes.

There is evidence that nudges can be used to make people drive more safely (Choudhary et al., 2019). Future research should investigate if results are transferable to micromobility riders. Currently, the "MeBeSafe" European project (Twisk and De Hair-Buijssen, 2017) is focussing on enhancing safety for cyclists, car drivers and truckers, with an innovative in-vehicle ADAS and on-road infrastructure.

Governments and enforcement technology providers should work together and develop a speed control tool capable of capturing (a) speed, (b) acceleration and (c) the presence or absence of pedalling. This is to ensure throttle assisted e-bikes are not used where they should not be.

Regulators may require a downhill speed limiter on e-scooters, a feature that some companies like VOI have equipped their vehicles with. At least one fatality listed in Annex A involved a loss of control when 
riding downhill (Bellido, 2019). Roads on the steepest hills are off-limits to e-scooters in some cities, including San Francisco, to prevent crashes through loss of control.

\section{Pedestrian protection}

Pedestrian safety is negatively impacted where micro-vehicles are used and parked on sidewalks. Wheelchair users and the blind are particularly affected. In their most recent report, the City of Santa Monica (2019b) found that "these user behaviours contribute to pedestrian discomfort and are currently infeasible to eliminate through field enforcement due to dispersion and ongoing movement of the devices." The use of sidewalks by micro-vehicle riders is more likely in areas where a safe cycling infrastructure is lacking, as discussed in the next chapter.

Yet motor vehicles represent a much greater fatality risk to pedestrians, both in absolute terms and per unit of vehicle travel (ITF, 2019a). Policies reducing speeds in urban areas should be considered, as they will prevent traffic deaths in all user groups and especially among pedestrians. Governments should plan for all motor vehicles (including cars, ride-sourcing and parcel delivery vehicles) to adopt strict speed limits inside geo-fences, learning from the experience acquired with e-scooter companies.

E-scooter companies Lime, Jump and Bird are working to develop solutions to detect and prevent sidewalk riding. Vehicle sensor data would assess vehicle position and road conditions during the trip to determine when a user is riding on the sidewalk. Upon detection, the company could trigger real-time on-vehicle alerts and a possible penalty system. (Marschall, 2018; Jump, 2019; Bitters, 2020)

Various technologies could be used or combined for the detection of sidewalk riding. Experts have noted the prospect of five-centimetre GPS accuracy and $5 \mathrm{G}$ positioning, but the technologies that would support these are not yet deployed. With current technology, and due to GPS signal being obstructed in urban canyons, GPS positioning simply is not precise enough, at least at present. This is true even when using Hybrid Positioning Systems that combine, for instance, GPS with WiFi-based positioning. Some cities report that partnerships are being forged with universities to develop technologies capable of restricting sidewalk riding (City of Santa Monica, 2019b). Irish start-up Luna is developing GPS signal processing technologies to deliver centimetre-level precision and support the operational needs of micromobility companies (Taylor, 2019). Testing should reveal if the solution works in urban canyons and when the vehicle is in motion.

Computer vision may be used to detect sidewalk riding on shared micro-vehicles. Companies are also working on solutions to detect sidewalk riding using video cameras (Silicon Canals, 2019). In the longer term, vehicles may be able to detect sidewalks and pedestrians and limit vehicle speed accordingly.

\section{Geofences}

A geofence is a set of lines, defined by geographic co-ordinates, that delimit an area where special regulations apply. This is an example of algorithmic governance: a machine-readable regulation that can be pushed straight from the street management authority to the back-office of shared mobility companies. Geofences can restrict speed, access and parking, reducing pedestrian discomfort and injury risk. They form a flexible solution and are widely used. That said, authorities should bear in mind that shared micromobility ridership can be negatively affected by constraints imposed by geofences.

Examples of cities applying an $8 \mathrm{~km} / \mathrm{h}$ speed limit geofence include the US city of Santa Monica and the French cities of Lyon and Paris. The goal is to limit the speed of e-scooters in pedestrian areas. In Paris, 
the $8 \mathrm{~km} / \mathrm{h}$ speed limit applies also on streets where traffic speed limit is $20 \mathrm{~km} / \mathrm{h}$, giving a competitive advantage to people cycling or using other modes of transport.

Cities should take full advantage of geofences to reduce speed in pedestrian areas, and potentially during special mass participation events. Speed regulations should also apply on shared e-bikes, whereby power assistance would be cut-off when the speed limit is reached. Regulations should ensure that all operators face the same requirements and implement them in the same way. Where such limits are applied today there is often a patchwork of different implementation, prompting users to switch operator. Needless to say, intelligent speed adaptation of this kind is most relevant for heavier and faster vehicles such as automobiles, buses and trucks.

Figure 17. E-scooter identification plate in Europe

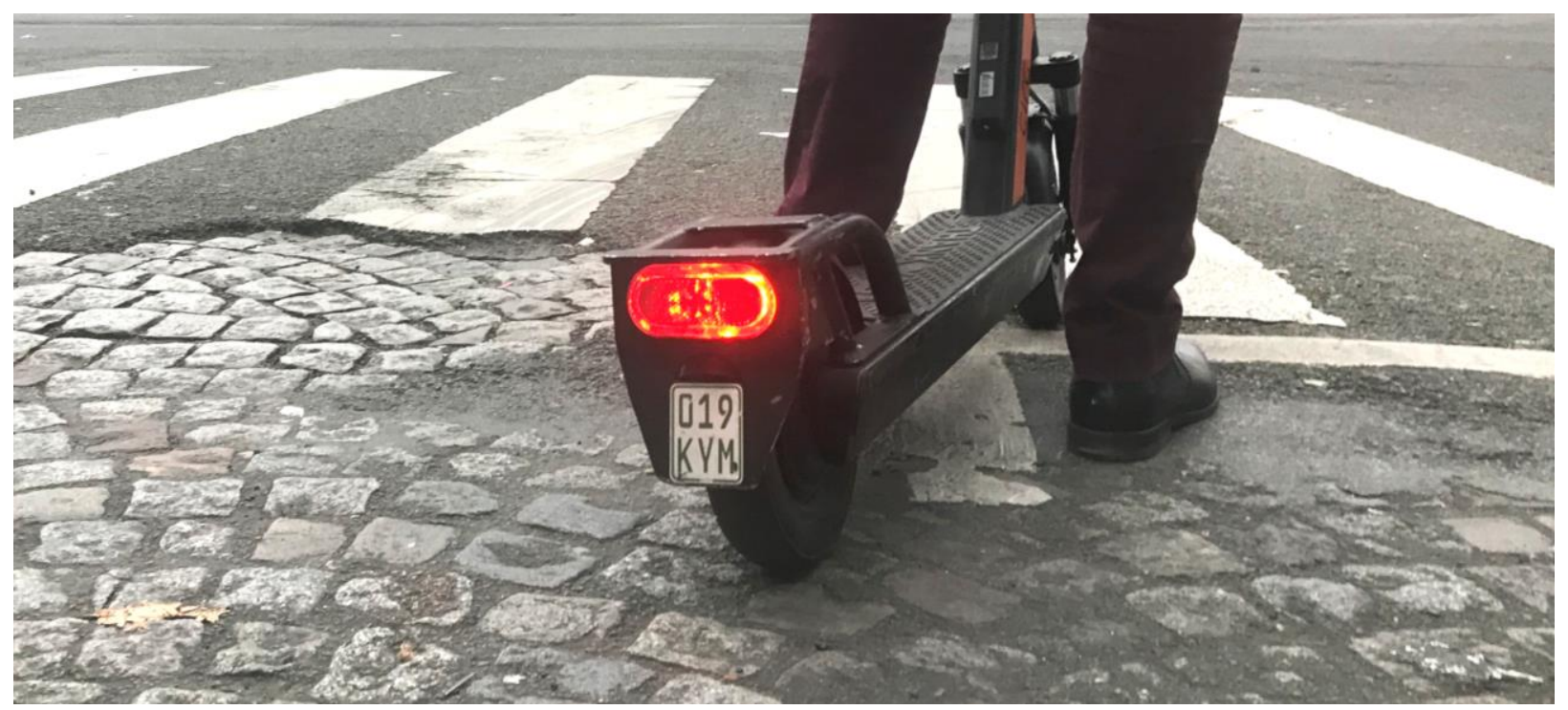

(C) Alexandre Santacreu

Geofences are powerful tools to manage shared fleets of micro-vehicles, but are not (yet) applicable to privately owned micro-vehicles. Some cities may wish to limit the speed of all micro-vehicles in specific areas. Manufacturers of micro-vehicles should develop a solution to help riders comply with relevant speed limits. Riders of privately owned vehicles may indeed benefit from some help, as they cross a number of geo-fences and travel across different municipalities where different speed limits may apply. Intelligent speed assistance, discussed earlier, is a similar solution for cars. Since many micro-vehicles are already connected to a smartphone app, adding a speed management solution does not seem a difficult step to take. Such a technology would be particularly relevant for the management of faster e-bikes when they enter urban areas. Visible on-street signage and enforcement of speed limits may contribute to a faster uptake of such a technology.

\section{Number plates and enforcement}

It is difficult to enforce sidewalk bans because of the lack of identifiable features on micro-vehicles and the ease with which riders can disappear quickly. This is why some countries, such as Singapore and Japan, impose an identification plate on micro-vehicles. Germany imposes a visible insurance sticker on e-scooters in a format that can help identify a vehicle at a distance.

In Singapore, the Land Transport Authority (LTA) introduced a new function to its smartphone app for members of the public to report inconsiderate use of micro-vehicles. In only one month, members of the 
public filed 270 reports (Toh, 2019). Already in 2017, the LTA had a team of 24 active mobility enforcement officers working to deter reckless riding of e-scooters, bicycles and e-bikes (Zhaki, 2017). It increased its efforts in 2019 and seized 400 illegal devices in a three-month period (Cheng, 2019). Illegal devices include those exceeding the 20-kg weight limit imposed on e-scooters (Qishin, 2019).

Figure 18. Design standard for identification stickers in Singapore

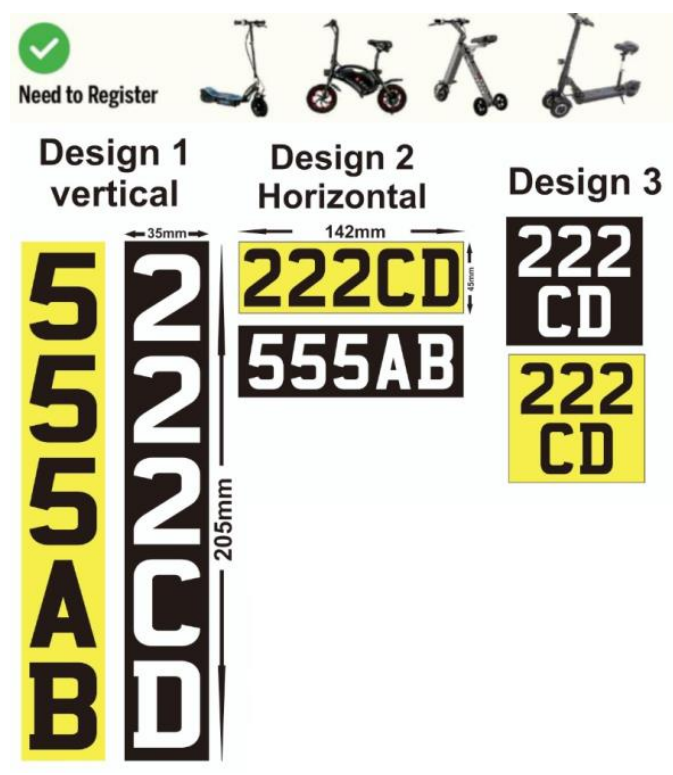

Source: adapted from https://sg.carousell.com/p/e-scooter-pmd-plate-number-stickers-one-piece-8-dollarsincluding-normal-mail-more-than-5-pieces-no-mailing-fees-self-collect-6-dollars-207785154/.

Most European countries require fast e-bikes to display an identification plate, similar to what is imposed on a moped. When it comes to preventing deaths and serious injuries, however, identification plates should not be seen as the silver bullet. Imposed on cars all over the world, number plates have failed to prevent an excessive number of hit-and-run crashes. In Belgium and in the United Kingdom, over 10\% of injury crashes involve a hit-and-run driver (Kluppels, 2016). Policies should incentivise the use of lowspeed micro-vehicles, and allocate on-street space to micro-vehicles so they do not encroach on sidewalks. 


\section{Safe infrastructure}

Government can have the most significant impact on traffic safety through investment in infrastructure and the adoption of sound design guidelines. Developing a safe network for micromobility has a positive and lasting impact on the safety of all road users, including pedestrians. For this reason, efforts at creating a safe network should be seen as complimentary to vehicle safety regulation and smart road user behaviour when responding to micromobility safety issues. An ITF report will investigate how the large-scale deployment of safe and connected micromobility infrastructure could impact travel and safety (ITF, forthcoming b).

This report refers to spaces reserved for the movement of micro-vehicles as cycling infrastructure or cycling facilities. Box 7 reports on early efforts to name these spaces in less bicycle-specific language. This reports uses the term "protected cycling facility" to designate all types of cycling infrastructure benefitting from physical protection, be it bollards, planters, parked vehicles, curb or other.

Space is available in cities to accommodate micromobility, but the case must be made for the reallocation of surfaces currently occupied by motor vehicles. The demand for micromobility is an opportunity for local government to redistribute street space and to challenge outdated street design principles which gave priority to motor vehicles over people. Industry experts have expressed the need to actively reduce how much space is dedicated to car traffic in cities, so that the mode shift to micromobility comes not only from walking and public transport, but from driving, too.

The city of Atlanta, Georgia in the United States experienced three fatal e-scooter crashes in only three months in 2019 (Annex A), evidence of the lack of protected space for micromobility in the city. The city reacted with plans for a connected and protected cycling network, including temporary barriers for rapid deployment (Abend, 2019).

Over $80 \%$ of e-scooter and bicycle fatalities involve heavier motor vehicles, making the case for greater protection. But why wait for fatal crashes to happen before reacting? Local governments and advocacy groups should take advantage of the rise in e-scooter use to further support the case for faster development of better quality cycling infrastructure.

The politics of developing a protected cycling network often revolve around the same argument: "Why make space for cycling? Nobody cycles here!" This is where micromobility has the strategic potential to support local governments, by creating a visible demand and by filling new sections of infrastructure as quickly as they open. (Polis, 2019)

Industry experts support the re-allocation of space otherwise occupied by car parking or car traffic in places where space is scarce. The ITF notes that the shared nature of cycle tracks (accommodating both pedal cycles and powered micromobility vehicles) and their visible use by a critical mass of people would facilitate the acceptance of such a reallocation.

Physical protection from motor vehicles not only makes people feel safer riding bikes and embracing micromobility in general, it can make the city safer for everyone. Pedestrian injuries fell by $22 \%$ along seven miles of newly protected bike lane installed between 2007 and 2010 in New York City (NYCDOT, 2014). Data from 12 major US cities reveals that protected bicycle facilities are associated with safer cities for all (Marshall and Ferenchak, 2019). 


\section{Box 7. New terms to describe a micromobility infrastructure?}

The rise in use of light individual mobility vehicles (i.e. micromobility) poses several longer-term design challenges regarding road space and its allocation to different users and uses. Understanding of how, exactly, these will evolve is limited at present; as of the writing of this report, there are no formal design guidelines for micromobility infrastructure beyond existing guidance for bicycle facilities, where these exist. Another report from the ITF's Corporate Partnership Board (ITF, forthcoming b) addresses this but even in the writing of the present report, it seems clear that the conflation of all micromobility infrastructure with the term "bicycle" infrastructure, is problematic at best and outdated at worst. This is especially true where micromobility devices are as numerous as, or even outnumber, bicycles.

On the one hand, there is both regulatory and popular clarity on what constitutes "bicycle infrastructure" and along with this, considerable investment in signage and iconography; the bicycle logo is universal and well-understood. On the other hand, this signage and the focus on only one of several light mobility devices may decreasingly reflect the diversity of potential users of these facilities. This may have safety implications when the focus on the operating characteristics of only one type of vehicle may lead to conflicts with others.

The first efforts to name these spaces in less bicycle-specific language emerged in the Netherlands with the concept of living streets, "woonerf" in Dutch or "encounter zones". The emphasis was on all modes conforming to the speed and characteristics of pedestrians. The idea has since caught on in other countries. These terms describe one specific type of infrastructure and, in most cases, everything else that is built for light mobility references bicycles (e.g. bicycle streets or "fietstraat", bicycle lanes, bicycle tracks, etc.).

A new push to find a term for these spaces has emerged in North America, where the rise in micromobility has been most jarring - starting earlier than in other countries and with a higher and faster adoption rate - and where the implementation of safe bicycle facilities (and cycling) has been relatively low in comparison with several European countries. A number of terms have emerged - "slow lanes", "micromobility lanes", "third lanes", "BEST lanes" (Bikes Electric Scooter Transportation). One term, in particular, captures many of the speed and mass performance characteristics that should define those facilities - the Lite Individual Transportation (LIT) lane. First used in Portland, Oregon and in Atlanta, Georgia, the term LIT lane has several permutations (e.g. Light versus Lite) and an alternative meaning: Low Impact Transport lane. This term (or one that similarly captures the diversity of uses and users of these spaces) may gain in popularity in line with the increase in micromobility. It will necessarily require a more formal definition and specifications of the implicated transport infrastructure. Authorities should anticipate this.

The use of e-scooters is safer in cities most committed to cycling safety, according to e-scooter company Bird, which compared its reported crash rates with city safety scores developed by the organisation PeopleForBikes (Bird, 2019). PeopleForBikes studied cycling networks in over 500 cities in Canada and the United States. Its Bicycle Network Analysis (BNA) measures the degree to which people can comfortably bike to the places they want to go. Only a truly connected low-stress cycle network (Figure 19) attracts a high BNA score. The organisation found significant differences in the quality of the cycling networks it studied. Its work could facilitate governments' research on the links between network quality and micromobility uptake and casualties. It could help governments identify where there is room for progress and where to take action. 
Figure 19. Bicycle Network Analysis of New York City by PeopleForBikes

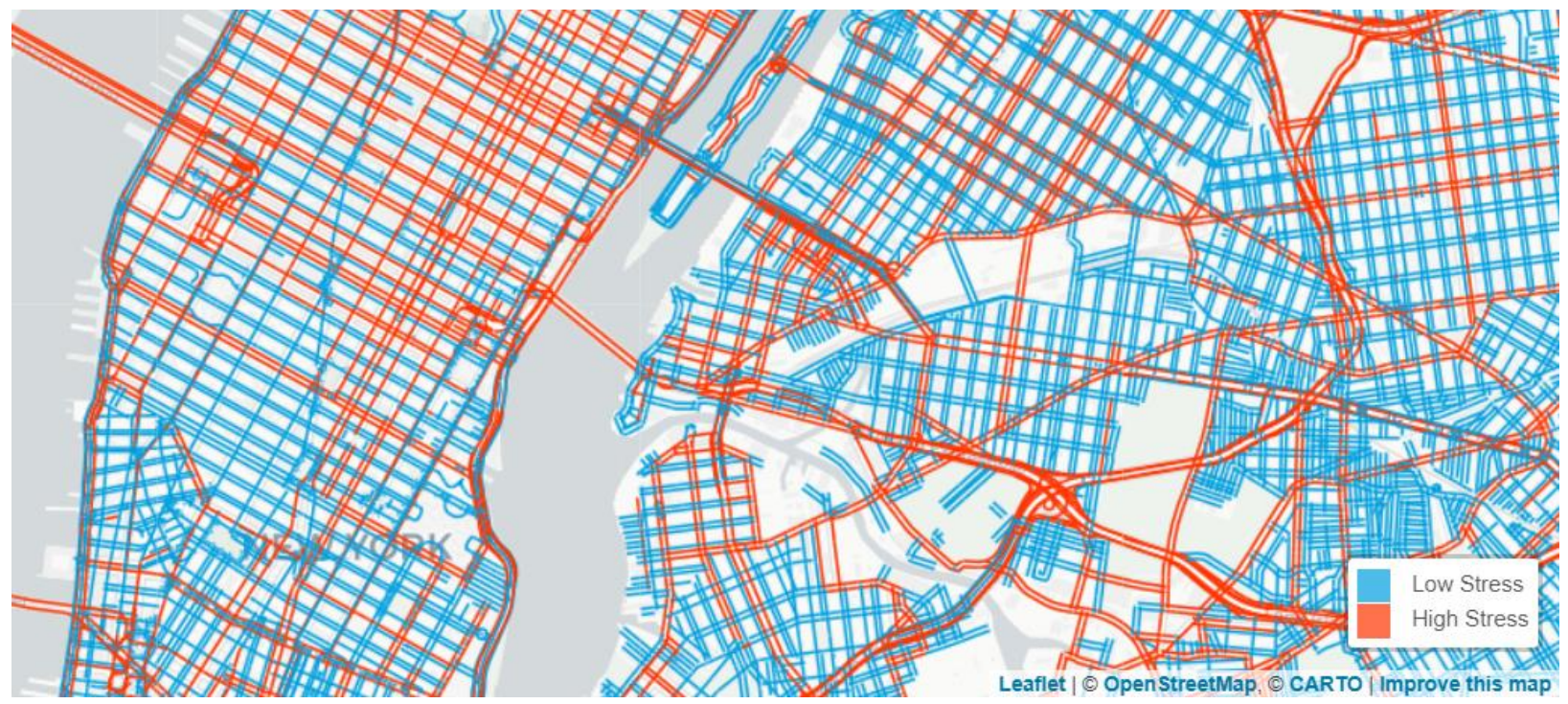

Source: PeopleForBikes (2019).

Where government fails to create a protected cycling environment, users may favour the safety of a private car or use faster micro-vehicles such as mopeds, capable of merging with the flow of traffic. Moped users will no doubt seek to access cycling facilities where they exist, which creates conflict with the cycling community. Cycling facilities should remain a place where people of all ages and abilities feel comfortable and safe on a bicycle. Sidewalks are more often used by e-scooter riders where the streets are hostile and missing safe cycling infrastructure. In the course of a 120-day e-scooter pilot in 2018, the Portland Bureau of Transportation found lower rates of sidewalk riding on low-speed streets or those with dedicated space for non-motorised users. E-scooter users ranked bike lanes as their preferred road type, and sidewalks last. (PBOT, 2019)

Traffic calming and the provision of a visible network of cycling facilities are the most important actions towards preventing sidewalk riding, according to industry professionals. Sharing a sidewalk should only be considered a short-term last-resort solution before on-street facilities are developed.

In many countries, especially those with an ageing population, there is a growing awareness of the need to preserve sidewalks for the near-exclusive use of pedestrians. The fear of having to share sidewalks with powered vehicles deters some people, especially older people, from their rightful use of public space (Cheng, 2019). Considering the public health benefits of walking as a form of physical activity, the protection of sidewalks is indeed a public health priority.

\section{Rethinking cycling facilities}

Riders of e-scooters appreciate the presence of protected and wider bike lanes (Figure 21). But are bike lanes and tracks fit for purpose? A discussion with micromobility companies and government officials resulted in the recommendation that design guidelines should be revised:

Wide bike lanes and tracks should no longer be seen as a luxury, but as a requirement, to accommodate a growing number of users in safe conditions. 
Speed humps, transverse rumble strips and cobblestone sections installed along the cycle network need to be carefully designed and safely passed by vehicles with small wheels and a short wheelbase. The most complex situation will be on residential roads, where micromobility shares the space with motor vehicles, and where speed humps are often deployed. This is an area where research is needed. Speed cushions may be an alternative to speed humps but are not recommended on micromobility routes (TfL, 2016). This is because: a) speed cushions can force riders to deviate from their line and into the dooropening space of parked cars and b) speed cushions rarely have a significant speed-reducing effect on powered two-wheelers and on wider-based vehicles such as SUVS and delivery vehicles.

Smooth and well-maintained road surfaces are important to people on bikes, even more so for people on micro-vehicles with smaller wheels.

Bus lanes that are shared with micro-vehicles do not qualify as truly protected spaces. People do not feel safe sharing space with heavier vehicles such as buses, taxis and motorcycles often using bus lanes. This poor perception of safety leads to sidewalk riding, which most cities seek to avoid. Bus lanes are even worse for micro-vehicles with smaller wheels: heavy vehicles inflict damage to the road surface (Figure 20) that exacerbates the risk of falling. This report, however, does not call for the replacement of bus lanes by a micromobility infrastructure. Since both public transport and micromobility can replace private motor vehicle trips and make a city safer, they each deserve their own space.

Legible intuitive routes, including efficient signage, should be offered to people who are new to micromobility and may be lacking the experience of navigating cycling facilities. This includes the careful design of junction layout, so people know which position to adopt when making a turn.

Figure 20. Road surface damage and illegal parking at a bus stop

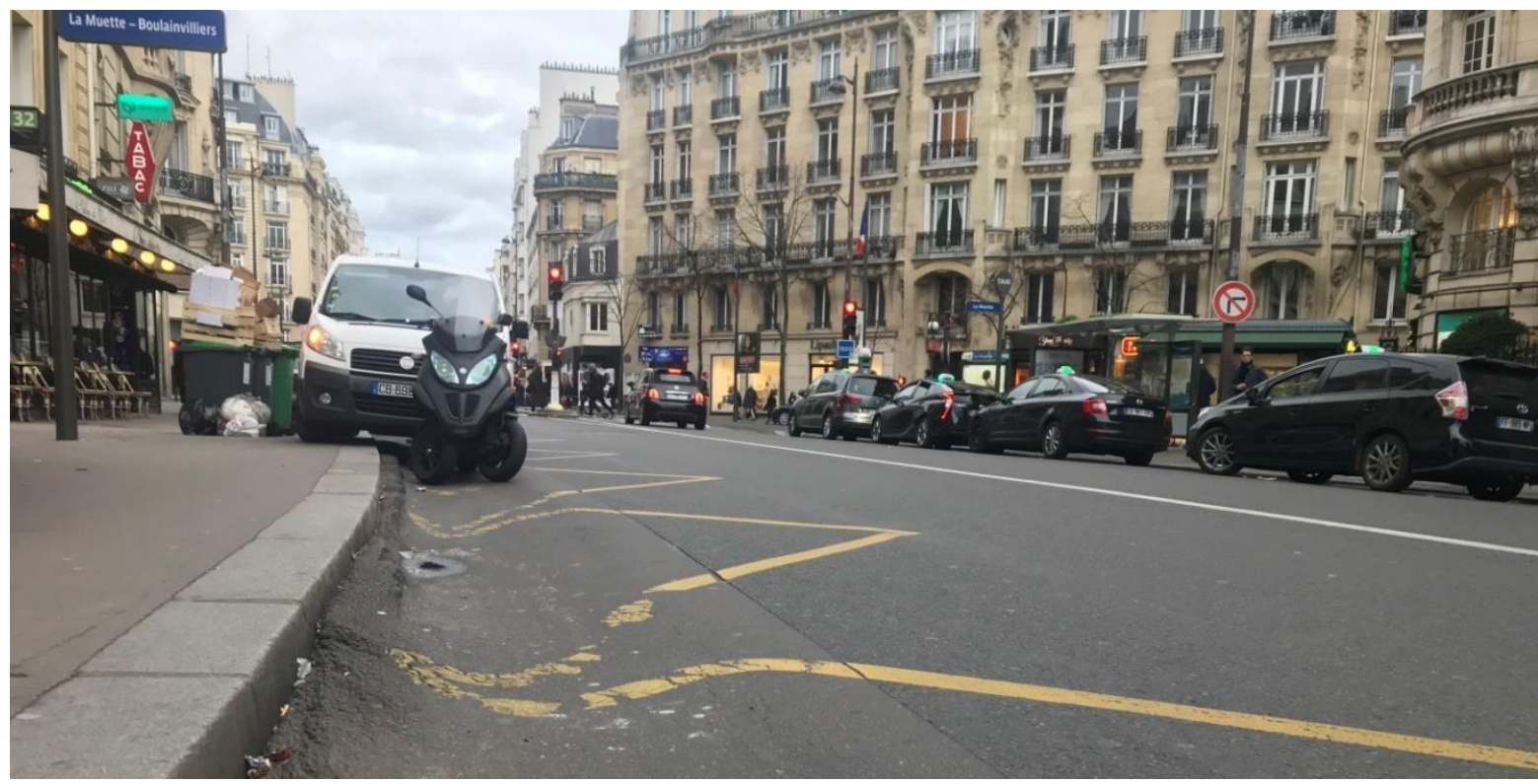

(c) Alexandre Santacreu

Traffic calming and traffic volume reduction represent an alternative to cycle infrastructure under certain conditions, as discussed by Santacreu (2018). Bike lanes make no sense in areas where traffic volume and speed reduction are already imposed, in $20 \mathrm{~km} / \mathrm{h}$ zones or bike priority streets, for instance. Safe System principles impose a $30 \mathrm{~km} / \mathrm{h}$ speed limit in urban areas where vulnerable road users, such as pedestrians, 
are in contact with traffic. The $30 \mathrm{~km} / \mathrm{h}$ limit should not, however, be interpreted as a minimum speed, and lower speed limits should be envisaged where relevant.

Allocating parking spots for micromobility near pedestrian crossings could prevent crashes whilst addressing sidewalk clutter. Industry experts often mention a technique called "daylighting", which consists of eliminating car parking at pedestrian crossings where the parked vehicles would interfere with the line of sight for pedestrians or drivers. Primarily intended to prevent pedestrian injuries, this technique frees up space that could be allocated to the parking of micro-vehicles. Some cities have already repurposed no-parking zones near intersections, reserving them as parking zones for bikes and e-scooters, which have a lower profile and do not interfere with the line of sight. (NACTO, 2018)

Figure 21. Desired infrastructure improvements, responses from a Bird Rider Survey

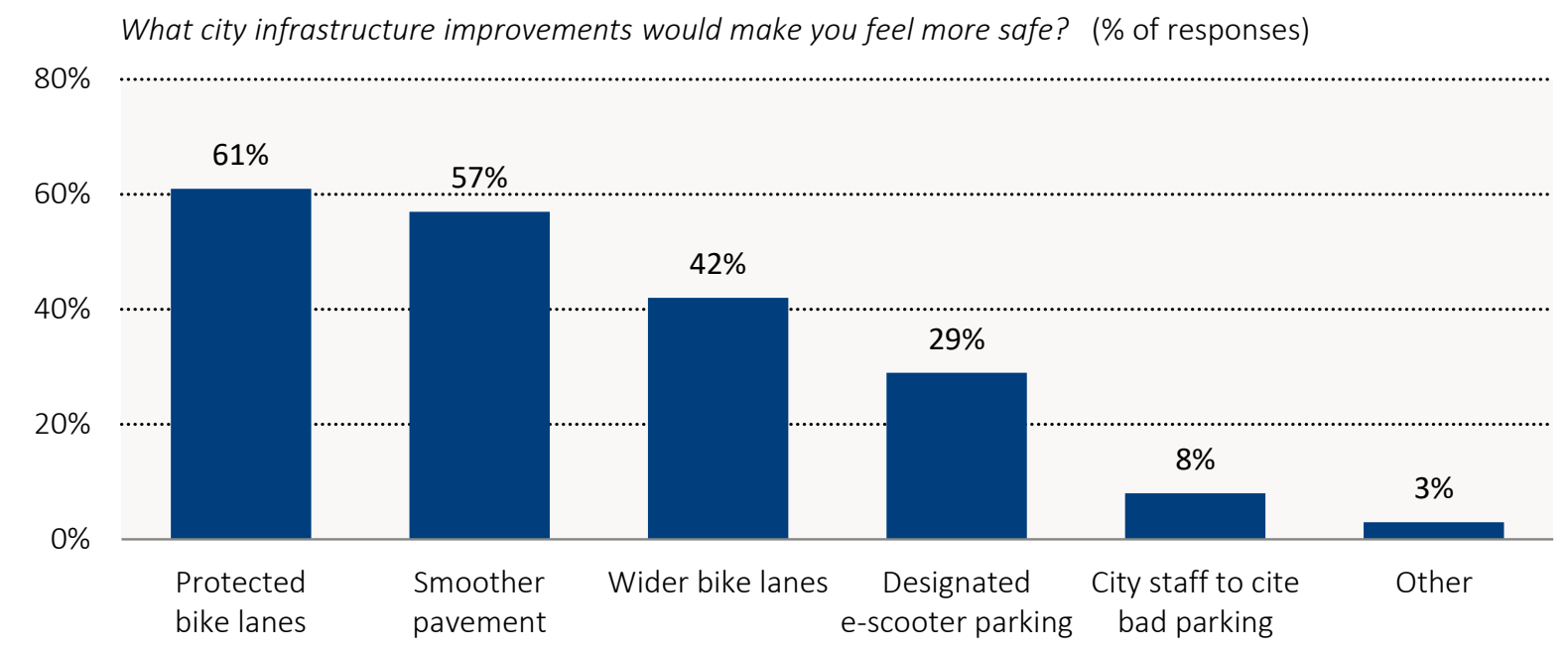

Source: Bird (2019).

Some cities make a point of not using sidewalks for the creation of micromobility parking spots. Not only does this strengthen the statement that sidewalks must be for pedestrians, it also has a substantial road safety rationale. First, sidewalk parking leads to sidewalk riding, simply to access and leave the location. There is little hope to enforce a sidewalk riding ban if parking is found on the sidewalk. Second, leaving a sidewalk to join the stream of traffic is qualified by some as a risky manoeuvre. Researchers are investigating this point.

\section{Can cycling facilities accommodate all types of micro-vehicles?}

Where should people use micro-vehicles? Could all micro-vehicles share the same space? Responses depend on the context. Most governments choose to ban mopeds and the most powerful e-bikes from bike lanes and tracks. This is motivated by the need to offer a comfortable and safe environment for cycling at low speeds to people of all ages and abilities.

Some jurisdictions allow faster e-bikes on all cycling facilities so to maximise the potential for replacing car trips (Box 4). Some allow the use of mopeds on bicycle routes outside of built-up areas, where their speed is closer to bicycle speed than to car speed. In Amsterdam, the use of mopeds on cycling facilities was only recently banned, due to the air pollution they generated but also to the congestion they caused on the cycling network (Boztas, 2019). 
Speeds are relatively consistent across Type A and Type B micro-vehicles, opening up the possibility of cycles, pedelecs, cargo bikes and e-scooters sharing the same space. Most people cycle at less than $20 \mathrm{~km} / \mathrm{h}$. The city of Paris imposes a $20 \mathrm{~km} / \mathrm{h}$ speed limit on shared e-scooters while the German regulatory framework sets a $20 \mathrm{~km} / \mathrm{h}$ maximum speed for all e-scooters. Finally, the speed of a pedelec, whose power assistance stops at $25 \mathrm{~km} / \mathrm{h}$, is similar to that of a conventional bike, at least on flat ground (Santacreu, 2018).

Road authorities should design wider bike lanes and tracks so to accommodate a larger amount of more diverse users. The steady uptake of cargo bikes is already putting pressure on cycling facilities in many countries, including cities in the Netherlands and Copenhagen. All sections, and uphill sections in particular, should allow room to overtake because of the speed differential between electric- and muscle-powered vehicles, and between users of all ages and abilities.

Many countries are mandating the use of cycling facilities by Type A powered micro-vehicles where such facilities exist. This is the case in France, where Type A micro-vehicles are now subject to most of the traffic management rules that apply to bicycles: where the manoeuvre is authorised by a dedicated street sign, they can give way on red signals or use both ways of a one-way street (Hiron, 2019).

There is little case for specifying new rules for Type A micro-vehicles which differ from those already applicable to bikes and pedelecs. Rules should reflect the vehicle speed, more than its form factor.

Legislators should avoid forcing micro-vehicles to the near-side of the road, a position often avoided by experienced riders so as to mitigate several risks. Such risks include "dooring" (collisions with car doors that are opened by car occupants who have not checked for approaching micro-vehicle riders), unsafe passing, and not being seen by other road users. French law mitigates the dooring risk as it enables all riders of Type A micro-vehicles to choose a safe distance from parked cars (Hiron, 2019). Policy makers should consider legislation which creates a safer and more pleasant micromobility experience: they could specify minimum passing distances and should allow motor vehicles to cross a continuous white line when overtaking a micro-vehicle.

More is yet to come in terms of bike lane utilisation. While urban logistics on micro-vehicles is not in the scope of this report, governments should consider the needs of micro-logistics as they revise their national cycle infrastructure design guides. Governments should develop a policy on autonomous delivery robots so to be proactive and mandate relevant regulations for the next innovations.

Rapid and low-cost solutions exist to protect people cycling. Authorities should consider traffic calming to reduce speeds, and revised circulation plans to reduce traffic volume. Traffic filtering is one such solution, where motor vehicle access to all address points is retained but driving through a residential area becomes impossible.

On main urban roads, a technique called "light separation" offers a rapid and affordable solution to create a protected cycling network. This involves the use of modular pre-fabricated poles, planters, curbs and other modular devices, including some which are called "armadillos" and "orcas". It has been used by the City of Seville to create a comprehensive, connected and protected network. With this technique, the cost of a protected cycling facility was estimated at EUR 100 000-250 000 per kilometre. This cost is several times lower than other forms of protection where, notably, drainage reconfiguration is required. The technique is suitable for trials due to its flexibility and low cost. A heavier separation can replace the light protection once the trial ends, if the speed and volume of motor vehicle traffic remain significant threats. (Deegan, 2018; Santacreu, 2018) 


\section{Collect data to identify dangerous locations}

Governments should identify dangerous locations by collecting data from various sources. This includes, but is not limited to, police data. Ambulance and hospital data could provide a greater sample, as not all those injured choose to report their crash to the police. New sources of data should not be neglected: they include direct user reports, surrogate safety data, and data from micromobility companies.

Most e-scooter injuries result from falls, suggesting that road surfaces could be improved by design and through maintenance. Road authorities should start by separating the cycling network from streets or lanes used by heavy vehicles. Heavy goods vehicles and buses are known to deteriorate both the road surface and the perception of safety.

Road authorities should monitor damages on the road surfaces as they appear and develop, so to intervene early and maintain a safe road surface for micro-vehicle users. A number of techniques can be used in isolation or combination, including video analysis, accelerometer data and direct user feedback.

Preventative maintenance of road structure and surfaces not only makes riders safer, it also saves money by reducing the frequency of the most expensive structural repairs and extending asset life. Separate, protected lanes dedicated solely to micro-vehicles would also save money. This is because motor vehicles - particularly trucks and buses - are by far the main source of road damage. Protected bike lanes and tracks would require less structural maintenance. Instrumented vehicles can patrol the network with a range of sensors, including laser, ground-penetrating radar, cameras and LiDAR. Highly precise but highly expensive, this solution is rarely used in urban environments. Progress in machine learning can diagnose road damage from smartphone images taken by floating vehicles (RoadBotics, 2019). However, the question remains on which vehicles such sensors could be attached, so as to make permanent monitoring possible without the congestion and cost associated with probe vehicle mileage.

Sensors should be placed on vehicles involved in municipal services and covering the entire street network at regular intervals. Examples of such fleets include municipal garbage collection vehicles and automatic number plate recognition vehicles used for parking enforcement. Street sweeping vehicles could be the ideal monitor of the condition of off-street cycle tracks.

There is arguably no better fleet than bicycles and micro-vehicles to collect data on road surface conditions. Some companies collect accelerometer data during cycle rides to detect potholes (ITF, 2019b). The technology could rely on dedicated equipment embedded into a bike light, as tested by a company called See.Sense in Dublin and Manchester. The technology could take advantage of smartphone sensors, as proposed by a cycling navigation company called Geovelo. Accelerometer data may, however, miss the worst potholes for the simple reason that people will swerve and avoid riding over them. It seems that every solution has its limitations and that various technologies can complement each other.

Already present in all smartphones, inertial measurement units (IMU) should be found on all shared micro-vehicles and used to sense potholes and report their precise location to the relevant road authority. One could argue that knowledge of exact pothole location is not the main barrier to repair, the lack of financial resources for road maintenance being the fundamental problem. One can, however, see in damage reporting a first step towards a greater allocation of resources.

Shared micro-vehicle companies should develop the capacity to automatically detect and report suspected crashes using motion sensors such as IMUs. A suspected crash in this context is identified by a sudden and brutal acceleration/deceleration observed on the vehicle when in motion. This would exclude cases where the vehicle topples over when idle. Surrogate safety metrics like this are used to 
monitor the occurrence and severity of incidents. They form an essential part of a proactive approach to road safety, as discussed in an earlier CPB report (ITF, 2019b). Calibration and self-calibration techniques have yet to be developed and micromobility companies should take the lead in this area. Would it be fair to impose on shared micromobility companies the reporting of potholes and suspected crashes? The next section examines the question of a regulatory balance between vehicle types. 


\section{Finding the right regulatory balance}

Powered micromobility has the potential to change cities for the better, reducing air pollution, congestion and road fatalities. Powered micromobility does not, however, bring all the physical activity benefits of human-powered micromobility. Authorities must balance their regulatory approach across modes in order to reach their policy goals, both within the micromobility universe and beyond and adapt according to the local context. This section examines the trade-offs between vehicle types, policy areas, and short- and long-term objectives.

This report seeks a balance between three key aspects of safety: safe infrastructure, safe vehicles and safe road users. Heavy regulation of the latter, for instance, should not distract from adding or updating infrastructure.

A balance between local and national regulation is important. Natural prerogatives of local government include the definition of low-speed zones and parking rules. Vehicle design, however, is best addressed at the national or international level, not least to promote competition. Indeed, having common rules helps businesses develop and compete in a clear legal framework. The idea, known as the "subsidiarity principle" in the European Union, is that issues should be dealt with at the most local level that is consistent with their resolution.

The short-term imperative of reacting to the surge in e-scooters in cities should be complimented by a longer-term objective of setting future-proof regulations. Policy makers should be "proactive and strategic" in the management of micromobility, according to the Polis network of cities and regions (Polis, 2019). In a context of rapid change, the most proactive approach to regulation is one that not only addresses the vehicle forms of today, but anticipates the forms to come. Flexible regulations prevent a race to the bottom whereby new entrants might modify form to bypass regulation, compromising safety. Flexibility supports innovation. This is especially important when innovation may deliver safety benefits not yet imagined. What if the industry moved towards extra wheels or seats intended to make e-scooters more stable? Novelty should be tested rather than banned. Flexible regulations would support innovation and not have to be revised each time a new form of vehicle hits the market.

A balance should be found between the urge to define detailed regulations and the need to see those regulations adopted by the public, industry and public authorities, including police forces. For this reason, this report encourages all stakeholders to seek simplification before adding regulatory layers. The regulation of standing e-scooters could be aligned, fully or mostly, on that of bicycles and slow ebikes. Similarly, the regulation of faster e-bikes and faster micro-vehicles could be aligned on existing moped regulations.

Traffic police resources have declined over the last decade in most countries. Would the police have the resources to enforce new micromobility regulations? An asymmetric focus by the police to enforce new micromobility regulations may neglect the enforcement of riskier and more dangerous behaviours in other user groups. 


\section{Vehicle types: Ensuring regulations are proportionate to public health and safety impacts}

Where people choose to replace car trips with micromobility, they generate a range of positive outcomes, from clean air to reduced congestion and better traffic safety. This is why a number of policy makers see a strategic value in and support the uptake of micromobility.

Regulators need to find a balance between the regulations imposed on shared vehicles and privately owned vehicles. Indeed, the heavy regulation of shared micromobility would encourage the alternative model which consists of private ownership. This model comes with some positive aspects but also with several drawbacks: owned vehicles share no data with local government, receive no geofence data on low-speed areas, and are unlikely to respect the same speed cap. Should the shared micromobility market disappear because of over-regulation, one might witness the rise of privately owned vehicles that do not adhere to speed limits. In Singapore, a person has already been killed by a high-speed, heavyweight e-scooter (Cheryl and Toh, 2019).

The speed of a Type A micro-vehicle should be comparable to the speed of a person cycling. This is to encourage their use on the roadway and on cycling facilities where they exist, as opposed to their use on sidewalks. France and Germany have imposed $25 \mathrm{~km} / \mathrm{h}$ and $20 \mathrm{~km} / \mathrm{h}$ speed limits respectively on powered micro-vehicles of Type A (Figure 1). This makes these vehicles at least as fast as an average person cycling. One could argue that the $25 \mathrm{~km} / \mathrm{h}$ limit applicable to the electric assistance on pedelecs should also apply to powered micro-vehicles. The argument will become stronger if consolidated evidence indicates that Type A powered micro-vehicles are no more dangerous than pedelecs.

Local government should seek fair treatment of all powered micromobility modes when imposing specific access, parking or speed limits through geofences. If the speed of shared e-scooters is limited in a pedestrian area, should not the speed of shared e-bikes be limited as well?

A Safe System approach focusses explicitly on eliminating fatal and serious injuries. Considering that motor vehicles are involved in the overwhelming majority of fatal micromobility crashes, this report recommends that all stakeholders remain focussed on motor vehicles as a major source of danger. Discussions on e-scooter vehicle design and rider behaviour should not distract decision makers from making progress on motor vehicle design and driver behaviour. This analysis does not make any assumption on the faults made by either parties involved in a collision. In a Safe System approach, errors are accepted as part of human nature and stakeholders should envisage all relevant strategies to prevent human errors from resulting in fatal or serious injuries.

Focussing a road safety conversation on a very precise group of vulnerable road users naturally leads to a discussion on their risky behaviours. However, one should not lose sight of the sources of danger in road transport as a system. The behaviour of motor vehicle drivers should be placed under greater scrutiny, with a particular focus on speed, distraction, intoxication and inexperience. Regulators are invited to consider such areas of intervention instead of dwelling on the helmet debate.

Several policy makers already see great strategic potential in developing low-speed micromobility (types $A$ and $B$ ). It can improve traffic safety and deliver other positive outcomes through a reduction in the number of car trips. It can increase the catchment area of public transport systems, making those networks more attractive. It offers a competitive door-to-door transport solution, especially on shortdistance trips, many of which are made by car. (Polis, 2019)

The use of e-scooters and other forms of micromobility will become safer over time as people acquire new skills, regulations are better targeted and a protected cycling network takes shape. But what will be 
the effect on the public health challenge of inactive lifestyles? A majority of adolescents (81\%) in the world do not meet current physical activity guidelines (Guthold et al., 2019). In high-income Western countries, $42 \%$ of adults do not meet recommended physical activity levels (Guthold et al., 2018). Type A micromobility makes a city safer where it contributes to a reduction in motorcycle and car traffic, but powered micro-vehicles require very little muscular input. Cycling, on the other hand, helps people live longer and healthier physically active lives. Pedal assisted bicycles also require physical activity and can compete with motor vehicles in a wider range of conditions (longer distances, sharp gradients, hot weather, and various rider fitness levels).

All this supports the argument for regulating active modes a little more favourably than fully powered modes. Many walking trips are currently replaced by e-scooter trips, whose average length is about two kilometres, a distance which can be qualified as "walkable". If and when e-scooters are integrated in MaaS platforms, some form of financial incentive should remain for people to walk short journeys.

Governments should seek to align micromobility regulation with existing regulation. This is unless current regulations on e-bikes and mopeds need be revised, in which case a comprehensive micromobility regulation can be elaborated. Safety regulation should be proportional to risks imposed on third parties and on riders themselves.

There is still a lot to learn about micromobility before precise and comprehensive policy recommendations can be made. In times of innovation, gathering data and conducting research is at least as urgent as defining new regulations. Micromobility data should be shared between operators, cities and academia so to facilitate research.

\section{Data sharing}

A balance also needs to be found in how much data is requested from shared mobility companies. The potential for data to support policy making is immense, but data collection comes at a cost and should not give a competitive advantage to traditional modes of transport from which very little data, if at all, is required. Data collection also comes with fundamental privacy protection questions.

Shared micromobility data could support policy making in several ways:

- Trip data can reveal potential demand for new public transport routes.

- Trip destinations help identify demand for parking. Monitoring that demand can help cities provide adequate on-street space for micro-vehicles, as well as for the parking of vehicles used to maintain, recharge and rebalance the fleet.

- Trip data can give an indication of the level of interchange with public transport.

- Trip routes can support the planning and maintenance of a cycling network. Such data can also be used to control for exposure in crash risk investigations.

Detailed trip data can be invasive to users' privacy and difficult for local governments to manage due to limited resources. A new business model has emerged in response to this called data aggregator. Academic institutions and private third-party data aggregation companies such as Populus are heading this development. Another approach would be to move away from open and unrestricted (within the receiving public authority) API feeds to API feeds whose access would be more tightly restricted alongside specific data use, retention and destruction protocols. Such protocols are the feature of many Mobility Data Specification (MDS) implementations such as that of Los Angeles (LADOT, 2019). 
The European Union's General Data Protection Regulation (GDPR) imposes that data sharing is carefully calibrated so to protect the privacy of individuals. An organisation must collect and process personal data for a specific and transparent purpose ("purpose limitation") and must collect and process only the personal data that is necessary to fulfil that purpose ("data minimisation").

Data exchange should not be a one-way protocol. Local government should consider which data and regulation could be pushed instantaneously towards the back-office of micromobility companies in a machine-readable format (ITF, 2019c). Data shared by local government could include the geofences governing the operation of e-scooters, their parking and the low-speed zones. Data standards exist to support such two-way information exchanges. MDS is the most widely known and used of such standards.

More than 80 cities across the globe have implemented MDS, including Chicago, Los Angeles, Seattle and Santa Monica (NACTO, 2019b; City of Santa Monica, 2019b) in the United States. Lisbon, Portugal was among the first European cities to impose MDS on shared mobility operators. MDS has evolved from an earlier standard designed specifically for bicycle sharing applications: the General Bikeshare Feed Specification (GBFS). Many other cities use GBFS or the GBFS component of MDS for micromobility companies to report to local government.

The point of several cities sharing the same data standard is to save on resources that would otherwise be wasted in duplicated efforts, both on the government and on the industry side.

Telematics enable the tracking of virtually all delivery vehicles and personnel in cities, from cycle courier to trucks. The same is true for taxis and private hire vehicles. Imposing requirements on shared microvehicles which are not imposed on more traditional traffic participants could be seen as unfair, but could also set a precedent and facilitate the collection of data from an increasing number of modes. The collection of micromobility data could transform the management of urban transportation. (Polis, 2019)

\section{Potential for self-regulation}

Not all road safety solutions are popular. One can expect little public enthusiasm for a lower speed limit for new riders in a shared powered micromobility system, for example. This idea could be described as a graduated speed limit system for novice riders, but might best be presented as a loyalty reward system. Such a measure would only work if it was applied across all operators in a given city, either with an industry charter or with local government regulation. Measures likely to affect the revenues of micromobility companies may not be implemented unless imposed across all operators. For example:

- a graduated speed limit applied on the first rides of a new user

- lower maximum speed when double riding is detected or suspected

- in-app alcohol testing ${ }^{9}$ before late-night rentals around bars

- pricing structures that do not encourage speeding and red light violations.

\section{Insurance companies: What is their role?}

Third-party liability insurance covers the damages inflicted on third parties, such as pedestrians. Such insurance is mandatory for motor vehicles in most jurisdictions. For bicycles, the contractual frameworks and regulations vary across countries, as there is no one-size-fits-all solution. What matters is that no pedestrian is left without coverage for the injuries they sustain. 
Should individual owners of micro-vehicles contract third party liability insurance? This requirement exists in French and German regulations on e-scooters. Yet most people are unaware of the legal requirement to insure an e-scooter, according to a survey conducted in France in late 2018 (Chabrier, 2019). In Germany, e-scooter riders must display an insurance sticker, which could both facilitate enforcement and raise awareness. Other countries, such as Spain, do not require Type A e-scooter riders to be insured. When updating their regulations, authorities should seek solutions for the full compensation of pedestrian injury costs which do not discourage the use of Type A micro-vehicles.

Authorities should clarify which vehicle types must come with third-party liability insurance. They must decide if every person cycling must be insured, taking into account the extent to which such a requirement might discourage the use of bicycles. The same question applies to the broader category of Type A micro-vehicles, considering the positive outcomes their use could deliver in cities.

In France, a typical household multi-risk insurance policy includes third party damages occurring when a person is riding a bicycle or pedelec. In practical terms, this means virtually every person cycling is covered without incurring the additional cost of a dedicated contract. On the other hand, people riding a powered micro-vehicle in France must hold a third party liability cover.

The European Commission proposed that all powered vehicles - including micro-vehicles - should have mandatory vehicle insurance. However, the European Parliament and the Council seem to have a different opinion (still under discussion as of the writing of this paper) and will probably exclude pedelecs from the forthcoming directive. This decision is likely to have a positive effect on public health, making pedelecs more convenient and attractive than less "active" alternatives, but creates a responsibility for national governments to clarify how third party injuries will be covered.

The maximum damage value which is covered in a micromobility insurance contract should be lower than that applicable to motor vehicle insurance contracts. This is due to the lower mass and kinetic energy of micro-vehicles.

Shared micromobility companies should also contract a third party insurance policy, as imposed by the local governments in Montreal and Buenos Aires. This is an area where self-regulation may be observed in the long term. As insurance companies collect data to assess and compare the risk of each shared micromobility service, a price signal could ultimately reward companies investing in safe micro-vehicles and in rider training.

Shared micromobility may offer personal injury insurance coverage to their riders in addition to obligatory third party coverage. This may raise awareness of the risk of injury, and may also create an incentive for shared micromobility companies to invest in safe micro-vehicles and in rider training. There is a fledgling (but growing) number of insurance companies around the world that offer free driving lessons to their customers (e.g. in New Zealand and Ireland). Partnerships between insurance companies and micromobility companies could result in more training for riders. 


\section{Notes}

1 The City of Santa Monica reports a single set of usage and collision statistics for e-bikes and e-scooters together. Over the data collection period, e-scooters represented about $80 \%$ of the shared micromobility fleet.

2 In Auckland, New Zealand, ACC said it received 22 e-scooter-related claims per week. Over the same period and also per week, it recorded 29 push scooter claims, 19 skateboard claims, and 73 cyclist claims. In comparison, ACC records 1000 new claims for falls every week in the Auckland area (ACC online database).

3 Over 90\% of injuries occur when using shared e-scooters, according to the observation of insurance data time series (Bekhit et al. 2020).

4 French police use revised data collection tools since 2018 that identify powered personal mobility devices. This category is separate from bicycles and slow e-bikes, facilitating the analysis and interpretation of micromobility crash data.

5 The International Road Traffic safety Analysis and Data group (IRTAD) is the permanent working group for road safety of the International Transport Forum. It brings together road safety experts from national road administrations, road safety research institutes, International Organisations, automobile associations, insurance companies, car manufacturers and others.

6 The cities where Jump is doing this are (as of the writing of this report): Paris, France; London, England; Brussels, Belgium; Berlin, Germany; Rome, Italy; and the US cities of San Francisco, California; Denver, Colorado; and Los Angeles, California. The author is grateful to Garance Lefevre at Uber for providing this information.

7 The author is grateful to Chris Bruntlett of the Dutch Cycling Embassy for providing the information on the Netherlands' national traffic test.

8 The author is grateful to George Yannis of the National Technical University of Athens for providing the information on the training programmes in the United Kingdom, New Zealand and Australia.

9 Smartphone apps exist which claim to assess the user's psychomotor functions through a test lasting a few minutes. Degraded accuracy or reaction time could reveal that a user is unfit to drive or ride a vehicle. 


\section{References}

6t-bureau de recherche (2016), Etude sur les impacts des services de vélo en free-floating sur les mobilités actives, https://www.ademe.fr/etude-impacts-services-velos-free-floating-mobilites-actives.

6t-bureau de recherche (2019a), Usages et usagers de services de trottinettes électriques en freefloating en France, Juin 2019, https://www.ademe.fr/usages-usagers-trottinettes-electriques-freefloating-france.

6t-bureau de recherche (2019b), Enquête auprès des utilisateurs de Cityscoot à Paris, https://6t.co/enquete-cityscoot/.

6t-bureau de recherche (2019c), Enquête auprès des utilisateurs de trottinettes en free-floating Dott à Paris, Novembre 2019, https://6-t.co/utilisateurs-trottinettes-dott/.

Abend, L. (2019), "Cyclists and E-Scooters are Clashing in the Battle for Europe's Streets", https://time.com/5659653/e-scooters-cycles-europe/ (accessed on 03 February 2020).

ACC (2019), ACC online database, https://catalogue.data.govt.nz/dataset/fall-data/resource/8f70c6b933ad-4a6b-908f-e7c3cfbd82f8 (accessed on 03 February 2020).

Acciaro, M. (2014), "Real option analysis for environmental compliance: LNG and emission control areas", Transportation Research Part D: Transport and Environment, Vol. 28, pp. 41-50, https://doi.org/ 10.1016/j.trd.2013.12.007.

AEA (2009), "Cost Benefit Analysis to Support the Impact Assessment accompanying the revision of Directive 1999/32/EC on the Sulphur Content of certain Liquid Fuels", with Association Aspen, IVL, TNO, Report to European Commission, ED45756, Issue 3.

Albrecht, J. (2015), "Stakeholder involvement in developing LNG as ship fuel in the Baltic Sea region", University of Jyväskylä, http://urn.fi/URN:NBN:fi:jyu-201506012116.

Aldred, R. (2018), "Inequalities in self-report road injury risk in Britain: A new analysis of National Travel Survey data, focusing on pedestrian injuries", Journal of Transport and Health, Vol. 9, pp. 96-104.

Allen, D. et al. (1998), "Operational Analysis of Uninterrupted Bicycle Facilities", Transportation Research Record, pp. 29-36, doi: 10.3141/1636-05.

Attefors, M. (2019) Lär dig trafikreglerna med VOI och få en gratis åktur, https://bubblan.teknikveckan.com/t/lar-dig-trafikreglerna-med-voi-och-fa-en-gratis-aktur/2896 (accessed on 03 February 2020).

Austin Public Health (2019), Dockless Electric Scooter-related Injuries Study, https://www.austintexas.gov/sites/default/files/files/Health/Epidemiology/APH_Dockless Electric Scoot er Study 5-2-19.pdf (accessed on 03 February 2020).

Bahk, E. (2019), "Electric scooter accidents on the rise", The Korea Times, 6 December 2019, https://m.koreatimes.co.kr/pages/article.asp?newsldx=277033 (accessed 6 December 2019).

Baltimore City (2019), Dockless Vehicle Pilot Program Evaluation Report, Department of Transportation, Baltimore City, https://transportation.baltimorecity.gov (accessed on 03 February 2020). 
Bassil, K. et al. (2015), "Pedestrian and Cyclist Safety in Toronto", https://www.researchgate.net/ publication/280576352 Pedestrian and Cyclist Safety in Toronto (accessed on 03 February 2020).

Bekhit, M. N. Z., J. Le Fevre, C. J. Bergin (2020), Regional healthcare costs and burden of injury associated with electric scooters, Injury, Volume 51, Issue 2, 2020, https://doi.org/10.1016/i.injury.2019.10.026.

Bellet, T. and A. Banet (2012), "Towards a conceptual model of motorcyclists' risk awareness: A comparative study of riding experience effect on hazard detection and situational criticality assessment", Accident Analysis and Prevention, Vol. 49, pp. 154-164, Elsevier Ltd, doi: 10.1016/j.aap.2011.10.007.

Bellido, E. (2019), Muere un francés de 15 años por una caída en patinete en Oropesa - Todo Oropesa, http://todooropesa.com/sucesos/muere-un-frances-de-15-anos-por-una-caida-en-patinete-en-oropesa.

Bernardi, S. and F. Rupi (2015), "An Analysis of Bicycle Travel Speed and Disturbances on Off-street and On-street Facilities", Transportation Research Procedia, Vol. 5, pp. 82-94.

Bike Europe (2017a), "Rules and regulations on electric cycles in European Union", White paper, http://bike-eu.com.s3-eu-central-1.amazonaws.com/app/uploads/2015/09/rules-regulation-on-electriccycles-in-the-european-union-may-2017.pdf (accessed on 03 February 2020).

Bike Europe (2017b), "Revised EN 15194 E-Bike Safety Standard Implemented”, https://www.bikeeu.com/laws-regulations/nieuws/2017/11/revised-en-15194-e-bike-safety-standard-implemented10132012 (accessed on 03 February 2020).

Bikeability (2019), https://bikeability.org.uk/ (accessed on 05 December 2019).

Bird (2019), "A Look at e-Scooter Safety: Examining risks, reviewing responsibilities, and prioritizing prevention", https://www.bird.co/wp-content/uploads/2019/12/Bird-Safety-Report-April-2019.pdf (accessed on 03 February 2020).

Bitters, J. (2020), "San Jose city, business leaders announce new 'Innovation Zone'”, San Jose Spotlight, https://sanjosespotlight.com/san-jose-city-business-leaders-announce-new-innovation-zone/ (accessed on 03 February 2020).

Blaizot, S. et al. (2012), "Accidentalité à Vélo et Exposition au Risque (AVER) - Risque de traumatismes routiers selon quatre types d'usagers", HAL Id: hal-00768484, https://hal.archives-ouvertes.fr/hal00768484 (accessed on 03 February 2020).

Blaizot, S. et al. (2013), "Injury incidence rates of cyclists compared to pedestrians, car occupants and powered two-wheeler riders, using a medical registry and mobility data, Rhône County, France", Accident Analysis and Prevention, Vol. 58, pp. 35-45, https://doi.org/10.1016/j.aap.2013.04.018.

BMVI (2019), Verordnung über die Teilnahme von Elektrokleinstfahrzeugen am Straßenverkehr (Elektrokleinstfahrzeuge-Verordnung - eKFV), https://www.gesetze-im-internet.de/ekfv/ BJNR075610019.html (accessed on 03 February 2020).

Boztas, S. (2019), Unwelcome guests: moped riders protest as Amsterdam drives them from bike lanes, The Guardian, 4-June-2019, www.theguardian.com/cities/2019/jun/04/unwelcome-guests-mopedriders-protest-as-amsterdam-drives-them-from-bike-lanes

Buehler, R. and J. Pucher (2017), "Trends in walking and cycling safety: Recent evidence from highincome countries, with a focus on the United States and Germany", American Journal of Public Health, Vol. 107/2, pp. 281-287, doi: 10.2105/AJPH.2016.303546.

Calinescu, T. and D. Adminaite (2018), "Progress in reducing drink driving in Europe", European Transport Safety Council, https://etsc.eu/wp-content/uploads/report reducing drink driving final.pdf. 
Castro, A., S. Kahlmeier and T. Gotschi (2018), "Exposure-adjusted Road Fatality Rates for Cycling and Walking in European Countries", Discussion Paper, International Transport Forum, Paris, https://www.itfoecd.org/sites/default/files/docs/exposure-adjusted-road-fatality-rates-cycling-walking-europe.pdf.

CDC WISQARS (2019), Web-based Injury Statistics Query and Reporting System, https://www.cdc.gov/injury/wisqars/index.html

CEN (2016), "Light electric vehicles and self-balancing vehicle", CEN/TC 354/WG 4, European Committee for Standardization, https://standards.cen.eu/dyn/www/f?p=204:22:0:..:FFP ORG ID,FSP LANG ID:1199144,25\&cs=159F5A57E039125FD59FFEC5C5DD066D9 (accessed on 2 December 2019).

CEN (2019), "Work program 2020", European Committee for Standardization and European Committee for Electrotechnical Standardization, https://www.cencenelec.eu/News/Publications/Publications/CENCENELEC WP 2020 EN.pdf (accessed on 29 January 2020).

Chabrier, B. (2019), NVEI : le devoir d'information, chantier prioritaire, https://www.argusdelassurance.com/assurance-dommages/auto/nvei-le-devoir-d-information-chantierprioritaire.140264.

Chang, A. (2019), "A Micro-Glossary on Micromobility", Medium, https://medium.com/@annieyjchang/amicro-glossary-on-micromobility-e9f02b88fb49 (accessed 5 December 2019).

Cheng, K. (2019), "The Big Read: Calls to ban PMDs mount as accidents persist - but is it the best option?", Channel News Asia, https://www.channelnewsasia.com/news/singapore/ban-pmd-personalmobility-device-e-scooter-accidents-singapore-11568106.

Cherry, C. and J. MacArthur (2019), "E-bike safety. A review of Empirical European and North American Studies", White paper, prepared for PeopleForBikes, https://peopleforbikes.org/wp-content/uploads/ 2019/10/EbikeSafety-VFinal.pdf (accessed on 03 February 2020).

Cheryl, T. and T. Toh (2019), E-scooter that knocked into cyclist in fatal Bedok accident should not have been used on public paths, The Straits Times, www.straitstimes.com/singapore/transport/e-scooter-thatknocked-into-65-year-old-cyclist-in-fatal-accident-was-non

Choudhary, V., M. Shunko, S. Netessine and S. Koo (2019), "Nudging Drivers to Safety: Evidence from a Field Experiment", INSEAD Working Paper No. 2019/52/TOM., http://dx.doi.org/10.2139/ssrn.3491302.

City of Santa Monica (2019a), Shared Mobility Device Pilot Program User Survey Results, https://www.smgov.net/uploadedFiles/Departments/PCD/Transportation/SharedMobility UserSurveySu mmary 20190509 FINAL.PDF (accessed on 05 December 2019).

City of Santa Monica (2019b),"Shared mobility pilot program summary report", November 2019, https://www.smgov.net/uploadedFiles/Departments/PCD/Transportation/SantaMonicaSharedMobilityEv aluation Final 110419.pdf (accessed 05 December 2019).

Civity (2019), "E-Scooters in Germany: A data-driven contribution to the ongoing debate", http://scooters.civity.de/en (accessed on 03 February 2020).

Clewlow, R. (2018), "DC is growing its dockless bike and scooter program: We partnered with them to evaluate how it's expanding access in underserved communities", Medium, https://medium.com/ populus-ai/measuring-equity-dockless-27c40af259f8 accessed on 03 February 2020).

Commission Delegated Regulation (EU) No 3/2014 of 24 October 2013 supplementing Regulation (EU) No 168/2013 of the European Parliament and of the Council with regard to vehicle functional safety requirements for the approval of two- or three-wheel vehicles and quadricycles, Official Journal of the 
European Union, https://eur-lex.europa.eu/legal-content/EN/TXT/PDF/?uri=CELEX:32014R0003\& from=EN (accessed on 03 February 2020).

Commission Delegated Regulation (EU) No 44/2014 of 21 November 2013 supplementing Regulation (EU) No 168/2013 of the European Parliament and of the Council with regard to the vehicle construction and general requirements for the approval of two- or three-wheel vehicles and quadricycles, Official Journal of the European Union, https://eur-lex.europa.eu/legal-content/EN/TXT/PDF/?uri=CELEX: 32014R0044\&from=EN (accessed on 03 February 2020).

CPSC (2019), "Requirements for bicycles", Electronic Code of Federal Regulations, Title 16, Chapter II, Subchapter C, Part 1512, https://www.ecfr.gov/cgi-bin/text-idx?SID=2d5c62bb5ac809e995f9207 b7c375103\&mc=true\&tpl=/ecfrbrowse/Title16/16cfr1512 main 02.tpl.

Cripton, P. et al. (2015), "Severity of urban cycling injuries and the relationship with personal, trip, route and crash characteristics: Analyses using four severity metrics", BMJ Open, Vol. 5/1, doi: 10.1136/ bmjopen-2014-006654.

Crundall, D. et al. (2014), "The role of experience and advanced training on performance in a motorcycle simulator", Accident Analysis and Prevention, Vol. 73, pp. 81-90, Elsevier Ltd, doi: 10.1016/j.aap. 2014.08.009.

CSCRS (2019), "Understanding micromobility safety behavior and standardizing safety metrics for transportation system integration", Collaborative Sciences Center for Road Safety, https://www.roadsafety.unc.edu/research/projects/2019r26/.

Curry, A. et al. (2017), "Comparison of older and younger novice driver crash rates: Informing the need for extended Graduated Driver Licensing restrictions", Accident Analysis and Prevention, Vol. 108, pp. 66-73, Elsevier Ltd, doi: 10.1016/j.aap.2017.08.015.

De Ceunynck, T. et al. (2019), "Determinants and barriers of walking, cycling and using Personal eTransporters: A survey in nine European cities", Conference of European Directors of Roads, https://www.vias.be/publications/ (accessed on 03 February 2020).

Dediu, H. (2019) "Where does the Word Micromobility come From?", Micromobility industries, https://micromobility.io/blog/2019/8/1/where-does-the-word-micromobility-come-from (accessed on 26 November 2019).

Deegan, B. (2018), "Light Protection of Cycle Lanes: Best Practices", Discussion Paper, International Transport Forum, Paris, https://www.itf-oecd.org/sites/default/files/docs/light-protection-cyclelanes 2.pdf.

Deery, H. (1999), "Hazard and Risk Perception among Young Novice Drivers", Journal of Safety Research, Vol. 30/4, pp. 225-236, Elsevier Ltd, https://doi.org/10.1016/S0022-4375(99)00018-3.

DGT (2019), "Aclaraciones técnicas y criterios para la formulación de denuncias de vehículos ligeros propulsados por motores eléctricos", Instruccion 2019/S-149 TV-108, Direccion General del traffico, Ministerio del Interior, http://www.dgt.es/Galerias/seguridad-vial/normativa-legislacion/otrasnormas/normas-basicas/Intruccion-VMP-y-otros-vehiculos-ligeros.pdf (accessed on 03 February 2020).

Directive 2001/95/EC of the European Parliament and of the Council of 3 December 2001 on general product safety, Official Journal of the European Communities, https://eur-lex.europa.eu/legalcontent/EN/TXT/PDF/?uri=CELEX:32001L0095\&from=EN. 
Directive 2006/42/EC of the European Parliament and of the Council of 17 May 2006 on machinery, and amending Directive 95/16/EC (recast), Official Journal of the European Union, https://eurlex.europa.eu/LexUriServ/LexUriServ.do?uri=OJ:L:2006:157:0024:0086:EN:PDF.

Directive 2006/66/EC of the European Parliament and of the Council of 6 September 2006 on batteries and accumulators and waste batteries and accumulators and repealing Directive 91/157/EEC, Official Journal of the European Union, https://eur-lex.europa.eu/legal-content/EN/TXT/PDF/?uri=CELEX: 32006LO066\&from $=$ FR.

Directive 2009/48/EC of the European Parliament and of the Council of 18 June 2009 on the safety of toys, Official Journal of the European Union, https://eur-lex.europa.eu/legal-content/EN/TXT/PDF /?Uri=CELEX:32009L0048\&from=EN.

Directive 2011/65/EU of the European Parliament and of the Council of 8 June 2011 on the restriction of the use of certain hazardous substances in electrical and electronic equipment, Official Journal of the European Union, https://eur-lex.europa.eu/legal-content/EN/TXT/PDF/?uri=CELEX:32011L0065\& from $=F R$.

Directive 2014/30/UE of the European Parliament and of the Council of 26 February 2014 on the harmonisation of the laws of the Member States relating to electromagnetic compatibility, Official Journal of the European Union, https://eur-lex.europa.eu/legal-content/EN/TXT/PDF/?uri= CELEX:32014L0030\&from=FR.

Directive 2014/35/EU of the European Parliament and of the Council of 26 February 2014 on the harmonisation of the laws of the Member States relating to the making available on the market of electrical equipment designed for use within certain voltage limits, Official Journal of the European Union, https://eur-lex.europa.eu/legal-content/EN/TXT/PDF/?uri=CELEX:32014L0035\&from=EN.

Directive 2014/45/EU of the European Parliament and of the Council of 3 April 2014 on periodic roadworthiness tests for motor vehicles and their trailers and repealing Directive 2009/40/EC, Official Journal of the European Union, https://eur-lex.europa.eu/legal-content/EN/TXT/PDF/?uri=CELEX: 32014L0045\&from=EN.

EC/134/2014, "Commission Delegated Regulation (EU) No 134/2014 of 16 December 2013 supplementing Regulation (EU) No 168/2013 of the European Parliament and of the Council with regard to environmental and propulsion unit performance requirements and amending Annex V", Official Journal of the European Union, https://eur-lex.europa.eu/legal-content/EN/TXT/PDF/?uri=CELEX: 32014R0134\&from=EN.

EN 15194 (2009), Safety standard adapted for Electrically Power Assisted Cycles (EPAC), https://shop.bsigroup.com/ProductDetail?pid=000000000030335500

EN 50604 (2016), Secondary lithium batteries for light electric vehicle applications. General safety requirements and test methods. https://shop.bsigroup.com/ProductDetail/?pid=000000000030303915

European Commission (2015), "Serious Injuries", European Road Safety Observatory, http://ec.europa.eu/transport/road safety/sites/roadsafety/files/ersosynthesis2015seriousinjuries 25 en.pdf.

European Commission (2019a), "FAQ: Type approval of vehicles", https://ec.europa.eu/growth/sectors/ automotive/technical-harmonisation/faq-auto en (accessed on 02 December 2019). 
European Commission (2019b), "Study on the inclusion of light trailers and two- or three-wheel vehicles in the scope of the periodic roadworthiness testing", MOVE/C2/SER/2017-295- SI2.772857, Final report, European Commission, https://citainsp.org/wp-content/uploads/2019/02/LO.pdf.

Feleke, R. et al. (2018), "Comparative fatality risk for different travel modes by age, sex, and deprivation", Journal of Transport and Health, Vol. 8, pp. 307-320, https://doi.org/10.1016/j.jth.2017.08.007.

Felton, R. (2019), "National Crash Data From E-Scooter Ride-Share Companies Revealed for the First Time", ConsumerReports.com, https://www.consumerreports.org/product-safety/national-crash-datafrom-e-scooter-ride-share-companies-revealed-for-first-time/ (03 February 2020).

FHSA (2019), "Federal Hazardous Substances Act”, Electronic Code of Federal Regulations,

Title 16, Part 1500, US Government Publishing Office, https://www.ecfr.gov/cgi-bin/text-idx?SID= 7ad2f4fd3ce5aa8107effa41ac55a907\&mc=true\&tpl=/ecfrbrowse/Title16/16CllsubchapC.tpl (accessed on 03 February 2020).

Fitt, H. and A. Curl (2019), "E-scooter use in New Zealand: Insights around some frequently asked questions", University of Canterbury, http://hdl.handle.net/10092/16336.

Freydier, C., C. Berthelon and M. Bastien-Toniazzo (2016), "Does early training improve driving skills of young novice French drivers?", Accident Analysis and Prevention, Vol. 96, pp. 228-236, Elsevier Ltd, doi: 10.1016/j.aap.2016.07.026.

Garrard, J., S. Handy and J. Dill (2012), Women and Cycling, pp 211-234 in City Cycling, The MIT Press, Cambridge, MA, https://mitpress.mit.edu/books/city-cycling

Gibson, A. (1915) "Self-propelled vehicle", Patent registered with the United States Patent and Tradmark Office on July 25, 1916, https://pdfpiw.uspto.gov/.piw?Docid=01192514 (accessed on 5 December 2019).

Girotto, E. et al. (2016), "Professional experience and traffic accidents/near-miss accidents among truck drivers", Accident Analysis and Prevention, Vol. 95, pp. 299-304, doi: 10.1016/j.aap.2016.07.004.

GLA (2015), "Health impacts of cars in London", Greater London Authority, London, https://www.london.gov.uk/sites/default/files/health impact of cars in london-sept 2015 final 0.pdf (accessed on 03 February 2020).

Greibe, P. and T. Buch (2016), "Capacity and Behaviour on One-way Cycle Tracks of Different Widths", Transportation Research Procedia, Vol. 15, pp. 122-136, https://doi.org/10.1016/i.trpro.2016.06.011.

Guthold, R. et al. (2018), "Worldwide trends in insufficient physical activity from 2001 to 2016: a pooled analysis of 358 population-based surveys with 1.9 million participants", The Lancet, Vol. 6/10, DOI:https://doi.org/10.1016/S2214-109X(18)30357-7.

Guthold, R. et al. (2019), "Global trends in insufficient physical activity among adolescents: a pooled analysis of 298 population-based surveys with 1.6 million participants", The Lancet, Vol. 4/1, pp. 23-35, DOI:https://doi.org/10.1016/S2352-4642(19)30323-2.

Harrison, W. (1999), The role of experience in learning to drive: A theoretical discussion and an investigation of the experiences of learner drivers over a two-year period, Report no. 156, Monash University Accident Research Centre, Melbourne, https://www.monash.edu/ data/assets/ pdf file/0005/216446/muarc156.pdf (accessed on 18 November 2019). 
Hawkins, A. (2019), "Lime's electric scooters will be able to tell when you're too drunk to ride", The Verge, https://www.theverge.com/2019/4/17/18411127/lime-brad-bao-electric-scooter-drunkdetection-vergecast (accessed on 04 February 2020).

Haworth, N. and A. Schramm (2019), "Illegal and risky riding of electric scooters in Brisbane", Medical Journal of Australia, https://doi.org/10.5694/mja2.50275.

Hay, M., V. Etienne and L. Paire-Ficout (2017), "Driver training and licensing: Formal pre-license training, graduated driver licensing and probation", European Road Safety Decision Support System, developed by the H2020 project SafetyCube, https://www.roadsafety-dss.eu/assets/data/pdf/synopses/Driver training and Licensing formal prelicense training graduated driver licensing and probation 130620 17.pdf (accessed on 21 November 2019).

Hiron, B. (2019), "La nouvelle réglementation pour les Engins de Déplacements Personnels motorisés (EDPM)", Cerema, https://www.cerema.fr/fr/actualites/nouvelle-reglementation-engins-deplacementspersonnels (accessed on 04 February 2020).

Hosking, S., C. Liu and M. Bayly (2010), "The visual search patterns and hazard responses of experienced and inexperienced motorcycle riders", Accident Analysis and Prevention, Vol. 42/1, pp. 196-202, Elsevier Ltd, https://doi.org/10.1016/i.aap.2009.07.023.

Insurance Business (2019), "E-scooter injuries cost ACC nearly \$1.5 million", Insurance Business Magazine, https://www.insurancebusinessmag.com/nz/news/breaking-news/escooter-injuries-cost-accnearly-1-5-million-170310.aspx (accessed on 03 February 2020).

ISO (2020), "ISO 43.150: Cycles, including their components and systems", International Organization for Standardization, https://www.iso.org/ics/43.150/x/.

ITF (2011), Reporting on Serious Road Traffic Casualties: Combining and using different data sources to improve understanding of non-fatal road traffic crashes, International Transport Forum, Paris, https://www.itf-oecd.org/sites/default/files/docs/road-casualties-web.pdf.

ITF (2015), Improving Safety for Motorcycle, Scooter and Moped Riders, ITF Research Reports, OECD Publishing, Paris, https://doi.org/10.1787/9789282107942-en.

ITF (2016), Zero Road Deaths and Serious Injuries: Leading a Paradigm Shift to a Safe System, OECD Publishing, Paris, https://doi.org/10.1787/9789282108055-en.

ITF (2018), Alcohol-Related Road Casualties in Official Crash Statistics, IRTAD Research Report, International Transport Forum, Paris, https://www.itf-oecd.org/sites/default/files/docs/alcohol-relatedroad-casualties-official-crash-statistics.pdf.

ITF (2019a), "Road Safety in European Cities: Performance Indicators and Governance Solutions", International Transport Forum Policy Papers, $n^{\circ}$ 67, OECD Publishing, Paris, https://doi.org/ 10.1787/ad4de8a1-en.

ITF (2019b), New Directions for Data-Driven Transport Safety, International Transport Forum, Paris, https://www.itf-oecd.org/new-directions-data-driven-transport-safety-0.

ITF (2019c), Governing Transport in the Algorithmic Age, International Transport Forum, Paris, https://www.itf-oecd.org/governing-transport-algorithmic-age.

ITF (forthcoming a), Good to Go? Assessing the Environmental Performance of New Mobility, International Transport Forum, Paris.

ITF (forthcoming b), Streets That Fit: Reallocating City Space, International Transport Forum, Paris. 
JORF (2019), “Décret n²019-1082 du 23 octobre 2019 relatif à la réglementation des engins de déplacement personnel", Journal Officiel de la République Française, JORF n0249 du 25 octobre 2019 texte $n^{\circ} 19$.

Jump (2019), SFMTA Powered Scooter Share Program - Permit Application, https://www.sfmta.com/sites/default/files/reports-and-documents/2019/09/jump.pdf

Kluppels, L. (2016), "Beyond shame and guilt: What's inside a hit and run accident", Belgian Road Safety Institute, http://traffic-psychology-international.eu/wp-content/uploads/2016/01/Beyond-shame-andguilt.pdf (accessed on 04 February 2020).

KMVSS (2019), "Regulations for Performance and Safety Standards of Motor Vehicle and Vehicle Parts", Korea Motor Vehicle Safety Standards, https://chemycal.com/news/18676d1d-7128-4f81-84de-e4f7a 9e5dad4/Revision of Korean Safety and Performance Regulations for Motor Vehicles and Parts

Kobayashi, L. et al. (2019), "The e-merging e-pidemic of e-scooters", Trauma Surgery and Acute Care Open, Vol. 4/1, doi: 10.1136/tsaco-2019-000337.

Kollinger, C., R. Rzewnicki and R. Fismer (2011), "How to run a cycling action", Life Cycle Implementation Manual, 3rd Edition, LIFE CYCLE is a project funded by the EU Public Health Programme, FGM-Amor, https://ec.europa.eu/transport/sites/transport/files/cycling-guidance/life cycle implementation manual.pdf (accessed on 05 December 2019).

Lacey, J. et al. (2007), "Pilot test of new roadside survey methodology for impaired driving", National Highway Traffic Safety Administration, U.S. Department of Transportation, https://pdfs.semanticscholar. org/e53c/db34e024606f304c96c3a8884f336a61bfc6.pdf? ga=2.242491717.618539787.15808069581817405654.1580806958.

LADOT (2019), "LADOT data protection principles", Los Angeles Department of Transportation, https://ladot.io/wp-content/uploads/2019/03/2019-04-12 Data-Protection-Principles.pdf.pdf (accessed on 04 February 2020).

Lardelli-Claret, P. et al. (2005), "Driver dependent factors and the risk of causing a collision for two wheeled motor vehicles", Injury Prevention, Vol. 11/4, pp. 225-231, doi: 10.1136/ip.2004.006957.

Large (2019), "The electric bicycle is limited to speed of $25 \mathrm{~km} / \mathrm{h}$ and have an 11-month transition period", Large.net, https://www.large.net/news/79u43mp.html (accessed on 06 December 2019).

Lefrancq, M. (2019), "Shared freefloating micromobility regulations and results of e-scooter users' survey (summer 2019)", presentation on behalf of Bruxelles Mobilité for the ERSCharter Webinar, https://erscharter.eu//sites/default/files/resources/presentation martin lefrancq.pdf (accessed on 04 February 2020).

Lekash, S. (2019), "Bird hopes 'helmet selfies' will make riders safer", Mashable, https://mashable.com/ article/bird-helmet-selfie-escooters-safety/?europe=true (accessed on 04 February 2020).

Lime (2018), "San Francisco Scooter Use Survey Results", https://www.limebike.com/hubfs/Lime\%20 San\%20Francisco\%20Scooter\%20Survey\%20Findings.pdf (accessed on 04 February 2020).

Lime (2019), "Year End Report 2018", https://www.li.me/hubfs/Lime Year-End\%20Report_2018.pdf (accessed on 04 February 2020).

Lin, S. et al. (2008), "Comparison Study on Operating Speeds of Electric Bicycles and Bicycles: Experience from Field Investigation in Kunming, China", Transportation Research Record, Vol. 2048/1, pp. 52-59, https://doi.org/10.3141/2048-07. 
Liu, C., S. Hosking and M. Lenné (2009), "Hazard perception abilities of experienced and novice motorcyclists: An interactive simulator experiment", Transportation Research Part F: Traffic Psychology and Behaviour, Vol. 12/4, pp. 325-334, https://doi.org/10.1016/j.trf.2009.04.003.

Loritz, M. (2019), "We want our riders to feel like superheroes: Interview with Wind EMEA CEO Ed Schmidt", EU-Startups, https://www.eu-startups.com/2019/10/we-want-our-riders-to-feel-likesuperheroes-interview-with-wind-mobility-emea-ceo-ed-schmidt/ (accessed on 04 February 2020).

Lunden, I. (2019), "Berlin's Tier Mobility scoops up $\$ 60 \mathrm{M}$ as its scooter-based transportation service passes 10M rides", TechCrunch, https://techcrunch.com/2019/10/07/berlins-tier-mobility-scoops-up$60 \mathrm{~m}$-for-its-scooter-based-transportation-service/ (accessed on 04 February 2020).

Marschall, A. (2018), "Lime's new scooter is hardier, heavier, and built for life on the streets", Wired, https://www.wired.com/story/lime-scooter-gen3-design/\# (accessed on 04 February 2020).

Marshall, W. and N. Ferenchak (2019), "Why cities with high bicycling rates are safer for all road users", Journal of Transport and Health, Vol. 13, https://doi.org/10.1016/i.jth.2019.03.004.

Maus, J. (2016), "Portland now using pedal-powered trikes to help rebalance bike share stations", Bicycle Insurance Portland, http://www.bicycleinsuranceportland.com/24396/portland-now-using-pedalpowered-trikes-to-help-rebalance-bike-share-stations (accessed on 04 February 2020).

MDT (2017), Resolución 160 de 2017 Ministerio de Transporte, Por la cual se reglamenta el registro y la circulación de los vehículos automotores tipo ciclomotor, tricimoto y cuadriciclo y se dictan otras disposiciones, 2 Febrero 2017, https://www.alcaldiabogota.gov.co/sisjur/normas/Norma1.jsp?i=68085.

Multnomah County Health Department (2019), Scooter-related Injuries in Multnomah County JulyNovember 2018, https://www.portlandoregon.gov/transportation/article/709715

NACTO (2018), "NACTO Policy 2018: Guidelines for the Regulation and Management of Shared Active Transportation", National Association of City Transportation Officials, https://nacto.org/wp-content/ uploads/2018/07/NACTO-Shared-Active-Transportation-Guidelines.pdf (accessed on 04 February 2020).

NACTO (2019a), "Shared Micromobility in the U.S.: 2018", National Association of City Transportation Officials, https://nacto.org/shared-micromobility-2018/ (accessed on 04 February 2020).

NACTO (2019b), "Guidelines for Regulating Shared Micromobility", Version 2, National Association of City Transportation Officials, https://nacto.org/wp-content/uploads/2019/09/NACTO Shared Micromobility Guidelines Web.pdf (accessed on 04 February 2020).

NCSL (2019), "State Electric Bicycle Laws: A Legislative Primer", National Conference of State Legislatures, http://www.ncsl.org/research/transportation/state-electric-bicycle-laws-a-legislativeprimer.aspx (accessed on 05 December 2019).

NHTSA (2013), "Motor Vehicle Safety", Title 49, United States Code, Chapter 301, U.S. Department of Transportation, National Highway Traffic Safety Administration, https://www.nhtsa.gov/sites/nhtsa. dot.gov/files/documents/motor vehicle safety unrelated uncodified provisions may2013.pdf (accessed on 03 December 2019).

NHTSA (2017), "Part 570- in use inspection standards", Title 49, subtitle B, chapter V, National Highway Traffic Safety Administration, Code of Federal Regulations, https://www.govinfo.gov/content/pkg/CFR2017-title49-vol6/xml/CFR-2017-title49-vol6-part570.xml (accessed on 9 December 2019) 
NITC (2014), Regulations of e-bikes in North America, Report NITC-RR-564, National Institute for Transportation and Communities, https://ppms.trec.pdx.edu/media/project files/NITC-RR564 Regulations of E-Bikes in North America 1.pdf (accessed on 04 February 2020).

Nobel Prize (2019), "Scientific background on Nobel Prize in Chemistry 2019: Lithium-ion batteries", The Royal Swedish Academy of Sciences, Stockholm, https://www.nobelprize.org/uploads/2019/10/ advanced-chemistryprize2019.pdf (accessed on 05 December 2019).

NUMO (2020), "Vehicle profiles: A policy guidance tool by NUMO", webpage, https://vehicle-profileeditor.netlify.com/ (accessed on 04 February 2020).

NYCDOT (2014), "Protected bicycle lanes in NYC", presentation, New York City Department of Transportation, http://www.nyc.gov/html/dot/downloads/pdf/2014-09-03-bicycle-path-data-analysis.pdf (accessed on 04 February 2020).

NZ Transport Agency (2019), "Cycling education”, https://www.nzta.govt.nz/walking-cycling-and-publictransport/cycling/cycling-education/ (accessed on 05 December 2019).

O'Hern, S. and J. Oxley (2019), "Pedestrian injuries due to collisions with cyclists Melbourne, Australia”, Accident Analysis and Prevention, Vol. 122, pp. 295-300, https://doi.org/10.1016/j.aap.2018.10.018.

Paine, M. (2001), Analysis of relative safety performance of bicycles and scooters, report prepared for VecRoads, Vehicle Design and Research Pty Limited, http://mpainesyd.com/filechute/scooter report dec01.PDF (accessed on 04 February 2020).

PBOT (2018), "2018 E-Scooter Pilot User Survey Results", Portland Bureau of Transportation, www.portlandoregon.gov/transportation/article/700916.

PBOT (2019), "2018 E-Scooter Findings Report", Portland Bureau of Transportation, www.portlandoregon.gov/transportation/article/709719.

PeopleForBikes (2019), Bicycle Network Analysis webpage, https://bna.peopleforbikes.org/\#/.

Petrin, K. (2019), "St. Louis begins rolling out safety updates for Bird, Spin and Lime scooters", St. Louis Public Radio, https://news.stlpublicradio.org/post/st-louis-begins-rolling-out-safety-updates-bird-spinand-lime-scooters\#stream/0 .

Polis (2019), "Macro managing micro mobility: Taking the long view on short trips", Discussion Paper, Polis, https://www.polisnetwork.eu/wp-content/uploads/2019/11/Polis-Paper-MacromanagingMicroMobility.pdf.

Public Law 107-319 (2002), "An act to amend the Consumer Product Safety Act to provide that lowspeed electric bicycles are consumer products subject to such Act", H.R. 727, U.S. Government Publishing Office, https://www.govinfo.gov/app/details/PLAW-107publ319/summary.

Qishin, T. (2019), "Legality of e-scooters around the world", AsiaOne, https://www.asiaone.com/ digital/legality-e-scooters-around-world (accessed on 04 February 2020).

Regulation (EU) No 168/2013 of the European Parliament and of the Council of 15 January 2013 on the approval and market surveillance of two- or three-wheel vehicles and quadricycles, Official Journal of the European Union, https://eur-lex.europa.eu/LexUriServ/LexUriServ.do?uri=OJ:L:2013:060:0052: 0128:EN:PDF.

Rizzi, M., H. Stigson and M. Krafft (2013), "Cyclist injuries leading to permanent medical impairment in Sweden and the effect of bicycle helmets", presented at the International Research Council on the 
Biomechanics of Injury conference on 11-13 September 2013 in Gothenburg, Sweden, http://www.ircobi.org/wordpress/downloads/irc13/pdf files/46.pdf.

RoadBotics (2019), "North Huntingdon Township, Pennsylvania: Case Study", https://www.roadbotics.com/north-huntingdon-township-case-study/ (accessed on 04 February 2020).

Robbins, C. and P. Chapman (2018), "Drivers' Visual Search Behavior Toward Vulnerable Road Users at Junctions as a Function of Cycling Experience", Human Factors, Vol. 60/7, pp. 889-901, https://doi.org/ 10.1177/0018720818778960.

RTA (2006), Road Traffic Act $n^{\circ}$ 7969, Korea Legislation Research Institute, https://elaw.klri.re.kr/eng service/lawView.do?lang=ENG\&hseq=906 (accessed 05 December 2019).

Khorasani-Zavareh, D. et al. (2015), "Kinetic energy management in road traffic injury prevention: A call for action", Journal of Injury and Violence Research, Vol. 7/1, pp. 36-37, doi: 10.5249/jivr.v7i1.458.

SAE (2019) "J3194" Standard - Taxonomy and classification of powered micromobility vehicles", https://www.sae.org/standards/content/i3194 201911/.

Santacreu, A. (2018), "Cycling Safety", International Transport Forum, Paris, https://www.itfoecd.org/sites/default/files/docs/cycling-safety-roundtable-summary 0.pdf.

Schepers, P., K. Klein Wolt and E. Fishman (2018), "The Safety of E-Bikes in the Netherlands", Discussion Paper, International Transport Forum, Paris, https://www.itf-oecd.org/sites/default/files/docs/safety-ebikes-the-netherlands 1.pdf.

Schroten, A. et al. (2019), "Sustainable transport infrastructure charging and internalisation of transport externalities: Executive summary", European Commission, Brussels, doi: 10.2832/246834.

Scientific American (1906), Scientific American, Vol. 94/15, Munn and Co., New York, https://archive.org/ details/scientific-american-1906-04-14/mode/2up.

Scoot (2019), MTA Powered Scooter Share Permit Program, https://www.sfmta.com/sites/default/ files/reports-and-documents/2019/09/scoot.pdf.

Sikka, N. et al. (2019) "Sharing the sidewalk: A case of E-scooter related pedestrian injury", The American Journal of Emergency Medicine, Vol. 37/9, pp. 1807.e5-1807.e7, https://doi.org/10.1016/j.ajem. 2019.06.017.

Silicon Canals (2019), "Irish telematics startup Luna unveils a solution for mass adoption of e-scooters", https://siliconcanals.com/news/startups/irish-telematics-startup-luna-unveils-a-solution-for-massadoption-of-e-scooter/.

SLA (2019), "Complete guide to e-scooter and PMD laws for Singapore riders", Singapore Legal Advice, https://singaporelegaladvice.com/law-articles/e-scooter-laws-singapore (accessed 06 December 2019).

Small, A. (2019), "Who's ready for the electric moped moment?", Citylab, https://www.citylab.com/ transportation/2019/09/revel-electric-scooter-rental-review-moped-safety-tips-app/597367/ (accessed on 04 February 2020).

Sustrans (2019), “Bike It Plus London”, https://www.sustrans.org.uk/our-blog/projects/2019/london/ bike-it-plus-london/ (accessed on 05 December 2019).

SWOV (2019), "Fact sheet: Pedelecs and speed pedelecs", SWOV Institute for Road Safety Research, https://www.swov.nl/en/facts-figures/factsheet/pedelecs-and-speed-pedelecs (accessed 06 December 2019). 
Taylor, C. (2019), "US electronic scooter operator to pilot Irish GPS technology", The Irish Times, https://www.irishtimes.com/business/technology/us-electronic-scooter-operator-to-pilot-irish-gpstechnology-1.4110870 (accessed on 04 February 2020).

TfL (2016), London Cycling Design Standards, Chapter 3, Transport for London, http://content.tfl.gov.uk/ Icds-chapter3-streetsandspaces.pdf.

Toh, T. (2019), "270 reports of errant PMD and e-bike users received in a month through LTA transport app", The Straits Times, https://www.straitstimes.com/singapore/transport/270-reports-of-errant-pmdand-e-bike-users-received-in-a-month-through-Ita accessed on 04 February 2020).

Toosizadeh, N. et al. (2014), "Motorized mobility scooters: The use of training/intervention and technology for improving driving skills in aging adults - A mini-review", Gerontology, Vol. 60/4, pp. 357-365, https://doi.org/10.1159/000356766.

Transport for London (2015), Attitudes towards cycling, Library report, TfL n 05110, Transport for London, http://content.tfl.gov.uk/atc-online-autumn-2015-report.pdf.

Trivedi, T. et al. (2019), "Injuries associated with standing electric scooter use", JAMA Network Open, Vol. 2/1, doi:10.1001/jamanetworkopen.2018.7381.

TU Delft (2019), "Smart motor in handlebars prevents bicycles from falling over", Delft University of Technology, https://www.tudelft.nl/en/2019/tu-delft/smart-motor-in-handlebars-prevents-bicyclesfrom-falling-over/ (accessed on 04 February 2020).

Twisk, D. and S. de Hair-Buijssen (2017), "MeBeSafe: Developing and testing infrastructure and car based nudges to improve cyclist safety", presentation at the 6th Annual International Cycling Safety Conference, California, USA, 21-22 September 2017, https://icsc2017.figshare.com/articles/MeBeSafe Infrastructure car based nudges to improve cyclist safety/5405257 (accessed on 04 February 2020).

Underwood, G. (2007), "Visual attention and the transition from novice to advanced driver", Ergonomics, Vol. 50/8, pp. 1235-1249, https://doi.org/10.1080/00140130701318707.

UNECE (2017), "Consolidated Resolution on the Construction of Vehicles (R.E.3)", Revision 6, ECE/TRANS/WP.29/78/Rev.6, World Forum for Harmonization of Vehicle Regulations, United Nations Economic Commission for Europe, https://www.unece.org/fileadmin/DAM/trans/main/wp29/ wp29resolutions/ECE-TRANS-WP.29-78r6e.pdf (accessed 06 December 2019)..

UNECE (2019), "World Forum for Harmonization of Vehicle Regulations on its 179th session", United Nations Economic Commission for Europe, https://www.unece.org/fileadmin/DAM/ trans/doc/2019/wp29/ECE-TRANS-WP.29-1149e-final.pdf (accessed 06 December 2019).

VdTÜV (2019), "E-Scooter brauchen Blinker", https://www.vdtuev.de/news/E-Scooter-brauchen-Blinker (accessed on 04 February 2020).

Veryard, D. and S. Perkins (2018), "Integrating Urban Public Transport Systems and Cycling", Discussion Paper, International Transport Forum, Paris, https://www.itf-oecd.org/sites/default/files/docs/ integrating-urban-public-transport-systems-cycling-roundtable-summary $0 . p d f$.

VZSFIPR Collaborative (2019a), "E-scooter Collision and Injury Analysis", Vision Zero SF Injury Prevention Research Collaborative, San Francisco, https://www.sfdph.org/dph/files/EHSdocs/PHES/VisionZero/EScooter Collision Injury 2019.pdf.

VZSFIPR Collaborative (2019b), "A methodology for emerging mobility injury monitoring in San Francisco, California utilizing hospital trauma records", Version 2.0, Vision Zero SF Injury Prevention Research 
Collaborative, San Francisco, https://www.sfdph.org/dph/files/EHSdocs/PHES/VisionZero/Emerging Mobility Injury Monitoring Methodology.pdf.

Way2Go (2019), Way2Go Bike Ed webpage, https://www.dpti.sa.gov.au/Way2Go/bike ed (accessed on 05 December 2019).

Weijermars, W. et al. (2018), "Burden of injury of serious road injuries in six EU countries", Accident Analysis and Prevention, Vol. 111, pp. 184-192, https://doi.org/10.1016/i.aap.2017.11.040.

Weijermars, W., N. Bos and H. Stipdonk (2016), "Health burden of serious road injuries in the Netherlands", Traffic Injury Prevention, Vol. 17/8, pp. 863-869, doi: 10.1080/15389588.2016.1157591.

$\mathrm{Xu}, \mathrm{C}$. et al. (2015), "Modeling of speed distribution for mixed bicycle traffic flow", Advances in Mechanical Engineering, Vol. 7/11, p. 1-9, Sage, DOI: 10.1177/1687814015616918.

Yannis, G. et al. (2019), "Impaired cycling and crash involvement in OECD countries", presentation at the 9th International Congress on Transportation Research, Athens, Greece, 24-25 October 2019, https://www.nrso.ntua.gr/geyannis/wp-content/uploads/pc347-2019ICTR-Velivr fullpaper v6.pdf.

Yao, L. and C. Wu (2012), "Traffic safety for electric bike riders in China: Attitudes, risk perception and aberrant riding behaviors", Transportation Research Record, Vol. 2314/1, pp. 49-56, https://doi.org/ 10.3141/2314-07.

Zhaki, A. (2017), "Suspect nabbed for e-bike hit-and-run that killed man, 78", The Straints Times, https://www.straitstimes.com/singapore/courts-crime/suspect-nabbed-for-e-bike-hit-and-run-thatkilled-man-78 (accessed on 04 February 2020).

Zhu, M. et al. (2013), "Graduated driver licensing and motor vehicle crashes involving teenage drivers: An exploratory age-stratified meta-analysis", Injury Prevention, Vol. 19/1, pp. 49-57, http://dx.doi.org/ 10.1136/injuryprev-2012-040474. 


\section{Annex A. Standing e-scooter fatality details}

Table 6. Details of e-scooter related deaths, May 2018 to end October 2019

\begin{tabular}{|c|c|c|c|c|c|c|c|}
\hline Crash date & Country & City & $\begin{array}{l}\text { Victim } \\
\text { type }\end{array}$ & $\begin{array}{l}\text { Age of } \\
\text { victim }\end{array}$ & $\begin{array}{l}\text { Sex of } \\
\text { victim }\end{array}$ & $\begin{array}{l}\text { Collision } \\
\text { with }\end{array}$ & $\begin{array}{l}\text { Motor vehicle is } \\
\text { involved }\end{array}$ \\
\hline 01 May 2019 & Australia & Brisbane & $\begin{array}{l}\text { e-scooter } \\
\text { (Lime) }\end{array}$ & 50 & male & fall & \\
\hline 16 April 2019 & Belgium & Brussels & e-scooter & 41 & male & fall & \\
\hline $\begin{array}{l}16 \text { October } \\
2019\end{array}$ & Canada & Vancouver & e-scooter & 34 & male & car & yes \\
\hline 12 April 2019 & France & Levallois-Perret & pedestrian & 81 & male & e-scooter & \\
\hline 10 June 2019 & France & Paris & e-scooter & 25 & male & van & yes \\
\hline $\begin{array}{l}09 \text { August } \\
2019\end{array}$ & France & $\begin{array}{l}\text { Vélizy- } \\
\text { Villacoublay, } \\
\text { Paris region }\end{array}$ & e-scooter & 30 & male & motorcycle & yes \\
\hline $\begin{array}{l}01 \text { September } \\
2019\end{array}$ & France & Reims & $\begin{array}{l}\text { e-scooter } \\
\text { (private) }\end{array}$ & 25 & female & car & yes \\
\hline $\begin{array}{l}29 \text { September } \\
2019\end{array}$ & France & $\begin{array}{l}\text { Béthune area, } \\
\text { Hauts-de- } \\
\text { France region }\end{array}$ & $\begin{array}{l}\text { e-scooter } \\
\text { (private) }\end{array}$ & 17 & male & car & yes \\
\hline $\begin{array}{l}20 \text { October } \\
2019\end{array}$ & France & Bordeaux & $\begin{array}{l}\text { e-scooter } \\
\text { (free- } \\
\text { floating) }\end{array}$ & 25 & male & car & hit and run \\
\hline $\begin{array}{l}16 \text { September } \\
2019\end{array}$ & New Zealand & Auckland & $\begin{array}{l}\text { e-scooter } \\
\text { (Lime) }\end{array}$ & 23 & male & fall & \\
\hline 26 April 2019 & Singapore & Singapore & e-scooter & 39 & female & bus & yes \\
\hline $\begin{array}{l}21 \text { September } \\
2019\end{array}$ & Singapore & Singapore & cyclist & 65 & female & $\begin{array}{l}\text { e-scooter } \\
\text { (private) }\end{array}$ & \\
\hline $\begin{array}{l}24 \text { September } \\
2019\end{array}$ & Singapore & Singapore & e-scooter & 30 & male & not known & not known \\
\hline $\begin{array}{l}01 \text { August } \\
2018\end{array}$ & Spain & $\begin{array}{l}\text { Esplugues de } \\
\text { Llobregat, near } \\
\text { Barcelona }\end{array}$ & pedestrian & 92 & female & e-scooter & \\
\hline $\begin{array}{l}\text { 08 September } \\
2018\end{array}$ & Spain & $\begin{array}{l}\text { Niembro } \\
\text { (Asturias) }\end{array}$ & $\begin{array}{l}\text { e-scooter } \\
\text { (private) }\end{array}$ & 60 & male & fall & \\
\hline $\begin{array}{l}\text { 09 October } \\
2018\end{array}$ & Spain & Sabadell & e-scooter & 40 & female & truck & yes \\
\hline 30 April 2019 & Spain & Valencia & e-scooter & 20 & male & motorcycle & yes \\
\hline
\end{tabular}




\begin{tabular}{|c|c|c|c|c|c|c|c|}
\hline 27 June 2019 & Spain & $\begin{array}{l}\text { Oropesa del } \\
\text { Mar, Castellón } \\
\text { province }\end{array}$ & $\begin{array}{l}\text { e-scooter } \\
\text { (rental } \\
\text { shop) }\end{array}$ & 15 & male & fall & \\
\hline 01 May 2019 & Sweden & $\begin{array}{l}\text { Helsingborg, } \\
\text { north of Malmö }\end{array}$ & $\begin{array}{l}\text { e-scooter } \\
\text { (Voi) }\end{array}$ & 27 & male & car & yes \\
\hline 12 July 2019 & United Kingdom & London & $\begin{array}{l}\text { e-scooter } \\
\text { (private) }\end{array}$ & 35 & female & truck & yes \\
\hline 22 May 2018 & United States & NYC & $\begin{array}{l}\text { e-scooter } \\
\text { (private) }\end{array}$ & 7 & male & bus & yes \\
\hline $\begin{array}{l}\text { 04 September } \\
2018\end{array}$ & United States & Dallas & $\begin{array}{l}\text { e-scooter } \\
\text { (Lime) }\end{array}$ & 24 & male & not known & not known \\
\hline $\begin{array}{l}23 \text { September } \\
2018\end{array}$ & United States & Washington & $\begin{array}{l}\text { e-scooter } \\
\text { (Lime) }\end{array}$ & 20 & male & $\operatorname{car}(\mathrm{SUV})$ & yes \\
\hline $\begin{array}{l}01 \text { December } \\
2018\end{array}$ & United States & $\begin{array}{l}\text { San Diego, } \\
\text { California }\end{array}$ & $\begin{array}{l}\text { e-scooter } \\
\text { (Bird) }\end{array}$ & 26 & male & car & yes \\
\hline $\begin{array}{l}01 \text { February } \\
2019\end{array}$ & United States & Austin Texas & $\begin{array}{l}\text { e-scooter } \\
\text { (Lime) }\end{array}$ & 21 & male & car & yes \\
\hline $\begin{array}{l}01 \text { March } \\
2019\end{array}$ & United States & $\begin{array}{l}\text { San Diego, } \\
\text { California }\end{array}$ & $\begin{array}{l}\text { e-scooter } \\
\text { (Bird) }\end{array}$ & 53 & male & tree & \\
\hline $\begin{array}{l}15 \text { March } \\
2019\end{array}$ & United States & $\begin{array}{l}\text { Santa Monica, } \\
\text { California }\end{array}$ & $\begin{array}{l}\text { e-scooter } \\
\text { (private) }\end{array}$ & 41 & male & car & hit and run \\
\hline 13 April 2019 & United States & Los Angeles & $\begin{array}{l}\text { e-scooter } \\
\text { (Lime) }\end{array}$ & 31 & male & $\begin{array}{l}\text { car / } \\
\text { pickup } \\
\text { truck }\end{array}$ & yes \\
\hline 23 April 2019 & United States & $\begin{array}{l}\text { Tulsa, } \\
\text { Oklahoma }\end{array}$ & $\begin{array}{l}\text { e-scooter } \\
\text { (Lime) }\end{array}$ & 5 & male & car & hit and run \\
\hline 15 May 2019 & United States & $\begin{array}{l}\text { Nashville } \\
\text { Tennessee }\end{array}$ & $\begin{array}{l}\text { e-scooter } \\
\text { (Bird) }\end{array}$ & 26 & male & $\operatorname{car}(\mathrm{SUV})$ & yes \\
\hline 18 May 2019 & United States & Atlanta & $\begin{array}{l}\text { e-scooter } \\
\text { (Lime) }\end{array}$ & 20 & male & $\operatorname{car}(S U V)$ & yes \\
\hline 20 June 2019 & United States & Tampa & $\begin{array}{l}\text { e-scooter } \\
\text { (Lime) }\end{array}$ & 33 & male & truck & yes \\
\hline 20 June 2019 & United States & $\begin{array}{l}\text { San Diego, } \\
\text { California }\end{array}$ & $\begin{array}{l}\text { e-scooter } \\
\text { (Lime) }\end{array}$ & 48 & male & e-scooter & \\
\hline 17 July 2019 & United States & Atlanta & $\begin{array}{l}\text { e-scooter } \\
\text { (Bird) }\end{array}$ & 37 & male & bus & yes \\
\hline 27 July 2019 & United States & Atlanta & $\begin{array}{l}\text { e-scooter } \\
\text { (Bird) }\end{array}$ & 34 & female & not known & yes \\
\hline $\begin{array}{l}\text { O4 August } \\
2019\end{array}$ & United States & Denver & $\begin{array}{l}\text { e-scooter } \\
\text { (Lyft) }\end{array}$ & 26 & male & car & yes \\
\hline $\begin{array}{l}06 \text { August } \\
2019\end{array}$ & United States & $\begin{array}{l}\text { East Point, near } \\
\text { Atlanta }\end{array}$ & $\begin{array}{l}\text { e-scooter } \\
\text { (Jump) }\end{array}$ & 45 & male & truck & yes \\
\hline $\begin{array}{l}\text { O9 October } \\
2019\end{array}$ & United States & Spokane & $\begin{array}{l}\text { e-scooter } \\
\text { (Lime) }\end{array}$ & 28 & male & $\operatorname{car}(S U V)$ & hit and run \\
\hline $\begin{array}{l}27 \text { October } \\
2019\end{array}$ & United States & Boise, Idaho & $\begin{array}{l}\text { e-scooter } \\
\text { (Lime) }\end{array}$ & 16 & male & truck & yes \\
\hline
\end{tabular}

Note: unless otherwise specified, all mentions of e-scooters refer to standing e-scooters. 


\section{Annex B. Vehicle involvement in fatal crashes}

Table 7. Vehicle involvement in fatal crashes

\begin{tabular}{|c|c|c|c|c|c|}
\hline City & Dates & $\begin{array}{l}\text { Selected vehicle } \\
\text { type }\end{array}$ & $\begin{array}{l}\text { Fatalities } \\
\text { within user } \\
\text { group }\end{array}$ & $\begin{array}{l}\text { Fatalities in other } \\
\text { user groups } \\
\text { (in crashes involving } \\
\text { the selected vehicle } \\
\text { type) }\end{array}$ & $\begin{array}{l}\text { Fatalities within } \\
\text { user group (in } \\
\text { crashes with no } \\
\text { motor vehicle as } \\
\text { crash opponent) }\end{array}$ \\
\hline Inner London & 2013-2017 & Passenger car & 21 & 85 & 9 \\
\hline Inner London & 2013-2017 & $\begin{array}{l}\text { Powered two- } \\
\text { wheeler }\end{array}$ & 60 & 15 & 12 \\
\hline Inner London & 2013-2017 & Pedal cycle & 37 & 6 & 2 \\
\hline Inner London & 2013-2017 & Bus & 1 & 29 & 1 \\
\hline Paris City & 2013-2017 & Passenger car & 12 & 87 & 5 \\
\hline Paris City & 2013-2017 & $\begin{array}{l}\text { Powered two- } \\
\text { wheeler }\end{array}$ & 70 & 19 & 24 \\
\hline Paris City & 2013-2017 & Pedal cycle & 14 & 5 & 3 \\
\hline Paris City & 2013-2017 & Bus & 0 & 13 & 0 \\
\hline Bogota & 2017 & Passenger car & 25 & 167 & 11 \\
\hline Bogota & 2017 & $\begin{array}{l}\text { Powered two- } \\
\text { wheeler }\end{array}$ & 182 & 76 & 45 \\
\hline Bogota & 2017 & Pedal cycle & 59 & 4 & 13 \\
\hline Bogota & 2017 & Bus & 7 & 98 & 5 \\
\hline Rome & 2013-2017 & Passenger car & 233 & 235 & 109 \\
\hline Rome & 2013-2017 & $\begin{array}{l}\text { Powered two- } \\
\text { wheeler }\end{array}$ & 240 & 42 & 83 \\
\hline Rome & 2013-2017 & Pedal cycle & 23 & 1 & 2 \\
\hline Rome & 2013-2017 & Bus & 0 & 25 & 0 \\
\hline Milan & 2013-2017 & Passenger car & 48 & 86 & 22 \\
\hline Milan & 2013-2017 & $\begin{array}{l}\text { Powered two- } \\
\text { wheeler }\end{array}$ & 70 & 13 & 28 \\
\hline Milan & $2013-2017$ & Pedal cycle & 21 & 1 & 5 \\
\hline Milan & 2013-2017 & Bus & 0 & 7 & 0 \\
\hline World & $\begin{array}{l}2018-5- \\
2019-10\end{array}$ & Standing e-scooter & 36 & 3 & 7 \\
\hline
\end{tabular}

Note: The term "powered two-wheeler" includes motorcycles and mopeds, as per the Glossary.

Source: ITF Safer City Streets network. 


\section{Annex C. Micromobility safety research priorities: Survey results}

The ITF elaborated and circulated an online questionnaire to identify research priorities for micromobility safety. A wide range of stakeholders responded from 9 October 2019 to 6 November 2019.

From the 49 respondents, the majority represent government departments and government agencies. Remarkably, the ITF collected 17 responses from city-level government. This is thanks to the ITF Safer City Streets network, developed since 2016 to share experience on data-driven urban road safety policies. Other responses reflected the position of private companies, non-governmental organisations and academia, as presented on Table 8.

Table 8. Number of survey responses by type of organisation

\begin{tabular}{|l|l|}
\hline Type of organisation & $\begin{array}{l}\text { Number of survey } \\
\text { responses }\end{array}$ \\
\hline Local government or agency & 17 \\
\hline State- and national-level government or agency & 10 \\
\hline Corporate & 10 \\
\hline Non-governmental & 6 \\
\hline Academia & 6 \\
\hline Total & 49 \\
\hline
\end{tabular}

The survey asked respondents to "identify the most important questions for the ITF to investigate with regards to the safety of personal mobility vehicles such as e-scooters and e-bikes, be it private or shared vehicles." The survey asked respondents to set a priority level (low, medium, high or top) for each research question. Results are presented in Figure 22 (overleaf). 
Figure 22. Micromobility safety research priorities: Survey results

- Top priority

- High priority

Injury data collection methods (police, hospital, surveys, etc.) Impact of maintenance, re-charging and redistribution Insurance (personal injury, liability, etc.) Privacy protection Data sharing: format specification Data sharing: scope and requirement Mode shift and its road safety impact Definition of micromobility, in the context of safety regulations Application of the Safe System principles to micromobility

Updating the classic road safety education Training people how to ride a powered micro-vehicle Training people how to ride in traffic Age limits on riders Gathering evidence on the learning curve Mitigating the risks of the first few rides

Pedestrian detection and autonomous braking Third-party insurance Fine-scale geo-fencing Sidewalk parking Sidewalk riding and applicable speed limit

Use of personal protection equipment Vehicle overload Wrong-way riding Alcohol or drug intoxication

Acoustic vehicle alerting systems Cooperative ITS and turning-assistance systems

Use of reflective clothing Design standards for lights

Infrastructure design / Adapting the cycling infrastructure Geo-fencing to prevent access to unsafe locations

Collection of data on road surface conditions

Collection of location data for all falls, crashes and injuries

Maintenance obligations Anti-lock braking and electronic stability control systems Wheel size and steering dampening

Design standards on brakes, wheels, tyres and suspension Ability to carry passengers / solutions to detect number of riders Wet-weather operations Night-time operations

Graduated speed limit, as a function of rider experience Downhill speed limiter

Throttle design Enforcement Geo-fencing

Maximum speed

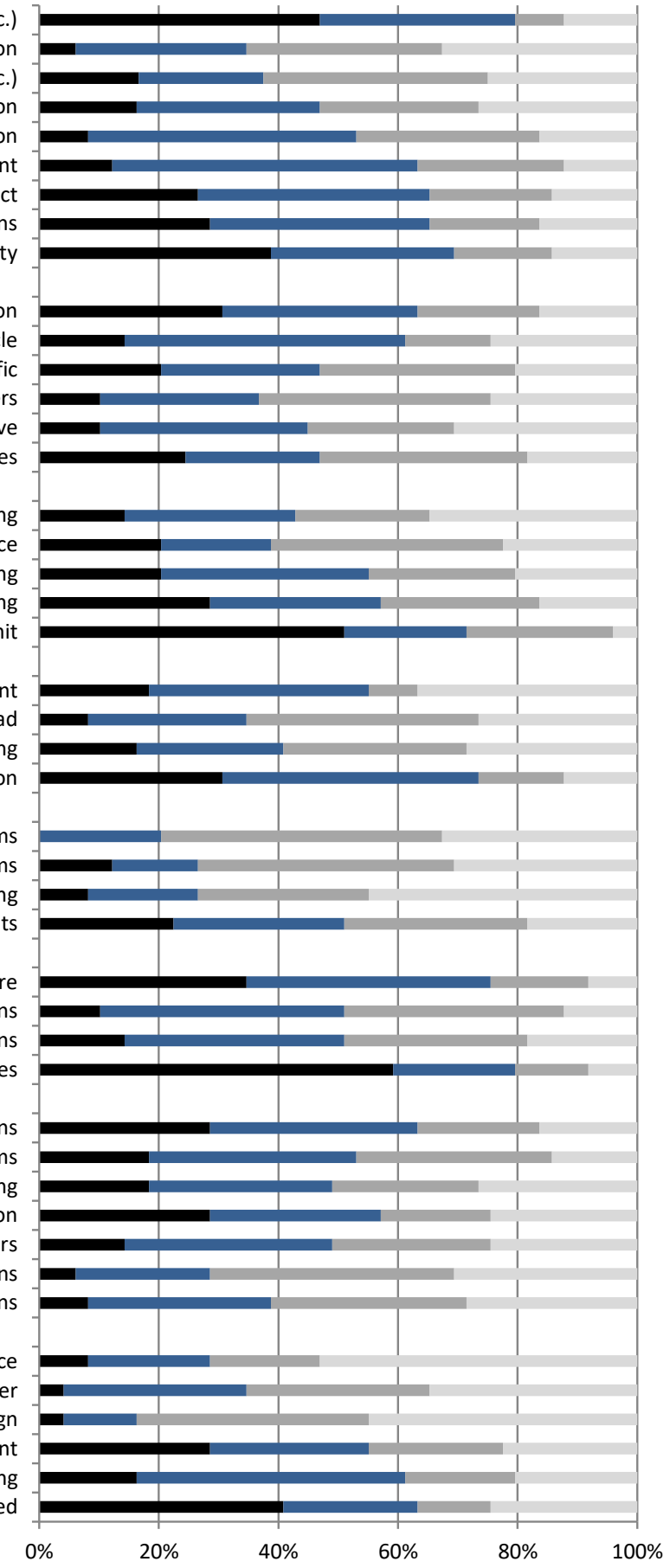




\section{Annex D. Summary of vehicle requirements in European regulation No. 168/2013}

Table 9. Summary of vehicle requirements in European regulation No. 168/2013

\begin{tabular}{|c|c|c|c|}
\hline Article & & L1e-A & L1e-B \\
\hline \multicolumn{4}{|c|}{ Vehicle functional safety requirements } \\
\hline \multirow[t]{12}{*}{22} & audible warning devices & & $\mathrm{x}$ \\
\hline & braking, including anti-lock and combined brake systems & $\mathrm{x}$ & $\mathrm{x}$ \\
\hline & electrical safety & $\mathrm{x}$ & $\mathrm{x}$ \\
\hline & $\begin{array}{l}\text { manufacturer declaration requirements regarding endurance testing of functional safety } \\
\text { systems, parts and equipment }\end{array}$ & $\mathrm{x}$ & $\mathrm{x}$ \\
\hline & driver-operated controls including identification of controls, tell-tales and indicators & & $\mathrm{x}$ \\
\hline & installation of lighting and light signalling devices, incl. automatic switching-on of lighting & $\mathrm{x}$ & $\mathrm{x}$ \\
\hline & rearward visibility & & $\mathrm{x}$ \\
\hline & seating position (saddles and seats) & $\mathrm{x}$ & $x$ \\
\hline & steer-ability, cornering properties and turn-ability & $\mathrm{x}$ & $x$ \\
\hline & installation of tyres & $\mathrm{x}$ & $x$ \\
\hline & maximum continuous rated or net power and/or vehicle speed limitation by design & $x$ & $\mathrm{x}$ \\
\hline & vehicle structure integrity & $\mathrm{x}$ & $\mathrm{x}$ \\
\hline \multicolumn{4}{|c|}{ Vehicle construction and general type approval requirements } \\
\hline 20 & anti-tampering measures & $\mathrm{x}$ & $\mathrm{x}$ \\
\hline 25 & arrangements for type-approval procedures & $\mathrm{x}$ & $\mathrm{x}$ \\
\hline 33 & conformity of production requirements & $x$ & $x$ \\
\hline \multirow[t]{7}{*}{18} & devices to prevent unauthorised use & $x$ & $x$ \\
\hline & electromagnetic compatibility (EMC) & $x$ & $x$ \\
\hline & masses and dimensions & $x$ & $x$ \\
\hline & passenger handholds and footrests & & $x$ \\
\hline & registration plate space & $x$ & $x$ \\
\hline & repair and maintenance information & $x$ & $\mathrm{x}$ \\
\hline & stands & $x$ & $x$ \\
\hline \multicolumn{4}{|c|}{ Environmental and propulsion performance requirements } \\
\hline \multirow[t]{2}{*}{$\begin{array}{l}23 \\
\& 24\end{array}$} & $\begin{array}{l}\text { environmental test procedures related to exhaust emissions, evaporative emissions, } \\
\text { greenhouse gas emissions, fuel consumption and reference fuels ; noise emissions }\end{array}$ & $x$ & $\mathrm{x}$ \\
\hline & $\begin{array}{l}\text { maximum design vehicle speed, maximum torque, maximum continuous total engine power } \\
\text { of propulsion }\end{array}$ & $x$ & $x$ \\
\hline
\end{tabular}

Source: EU Regulation 168/2013. 


\section{Annex E. List of Workshop participants}

Amos ALBERT, VP at Electrical Drives, Bosch, Germany

Rachel ALDRED, Reader in Transport, University of Westminster, United Kingdom

Mario ALVES, Secretary General, International Federation of Pedestrians, Portugal

Suzanne ANDERSSON, Senior Advisor, City of Gothenburg, Sweden

George BEARD, Head of Consumer Research, Ultra Low Emission Vehicles, TRL, United Kingdom

Wernher BRUCKS, Head Road Safety, City of Zürich, Switzerland

Diego CANALES, Global Partnerships Manager, Populus, United States

Christopher CHERRY, Professor, University of Tennessee, United States

Philippe CRIST, International Transport Forum (ITF)

Eric DE KIEVIT, Programme Manager Road Safety, CROW, Netherlands

Ombline DE SAINT LÉON, ITF

Haya DOUIDRI, Policy Affairs Representative, Bird, Netherlands

Mafalda FARMHOUSE, Architect, City of Lisbon, Portugal

Miguel GASPAR, Deputy Mayor for Mobility and Safety, City of Lisbon, Portugal

Richard GOEBELT, Director of the Division Automotive and Mobility, Verband der TÜV e.V.(VdTÜV), Germany

Pedro GOUVEIA, Planning Team Leader, Lisbon's Vision Zero Action Plan, City of Lisbon, Portugal

Susanna HAUPTMANN, Policy Officer, Kapsch TafficCom AG, Austria

Benoit HIRON, Head of Unit, Traffic Safety, Cerema, France

Daniel KIM, Manager, International Relations, Incheon Airport, Korea

Dagmar KÖHLER, Communications Manager and Road Safety Coordinator, Polis, Belgium

Takayuki KUSAJIMA, General Manager, Toyota, Japan

Jacqueline LACROIX, Head of Unit, DVR, Deutscher Verkehrssicherheitsrat, Germany

Darren LINDSEY, Lead on Safe Mobility, Michelin, France

Valentin LÖWENSTEIN, Senior Business Manager, Dekra, Germany

Sharon MASTERSON, ITF

Karsten MCFARLAND, Director New Mobility, PTV Group, Germany

Christina MOE GJERDE, Strategy and Planning Manager, Voi Technology AB, Sweden

Vasco MORA, Advisor to the Deputy Mayor, City of Lisbon, Portugal

Carlos Felipe PARDO, Senior Manager, City Pilots, New Urban Mobility Alliance, United States 
Won PARK, Director, International Relations, Incheon Airport, Korea

Luca PASCOTTO, Head of Road Safety and Global Advocacy, FIA, France

João Nuno PEREIRA DOS REIS, Head of Public Affairs and Public Relations, Circ, Portugal

Stephen PERKINS, ITF

Manuelle SALATHÉ, National Road Safety Observatory, Ministry of Interior, France

Alexandre SANTACREU, ITF

Helen SMIRNOVA, Senior Executive Engineer, City of Dublin, Ireland

Vicente TORRES, Head of Mobility Policies, Grow, Mexico

George URSACHI, Research Analyst, Agilysis, United Kingdom

James WOODCOCK, Programme Lead Public Health Modelling, University of Cambridge, United Kingdom Ceri WOOLSGROVE, Policy Officer, European Cyclists' Federation, Belgium

George YANNIS, Professor, National Technical University of Athens, Greece 


\section{EInternational Transport Forum}

\section{Safe Micromobility}

This report examines the safety aspects associated with the increasing use of e-scooters and other forms of micromobility in cities. The rise of micromobility challenges existing regulations for urban traffic and forces policy makers to rethink them. The report considers a range of actions to make urban traffic with micromobility safe, including in street layout, vehicle design and vehicle operation, user education and enforcement of rules. It also asks whether a shift towards micromobility can have potential safety benefits. 